\title{
Siegfried André
}

Membre de l'Académie française.

(1960)

\section{ITINÉRAIRES DE CONTAGIONS ÉPIDÉMIES ET IDÉOLOGIES}

\author{
Préface de Pasteur Vallery-Radot \\ De l'Académie française et de l'Académie de médecine
}

\begin{abstract}
Un document produit en version numérique par Mme Marcelle Bergeron, bénévole Professeure à la retraite de l’École Dominique-Racine de Chicoutimi, Québec Courriel: mabergeron@videotron.ca

$$
\text { Page web }
$$
\end{abstract}

Dans le cadre de la collection: "Les classiques des sciences sociales" Site web: http://classiques.uqac.ca/

Une collection développée en collaboration avec la Bibliothèque Paul-Émile-Boulet de l'Université du Québec à Chicoutimi Site web: http://bibliotheque.uqac.ca/ 


\section{Politique d'utilisation de la bibliothèque des Classiques}

Toute reproduction et rediffusion de nos fichiers est interdite, même avec la mention de leur provenance, sans l'autorisation formelle, écrite, du fondateur des Classiques des sciences sociales, JeanMarie Tremblay, sociologue.

Les fichiers des Classiques des sciences sociales ne peuvent sans autorisation formelle:

- être hébergés (en fichier ou page web, en totalité ou en partie) sur un serveur autre que celui des Classiques.

- servir de base de travail à un autre fichier modifié ensuite par tout autre moyen (couleur, police, mise en page, extraits, support, etc...),

Les fichiers (.html, .doc, .pdf, .rtf, .jpg, .gif) disponibles sur le site Les Classiques des sciences sociales sont la propriété des Classiques des sciences sociales, un organisme à but non lucratif composé exclusivement de bénévoles.

Ils sont disponibles pour une utilisation intellectuelle et personnelle et, en aucun cas, commerciale. Toute utilisation à des fins commerciales des fichiers sur ce site est strictement interdite et toute rediffusion est également strictement interdite.

\section{L'accès à notre travail est libre et gratuit à tous les utilisateurs. C'est notre mission.}

Jean-Marie Tremblay, sociologue

Fondateur et Président-directeur général, LES CLASSIQUES DES SCIENCES SOCIALES. 
Un document produit en version numérique par Mme Marcelle Bergeron, bénévole, professeure à la retraite de l’École Dominique-Racine de Chicoutimi, Québec.

Courriels : marcelle_bergeron@uqac.ca; mabergeron@videotron.ca

\section{André SIEGFRIED}

Itinéraires de contagions. Épidémies et idéologie.

Préface de Pasteur Vallery-Radot de l'Académie française et de l’Académie de médecine. Paris : Librairie Armand Colin, 1960, 165 pp.

Polices de caractères utilisée : Times New Roman, 12 points.

Édition électronique réalisée avec le traitement de textes Microsoft Word 2008 pour Macintosh.

Mise en page sur papier format : LETTRE US, 8.5'” x 11'”.

Édition numérique réalisée le 4 décembre 2011 à Chicoutimi, Ville de Saguenay, Québec. 


\section{André Siegfried}

(1960)

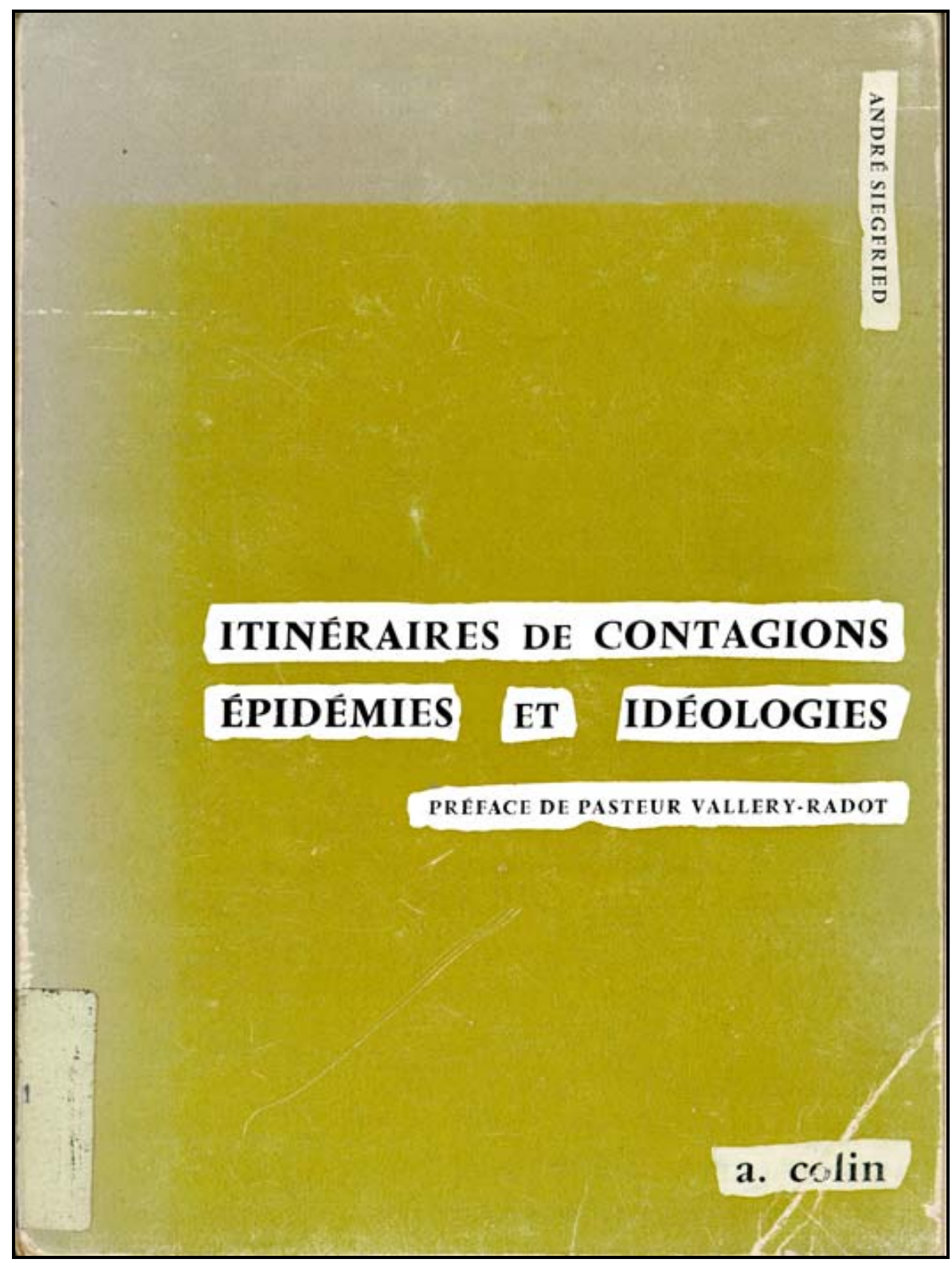

Préface de Pasteur Vallery-Radot de l'Académie française et de l’Académie de médecine. Paris : Librairie Armand Colin, 1960, 165 pp. 
REMARQUE

Siegfried André [1985-1959]

Ce livre est du domaine public au Canada parce qu'une œuvre passe au domaine public 50 ans après la mort de l'auteur(e).

Cette œuvre n'est pas dans le domaine public dans les pays où il faut attendre 70 ans après la mort de l'auteur(e).

Respectez la loi des droits d'auteur de votre pays. 
OUVRAGES D'ANDRÉ SIEGFRIED

CHEZ ARMAND COLIN

LA DÉMOCRATIE EN NOUVELLE-ZÉLANDE (THÈSE), 1904

EDWARD GIBBON WAKEFIELD ET SA DOCTRINE DE LA COLONISATION SYSTÉMATIQUE (THÈSE COMPLEMENTAIRE), 1904

LE CANADA, LES DEUX RACES, 1906.

TABLEAU POLITIQUE DE LA FRANCE DE L'OUEST SOUS LA TROISIÈME RÉPUBLIQUE, 1913.

DEUX MOIS EN AMÉRIQUE DU NORD, À LA VEILLE DE LA GUERRE (JUIN-JUILLET 1914), 1916.

LES ÉTATS-UNIS D'AUJOURD’HUI, 1927.

LA CRISE BRITANNIQUE AU XX ${ }^{\mathrm{e}}$ SIÈCLE, 1931.

AMÉRIQUE LATINE, 1934.

LE CANADA, PUISSANCE INTERNATIONALE, 1937.

SUEZ, PANAMA ET LES ROUTES MARITIMES MONDIALES, 1940

AFRIQUE DU SUD, 1949.

GÉOGRAPHIE ÉLECTORALE DE L'ARDÈCHE SOUS LA III ${ }^{\mathrm{e}}$ RÉPUBLIQUE, 1949.

VOYAGE AUX INDES, 1951.

LES FORCES RELIGIEUSES ET LA VIE POLITIQUE. LE CATHOLICISME ET LE PROTESTANTISME (EN COLLABORATION AVEC A. LATREILLE), 1951.

TABLEAU DES ÉTATS-UNIS, 1954. 
[p. 163]

\section{TABLE}

Préface

\section{PREMIÈRE PARTIE.}

Conditions générales de la diffusion des maladies contagieuses.

1. Intérêt de la géographie des maladies contagieuses, et notamment des conditions générales de leur diffusion

Le point de vue géographique

La contamination et les routes mondiales

2. Conditions déterminant les routes suivies par les maladies contagieuses

Conditions générales de la transmission des infections

Distribution géographique des maladies

Les routes suivies par les maladies dans leur diffusion

\section{DEUXIÈME PARTIE.}

Les Routes suivies par les maladies à transmission

3. Le choléra.

La maladie et les conditions de sa diffusion.

Les routes suivies par les épidémies de choléra

L'épidémie égyptienne de 1947

4. La grippe asiatique

Caractère et intérêt géographique de la grippe asiatique

Itinéraires suivis par l'épidémie 


\section{TROISIÈME PARTIE.}

Les Routes suivies par les diffusions s'exerçant par vecteurs.

5. La peste

Caractères de la maladie et conditions de transmission

Les épidémies de peste du passé

Géographie de la diffusion

6. La fièvre jaune

Définition, formes diverses et modes de transmission

Conditions de propagation

Distribution géographique de la fièvre jaune

Les routes suivies par la fièvre jaune

\section{QUATRIÈME PARTIE.}

Diffusion des idées et des propagandes.

7. Conditions de diffusion et détermination des routes suivies

Diffusion des germes et diffusion des idées

Conditions de diffusion du germe initial

Les routes suivies dans cette diffusion

Les conditions de milieu

Les mesures de défense et leur degré d'efficacité

Table des cartes 
[p. 161]

\section{TABLE DES CARTES}

Voies transarabiques.

Carte schématique des routes suivies par les maladies infectieuses.

Foyers méditerranéens de dispersion des maladies.

Choléra. Épidémie de 1827-1837.

Peste. Épidémie partie du Yunnan en 1893.

Domaine endémique de la fièvre jaune.

Voyages de saint Paul. 
Les premiers ouvrages d'André SIEGFRIED, ses deux thèses, furent édités par Armand COLIN en 1904. Depuis cette date, la liste des livres publiés chez le même éditeur, établit la carte de ses itinéraires et illustre l'éventail de ses curiosités. Elle témoigne aussi de la fidélité, du solide compagnonnage qui a uni l'auteur et son éditeur durant plus de cinquante années.

Grand voyageur, André SIEGFRIED, dont la documentation était aussi vaste que minutieuse, portait un regard neuf sur les groupes humains, dont il savait découvrir l'originalité profonde. Attentif aux changements comme aux permanences de l'histoire, ce savant méthodique, doublé d'un reporteur de grande classe, voulait tout voir pour tout comprendre.

Premiers éditeurs d'André SIEGFRIED, nous présentons ce dernier ouvrage du maître disparu, comme un hommage à la mémoire de notre ami, qui fut un grand humaniste de ce vingtième siècle.

Les Éditeurs. 
[p. 8]

Nous adressons tous nos remerciements au Professeur PAUL MILLIEZ qui a donné à M. André Siegfried

tous les renseignements nécessaires sur les épidémies

et au Docteur BIRAUD, Chef du Département d'Épidémiologie à l'Organisation Mondiale de la Santé, qui a bien voulu revoir le manuscrit que lui avait remis M. SIEGFRIED quelques mois avant sa mort. 
[p. 9]

\section{PRÉFACE}

\section{par \\ PASTEUR VALLERY-RADOT}

Retour à la table

Du temps où j'avais la chaire de clinique médicale propédeutique, j'avais coutume de demander à certaines personnalités éminentes, choisies hors du milieu médical, de faire la conférence inaugurale de mon cours d'actualités. C'est ainsi que Aragon, André Maurois, Jules Romains, Roger Heim, Mario Meunier, René Huyghe, André Roussin... me firent l'honneur d'exposer des sujets de leur choix devant un auditoire de médecins et d'étudiants qui, pour la plupart, ont la fâcheuse habitude de considérer l'univers spirituel a travers le prisme de la science médicale.

[p. 10]

Il y a trois ans, je demandai à André Siegfried cette conférence inaugurale. Il hésita. Je lui citai Paul Valéry que, selon son expression, j'avais "traîné » un matin de l'hiver 1941 sur «l'estrade» de ma chaire de l'Hôpital Bichat pour enflammer l'esprit des jeunes, trop enclins alors au désespoir devant une France piétinée et humiliée. Il n'avait rien préparé, j'en suis certain. Et, comme un feu qui couve devient flamme dans une atmosphère propice, peu à peu sa pensée s'exhaussa jusqu'aux sommets les plus élevés de l'intelligence. Paul Valéry nous montrait comment il concevait la physiologie et nous le suivions émerveillés car jamais avant lui les physiologistes, même les plus grands, que ce fussent Magendie, Claude Bernard ou Gley, n'avaient considéré avec une telle pénétration la science qu'ils créaient ou enseignaient ${ }^{1}$.

- Comme Valéry, dis-je à Siegfried, vous êtes capable de traiter n'importe quel sujet et de l'éclairer de vos vues personnelles.

1 Voir : «Propos sur la physiologie » par Paul Valéry dans Les Grandes Découvertes françaises en biologie médicale. Bibliothèque de philosophie scientifique, Flammarion éd., 1949. 
Siegfried accepta et prit pour thème «Les routes qu'ont suivies les maladies contagieuses pour leur diffusion ».

- C'est un sujet de géographie humaine qu'il m'amusera de traiter, me dit-il.

Pendant plusieurs mois Siegfried, avec la conscience qu'il apportait à tout ce qu'il entreprenait, étudia les maladies contagieuses et leurs modes d'invasion. Il prit maints conseils [p. 11] de mon ami le Professeur Paul Milliez «pour ne pas faire d'erreurs dans un sujet qui, disait-il, lui était jusque-là complètement étranger » et, en mai 1958, il fit sa conférence.

Avant qu'il prît la parole, nous nous demandions comment un homme à l'esprit encyclopédique, certes, mais non médical, pourrait apporter du nouveau dans un sujet aussi complexe que les voies de pénétration des grandes épidémies dans le monde. Dès les premiers mots, nous fûmes captivés. Siegfried montrait que les grandes routes économiques internationales, sillonnant la planète, ont toujours été les mêmes depuis l'antiquité. Parfois délaissées pendant des siècles, elles réapparaissent à la faveur de telle technique nouvelle qui les rend utilisables: c'est ainsi que, dans le désert, les camions automobiles retrouvent les traces millénaires des caravanes. Sur ces routes, qui semblent immuables depuis les temps les plus reculés, passent des hommes, des animaux sauvages ou domestiques, des produits de toutes sortes. Passent également les germes, transmis de l'homme à l'homme, de l'animal à l'animal ou encore de l'animal à l'homme, parfois par intermédiaire.

Les contaminations de région à région sont en rapport direct avec les progrès des communications. Avant le $X X^{e}$ siècle, la lenteur des trajets était une défense relative contre l'invasion des germes. Aujourd'hui, la rapidité effrayante qui permet à l'homme de se transporter en quelques heures d'un point du globe à un autre constitue une menace permanente. Mais, [p. 12] en contre-partie, les moyens de défense de l'homme contre l'invasion des épidémies vont chaque jour se perfectionnant. Le $X X^{e}$ siècle peut être fier des mesures qu'il a su prendre pour enrayer les épidémies qui étaient encore, à la fin du siècle dernier, la terreur des populations de l'ancien et du nouveau monde. Cependant, une sorte de vengeance de la nature, dont le jeu impénétrable mais certain est celui de l'équilibre, et les abus de l'hygiène moderne ont pour effet d'atténuer l'immunisation, d'où l'on peut considérer deux types de maladies sociales: celles qui sont la conséquence d'absence de mesures préventives et celles qui, à l'encontre, sont dues a un excès de soins.

Siegfried terminait la première partie de son exposé par des paroles frappantes, comme à son accoutumée, paroles qui révélaient le grand encyclopédiste, sachant s'élever au-dessus des faits particuliers :

«Les routes suivies par les germes sont aussi intéressantes à observer que celles suivies par les hommes ou les échanges. Nous savons par où a passé Alexandre pour déboucher en Inde, nous connaissons les routes suivies par les invasions mongoles, et dans les airs celles adoptées par les cigognes dans leurs migrations. Est-il moins suggestif de rechercher les voies que pratiquent, dans 
leurs déplacements planétaires, les rats porteurs de puces pesteuses, ou celles, plus secrètes, des singes d'Amérique centrale transportant d'arbre en arbre les germes de la fièvre jaune? Dans tous les cas envisagés il y a toujours au bout menace latente de mort pour l'humanité. »

[p. 13]

Écoutant Siegfried, j'admirais la clarté de son esprit, la façon remarquable dont il tirait des faits qu'il énonçait des déductions logiques, et ce don d'enchaînement des idées qui nous obligeait à le suivre pas à pas au cours de son exposé. J'admirais surtout cet esprit de généralisation qui était dans la belle tradition française.

Je me souvenais de ce petit livre qu'il avait publié quelques années auparavant, intitulé Savoir parler en public ${ }^{1}$. Certaines pages me semblent singulièrement applicables à l'auteur :

«La parole qui a l'enseignement pour objet ne procède que d'un seul moyen: la limpidité. On peut comparer la parole du professeur - et je classerais avec lui l'orateur d'affaires exposant une question ou bien encore le conférencier - à l'opération du filtre, qui transforme en eau claire un liquidé chargé de limon et d'impuretés, peut-être aussi de dynamiques alcools. Il s'agit de faire comprendre, d'intéresser, de séduire éventuellement, mais par les seuls prestiges de l'intelligence. La clarté résultera, soit de la précision du style, soit plus encore de la précision d'un plan bien construit, d'une exposition se développant logiquement. »

Siegfried continuait son exposé sur les routes suivies par les maladies dans leur diffusion, que celle-ci se fît directement de l'homme à l'homme, de l'animal à l'homme ou par l'intermédiaire [p. 14] d'un parasite venant d'un homme ou d'un animal infecté. Il s'émerveillait de la complexité qu'utilise, dans certains cas, la nature pour transmettre les germes d'infection. Il qualifiait cette transmission d'« extraordinaire », de "presque inimaginable». Il aurait pu citer l'exemple du mode de transmission de la fièvre récurrente par le pou : rien ne démontre mieux les détours qu'emploie parfois la nature pour arriver à ses fins. Voici l'historique de la découverte.

Edmond Sergent et Foley, à l'Institut Pasteur d'Algérie, avaient provoqué la fièvre récurrente chez deux hommes en leur inoculant sous la peau des poux broyés, nourris quelques jours auparavant sur des malades atteints de cette maladie. Mais il leur avait été impossible de transmettre la fièvre récurrente à l'homme ou au singe par piqures de poux infectés.

Nicolle, avec Blaizot et Conseil, reprit ces expériences: il n'eut que des échecs. Un de ses garçons de laboratoire subit volontairement plus de six mille

André Siegfried : Savoir parler en public, coll. «Les savoirs du temps présent », éd. Albin Michel, 1950. 
piqures de poux, nourris sur des malades souffrant de fièvre récurrente: l'infection ne se déclara pas.

Cependant Nicolle n'était pas ébranlé dans sa conviction que le pou devait être l'insecte transmetteur.

Nicolle, Blaizot et Conseil examinèrent à l'ultramicroscope des poux nourris sur les sujets atteints de fièvre récurrente. Quelle ne fut pas leur surprise de constater qu'en quelques heures les spirochètes, agents de la récurrente, disparaissaient du corps de l'insecte! Les jours suivants, même absence de spirochètes. Un esprit moins pénétrant que [p. 15] celui de Charles Nicolle en aurait inféré que le pou ne pouvait être l'agent transmetteur, puisque les spirochètes absorbés ne persistaient pas dans son organisme; malgré tout, Nicolle continuait à être persuadé de l'action du pou.

Il eut l'intuition qu'il fallait poursuivre les examens de ces poux jour par jour, bien que l'ultra-microscope ne montrât plus aucun spirochète. Et voici que, le huitième jour, des spirochètes nouveaux apparurent, très fins et très nombreux. Les spirochètes, pendant huit jours, avaient passé par un stade de granulations qui les avaient rendus indiscernables à l'ultramicroscope.

Ces spirochètes nouveaux, apparus le huitième jour, se rencontrent dans la cavité lacunaire et ses prolongements (pattes, antennes) qui sont sans communication avec le tube digestif ou l'extérieur : c'est pourquoi la piqûre est inoffensive. Il doit donc exister un autre mode d'infection, se dit Charles Nicolle. Voici l'explication :

«Le pou est un être fragile; ses pattes surtout sont d'une délicatesse extrême. Le moindre choc les brise ; il suffit du frottement d'un vêtement, du grattage. Par plaie minuscule de la fracture, le sang incolore de l'insecte souille la peau du porteur d'une gouttelette invisible, mais ou les spirochètes pullulent. La piqûre du pou cause des démangeaisons. L'homme se gratte. Ses doigts, ses ong1es, ramassent sur sa peau des traces du sang du pou et, avec elles, des spirochètes. Le grattage les inocule au voisinage de la piqûre. »(Charles Nicolle).

[p. 16]

Comme il aurait été plus aisé pour la nature de transmettre la maladie tout simplement par piqûre du pou ! On comprend que Charles Nicolle ait soutenu que la nature n'avait pas de logique. "Elle est aveugle. Où mettre une intelligence, une raison dans ce qui n'est qu'effet des circonstances? La vie ne connaît pas la raison; elle ne cherche que les possibilités de se transmettre; elle en essaye autant qu'elle en rencontre. Nous avons dit qu'elle allait le plus souvent à des échecs. Nous n'en pouvons rien connaître. Nous ne voyons que les succès. C'est pourquoi la nature nous paraît intelligente. »

Je ne sais rien de plus vrai que cette page de Charles Nicolle :

«Quand nous parlons d'intelligence, nous avons en vue la nôtre, cette intelligence rationaliste dont nous attribuons le bienfait aux Grecs. Que d'erreurs 
nous commettons en cherchant, en mettant cette intelligence où elle n'est pas: chez nos frères primitifs, chez les animaux, dont nous faisons des frères intellectuels, sans nous enquérir de savoir si leurs sens les renseignent comme les nôtres, s'ils n'en ont pas d'autres que nous ignorons. Or, sans identité de sensations, il ne saurait y avoir similitude d'intelligence.

«La pire, la plus commune des erreurs est de prêter notre intelligence aux causes, aux fins, aux incohérences, au chaos des actes de la nature.

"Il y a trois siècles, un esprit méditatif, Daniel Huet, l'évêque d'Avranches, écrivait que l'intelligence de Dieu n'avait [p. 17] rien à voir avec celle des hommes. Peu de pensées sont aussi justes, que nous entendions par Dieu le créateur de la nature ou que nous l'identifions avec la nature elle-même. Au regard de la nature, l'intelligence rationaliste est un phénomène particulier, une singularité, une exception dans la diversité des mécanismes de la cellule nerveuse. Au regard de notre intelligence, la nature est imbécile. »

Ces lignes sont parmi les plus suggestives qu'un biologiste ait écrites.

Siegfried nous montrait que deux foyers d'infection sont particulièrement à redouter : d'une part, l'Amérique du Sud, repaire de la fièvre jaune ; d'autre part, l'Inde et la Chine, où sévissent soit bruyamment soit insidieusement le choléra et la peste. Et il remarquait que les deux foyers sont distincts, ces maladies " ne s'échangeant pas », cependant que les conditions de leur expansion sont réalisées dans les deux continents et que les communications par la voie des airs devraient favoriser leur diffusion.

Faisant de brèves incursions dans les notes qu'il tenait à la main et qu'il regardait d'un air détaché avec un face-à-main qui avait pour ses auditeurs habituels un aspect familier, Siegfried donnait pour exemples de ce qu'il venait d'exposer les routes suivies par les épidémies de choléra, de grippe asiatique, de peste, de fièvre jaune.

Lisant aujourd'hui les pages de Siegfried qui constituent de remarquables introductions à l'étude de ces maladies, on [p. 18] évoque un livre qui fut célèbre il y a quelque quarante ans, intitulé Comment la route crée le type social. Nous savons maintenant grâce à Siegfried, comment la route propage les épidémies. Ces pages sont instructives non seulement pour les biologistes et les médecins, mais aussi pour les hommes cultivés qui s'intéressent à la "géographie humaine» dont Vidal de La Blache fut un des initiateurs et que Siegfried développa en toutes occasions d'une façon originale : c'est que son très subtil esprit d'observation lui révélait ce qui était resté pour ses prédécesseurs dans l'ombre. Sa remarquable perspicacité lui permettait de rattacher les effets constatés aux causes qui les ont produits, causes qu'il discernait avec une lucidité sans égale.

Écoutant Siegfried parler de la transmission du choléra par contacts directs d'homme à homme ou par l'intermédiaire des eaux souillées de matières cholériques, j'évoquais une terrible épidémie dont j'avais été témoin avec le Dr 
P.-L. Simond en 1912 pendant la guerre turco-balkanique. Cette épidémie, plus que les armes, mit fin à cette guerre. Les Turcs étaient retranches sur les contreforts de Tchataldja, à quelques cinquante kilomètres de Constantinople. En face d'eux était l'armée bulgare. Quelques cas de choléra étant survenus dans l'armée turque, l'épidémie s'étendit rapidement et se propagea dans les deux armées. Les hommes, du côté turc, étaient affaiblis par les fatigues et les privations. Couchant sur la terre nue par un temps pluvieux, ils étaient [p. 19] particulièrement exposés aux refroidissements nocturnes. Ils n'avaient à boire que de l'eau de ruisseaux souillés sur tout leur parcours par les déjections entraînées avec les pluies, déjections qui provenaient très souvent de malades cholériques. La contamination directe était aussi particulièrement facile et, pour ainsi dire, obligatoire, étant donné la promiscuité dans laquelle se trouvaient les fantassins.

Dans son petit livre Savoir parler en public Siegfried nous dit que le premier souci de celui qui parle doit être le contact avec le public. Il lui faut « sentir son public un peu comme le cavalier sent le cheval avec son genou ». Quelle jolie comparaison!

"Si l'attention est passionnée, continue Siegfried, les gens se penchent en avant pour mieux entendre. " Cette observation est singulièrement vraie. Ce jourlà, écoutant le conférencier, nous nous penchions tous en avant pour ne pas perdre une de ses paroles.

Je dois avouer cependant que, lorsque Siegfried parla (avec quelle précision !) du mode de transmission de la peste, j'eus un regret. J'aurais aimé qu'il citât le nom de mon maître, P.-L. Simond, médecin des Troupes coloniales, qui démontra le rôle de la puce du rat dans la contagion pesteuse.

C'était à Bombay en 1897, en pleine épidémie de peste. P.-L. Simond avait été frappé d'observer, chez un certain nombre de pesteux amenés à l'hôpital le premier jour, une [p. 20] petite bulle, souvent moins grosse qu'une tête d'épingle, parfois entourée d'une minuscule auréole rosée. Elle siégeait sur n'importe quelle partie $d u$ corps, mais toujours sur le trajet des vaisseaux lymphatiques correspondant a la région du bubon. Elle était un peu douloureuse. Elle s'accroissait, atteignant la dimension d'une lentille, quelquefois davantage. Le liquide de cette bulle ensemencé donnait une culture pure de bacilles pesteux.

P.-L. Simond fut persuadé que c'était la porte d'entrée de la peste. "Cette bulle ne serait-elle pas produite par une puce ? se demanda-t-il. Il y a une telle ressemblance entre la manifestation cutanée observée chez les pesteux et la trace que laisse sur la peau la piqûre d'une puce !»

P.-L. Simond donna la preuve que cet insecte était bien l'agent vecteur du microbe.

La Commission ang1aise de la poste aux Indes, instituée en 1905, confirma les recherches de P.-L. Simond et établit d'une façon définitive que la peste est transportée d'un rat malade à un rat sain par l'intermédiaire des puces du rat. 
Par suite de la mortalité des rats en période épidémique, un grand nombre de puces infectées se transportent sur l'homme.

Dans la transmission interhumaine, c'est encore la puce qui est l'agent vecteur.

Après l'étude sur la fièvre jaune, nous nous demandions si Siegfried allait nous parler de la transmission si curieuse [p. 21] du typhus. S'il ne le fit pas, c'est sans doute parce que Charles Nicolle a laissé une magistrale description du mode de propagation du typhus et que tout biologiste se souvient de cette page :

"Comme tous ceux qui, depuis de longues années, fréquentaient l'hôpital musulman de Tunis, je voyais, chaque jour, dans ses salles, des typhiques couchés auprès de malades atteints des affections les plus diverses. Comme mes devanciers, j'étais le témoin quotidien et insoucieux de cette circonstance étrange qu'une promiscuité, aussi condamnable dans le cas d'une maladie éminemment contagieuse, n'était cependant point suivie de contaminations. Les voisins de lit d'un typhique ne contractaient pas son mal. Et, presque journellement, d'autre part, au moment des poussées épidémiques, je constatais la contagion dans les douars, dans les quartiers de la ville et jusque chez les employés de l'hôpital, préposés à la réception des malades entrants. Les médecins, les infirmiers se contaminaient dans les campagnes, dans Tunis, et point dans les salles de médecine.

«Un jour, un jour comme les autres, un matin, pénétré sans doute de l'énigme du mode de contagion du typhus, ne pensant pas consciemment toutefois (de cela, je suis bien sûr), j'allais franchir la porte de l'hôpital lorsqu'un corps humain, couché au ras des marches, m'arrêta.

"C'était un spectacle coutumier de voir de pauvres indigènes, atteints de typhus, délirants et fébriles, gagner, d'une marche démente, les abords du refuge et tomber, exténués, [p. 22] aux derniers pas. Comme d'ordinaire, j'enjambai le corps étendu. C'est à ce moment précis que je fus touché par la lumière. Lorsque, l'instant d'après, je pénétrai dans l'hôpital, je tenais la solution du problème. Je savais, sans qu'il me fût possible d'en douter, qu'il n'en avait pas d'autre, que c'était celle-là. Ce corps étendu, la porte devant laquelle il gisait, m'avaient brusquement montré la barrière à laquelle le typhus s'arrêtait. Pour qu'il s'y arrêtât, pour que, contagieux dans toute l'étendue du pays, à Tunis même, le typhique devint inoffensif, le bureau des entrées passé, il fallait que l'agent de contagion ne franchît pas ce point. Or, que se passait-il en ce point ? Le malade y était dépouillé de ses vêtements, de son linge, rasé, lavé. C'était donc quelque chose d'étranger à lui, dans son linge, sur sa peau, qui causait la contagion. Ce ne pouvait être que le pou. C'était le pou. Ce que j'ignorais la veille, ce que nul de ceux qui avaient observé le typhus depuis le début de l'histoire (car il remonte aux âges les plus anciens de l'humanité) n'avait remarqué, la solution indiscutable, immédiatement féconde, du mode de transmission venait de m'être révélée » (Charles Nicolle). 
Ce qui nous étonna le plus dans la conférence de Siegfried, ce fut la dernière partie, tout à fait inattendue. Seul Siegfried, avec son esprit audacieux et perspicace, pouvait se permettre d'assimiler la diffusion des idées à celle des germes.

Le parallélisme est frappant, nous dit-il. Pour que la diffusion des idées s'opère, il faut nécessairement un individu, [p. 23] qui émette l'idée, un vecteur de l'idée et un milieu réceptif. C'est par les routes, les mêmes que celles rencontrées dans la diffusion des germes, que se propagent les idées, les doctrines, les religions. L'être humain est ici l'agent de transmission soit par sa parole soit par l'intermédiaire des livres, des pamphlets, des écrans qu'il transporte avec lui, comme il est le propagateur des germes soit directement soit par intermédiaires. "La sociologie et la biologie se rencontrent curieusement, " à tel point que le vocabulaire qui se présente normalement à l'esprit quand il s'agit de diffusion, de propagande des idées est, nous dit Siegfried, celui de la médecine. De même que la société lutte contre le germe envahisseur, elle se défend contre l'idée subversive.

Plus Siegfried avançait dans son exposé, plus ses auditeurs étaient convaincus de la similitude des modes de propagation entre les germes microbiens et les germes spirituels. Oui, certaines doctrines, certaines religions se sont répandues sur les grandes routes du monde à l'égal des épidémies.

Admirant Siegfried dans ses déductions logiques, je me disais : "Cet esprit tout en profondeur, visionnaire de ce qui pour nous est l'inconnu, le jamais pensé, cet esprit, un des plus pénétrants que notre époque ait produits avec Paul Valéry, une fois de plus réalise le but qu'il se propose chaque fois qu'il aborde un sujet, de quelque nature qu'il soit: persuader. " Par la magie de son raisonnement il nous persuadait de la vérité de ce qui, au début, nous semblait un paradoxe. Ses arguments étaient si convaincants que nous [p. 24] le suivions avec passion. Il termina par ces mots, lourds de signification: "Qu'il s'agisse du domaine biologique ou du rayonnement des idées, certaines réactions se manifestent qui sont communes à tous les êtres vivants. " Siegfried ne fragmentait pas la nature humaine, il l'envisageait toujours dans sa totalité.

Cette conférence, prononcée en mai 1958, Siegfried la développa l'hiver suivant, en s'aidant des lectures faites au début des matinées avec son épouse, compagne de toutes ses pensées.

Ces lectures matinales sur les sujets les plus divers, dont il ne pouvait se passer depuis bien des années, étaient pour lui une sorte de viatique avant de reprendre sa vie quotidienne qu'il voulait, dans la discipline qu'il s'imposait, aussi active que dans sa jeunesse.

Voici publié le petit livre qu'il avait l'intention de faire paraître sur la transmission des maladies et des idées, sujet qui l'avait profondément intéressé. Il composa ces pages, les dernières qu'il ait écrites, avec cette passion qu'il mettait à développer toute idée neuve. 
[p. 25]

C'est pour l'ardeur qui l'animait quand il se trouvait en présence d'un problème humain à résoudre, pour l'entrain qui jamais ne l'abandonnait, pour l'enthousiasme qui semblait sa vraie raison de vivre, que nous l'admirions et l'aimions. Depuis plus de quarante ans que sa pensée nous charmait, nous étions toujours prêts à le suivre dans ses déductions, jusqu'aux horizons insoupçonnés ou le poussait, sans une erreur, sans un faux-pas, son esprit, d'une éblouissante clarté.

Pasteur VALLERY-RADOT

de l'Académie française

et de l'Académie de médecine 
[p. 27]

\title{
PREMIÈRE PARTIE
}

\author{
Conditions générales \\ de la diffusion \\ des maladies contagieuses
}

$\underline{\text { Retour à la table }}$ 
[p. 29]

1

\section{Intérêt de la géographie des maladies contagieuses et notamment des conditions générales de leur diffusion}

\section{LE POINT DE VUE GÉOGRAPHIQUE}

Retour à la table

Il y a dans toute étude un point de vue géographique, dont l'importance primordiale ne saurait en aucun cas être négligée. La géographie est l'étude du sol, mais aussi de la vie qui se développe sur ce sol, en tant qu'elle est conditionnée par ce sol, sa composition, sa structure, par le climat, par les interventions de l'homme. La géographie humaine, dès lors, apparaît, et de plus en plus, comme un aspect essentiel de la géographie. C'est ainsi que, dans tout problème, il y a un point de vue géographique, comportant la [p. 30] recherche d'une répartition topographique, l'établissement d'une carte. Il arrive souvent que la répartition topographique éclaire, illumine une question. On pourrait presque dire que, sous cet angle de vision, il y a une géographie de tout. Le tempérament géographique se reconnaît à l'instinctif besoin d'établit une carte pour n'importe quoi.

Parmi les géographies, se distingue, comme particulièrement suggestive, la géographie des routes. Dans les relations entre les pays et les continents, les échanges suivent certains itinéraires, certaines voies, dont le tracé se détermine selon des raisons logiques et profondes. On connaît ces grandes routes, sillonnant la planète, qui s'appellent la route de la soie, la route des Indes par Suez, la route du Cap. On ne réalise pas à première vue toute la signification contenue dans cette 
expression « les communications mondiales ». Les peuples qui n'ont pas de contacts maritimes, qui sont en quelque sorte économiquement autonomes, n'en mesurent généralement pas toute la portée, mais, pour ceux qui vivent d'échanges, d'importations, d'exportations, de courtage ou de transit, les communications mondiales sont l'équivalent d'une nécessité vitale.

Mais qu'est-ce exactement qu'une route économique internationale ?

Il ne faut pas s'imaginer une chaussée artificielle, œuvre de l'homme, mais plutôt une direction suivie [p. 31] par les échanges, qui se groupent, se nouent en forme de faisceaux ou s'épanouissent en forme de gerbes. S'il s'agit éventuellement, et du reste de plus en plus, d'itinéraires aménagés par la technique humaine, on se trouve le plus souvent en présence de sillons issus de l'usage, d'un usage immémorial. Dans leur dessin se discerne une sorte de permanence historique : certains tracés, délaissés pendant de longues années, parfois durant des siècles, reparaissent ensuite à la faveur de telle technique nouvelle qui les rend de nouveau utilisables, à tel point qu'à deux ou trois mille ans de distance ils se retrouvent exactement les mêmes, en dépit des changements dans les moyens de transports. C'est ainsi que dans le désert le camion automobile retrouve les tracés millénaires des caravanes. Les facteurs en jeu dans leur détermination sont nombreux et complexes: il y a la structure géographique, l'aménagement technique, les conditions d'utilisation économique, les révolutions dans les modes de transport, les rivalités politiques, les transformations qui surviennent dans l'équilibre des continents. Quel que soit le type de route envisagé, maritime, terrien, aérien, souterrain, le jeu de ces facteurs demeure à peu près le même, de telle façon qu'on peut dire que le réseau des voies intercontinentales d'échanges à un moment donné reflète, révèle l'équilibre politique de la planète. Et comme les échanges sont obligés de passer par [p. 32] certains points, les détroits par exemple s'il s'agit de communications maritimes, tels cols ou défilés s'il s'agit de communications terrestres, tel arc de grand cercle s'il s'agit de liaisons aériennes, des nœuds stratégiques se dessinent dont il est important de posséder le contrôle. Les détroits artificiels que constituent les canaux interocéaniques sont l'équivalent de véritables guichets, grâce auxquels il est possible de mesurer l'intensité et la direction du trafic : d'une expression singulièrement évocatrice, Paul Morand a pu ainsi qualifier les statistiques relatives à Suez et Panama de «feuilles de température de la planète ». 


\section{LA CONTAMINATION ET LES ROUTES MONDIALES}

Retour à la table

Une question complémentaire se pose : qu'est-ce qui passe par ces routes ? Nous savons qu'il y passe des hommes, des produits, des animaux sauvages ou domestiques. Ce n'est pas tout, car avec les hommes, les produits, les animaux passent également des germes, transmis soit d'homme à homme, soit d'animal à animal ou d'animal à homme, soit indirectement par des vecteurs, et aussi des germes d'idées ou de doctrines, transmis selon le même processus, souvent selon les mêmes itinéraires. Il se produit ainsi des traînées [p. 33] de contaminations, correspondant aux systèmes de relations entre les humains, selon les contacts des races, des civilisations, des pays et en raison de leur fréquence, de leur perméabilité respective. Les facteurs en jeu sont essentiellement les contacts humains, échanges commerciaux, caravanes, pèlerinages, appels de main-d'œuvre, migrations, et aussi les guerres, les conquêtes, les colonisations, les mises en valeur de richesses naturelles. Il faut ajouter les transports de germes par les animaux, qu'ils suivent les mouvements des hommes ou obéissent à des migrations qui leur soient propres, et aussi, à l'occasion, la contamination par les produits.

On se rend compte tout de suite que l'intensité des contaminations est en rapport direct avec le progrès des communications. L'isolement géographique est par lui-même une défense : telles îles excentriques situées hors des itinéraires courants, telles zones montagneuses autonomes constituent des forteresses d'inertie. Vidal de la Blache a souligné l'importance de cette forme d'asepsie sociale : "Comment, écrit-il, par quelles voies, une vie générale parvient à s'introduire dans la diversité des pays locaux... aucune étape n'est plus décisive et ne met plus de différence entre les contrées. Il y en a qui ne la franchissent pas ${ }^{1}$. » [p. 34] À vrai dire il n'y a jamais eu de zones vraiment hermétiques : les caravanes, les pèlerinages, les invasions pénètrent partout. La lenteur des communications équivalait, jusqu'au $\mathrm{XX}^{\mathrm{e}}$ siècle, à une défense efficace encore que relative. Aujourd'hui les progrès fulgurants de la vitesse réduisent de plus en plus les domaines antérieurement épargnés du fait de leur isolement : la défense par la lenteur ne joue plus guère et il n'y a presque plus de régions répondant à la description de Vidal de la Blache, faite il y a plus de cinquante ans. Les pénétrations sont de plus en plus subtiles, de plus en plus inattendues. L'air, « cet océan navigable et ininterrompu qui va jusqu'au seuil de chaque maison », ouvre à l'avion toutes les portes qu'il était encore possible naguère de fermer.

Tableau de la France, p. 17. 
Cet isolement, en revanche, entraîne, quand il cesse, des conséquences éventuellement fatales, car les membres du groupe humain isolé perdent toute immunité acquise aux infections, la maladie introduite de ce fait ayant alors toute chance d'être mortelle. Telles populations de l'Océan Pacifique, restées longtemps à l'écart des routes maritimes, ont été pratiquement détruites quand elles sont entrées en contact avec ce que nous appelons la civilisation. «Tant que les populations des villages ont eu peu de contacts avec celles des villes, écrit le Dr Biraud, elles ont été réputées saines, mais lorsqu'elles ont pris contact avec [p. 35] ces dernières, elles ont été la facile proie des maladies contagieuses, la tuberculose notamment. C'est ce qui explique qu'à la fin du siècle dernier, en Europe, la solide recrue de campagne passait une grande partie de la première année de son service militaire à l'hôpital, alors que la chétive recrue des villes était rarement malade ${ }^{1}$. »

La défense contre la propagation des germes a progressé dans la mesure où les offensives de la vitesse se faisaient plus efficaces : c'est l'éternel dialogue de la plaque de blindage et de l'obus percutant, l'une ou l'autre ayant tour à tour l'avantage. Il est apparu du reste à l'expérience que la technique de protection médicale est éventuellement une arme à deux tranchants : la Nature, laissée à ellemême, possède un mécanisme d'équilibre, générateur d'immunisation, que l'on peut déranger en intervenant dans son fonctionnement.

L'intervention humaine sur ce terrain est cependant, il faut le dire, le plus souvent bienfaisante. Du fait des progrès immenses de la médecine et de la chirurgie, progrès qui vont constamment en s'intensifiant, plusieurs des maladies, hier encore considérées comme les plus fatales, sont maintenant vaincues, la peste, la [p. 36] syphilis par exemple. Plus étonnants encore sont les résultats obtenus grâce à l'hygiène, sous la forme des réglementations collectives instituées par l'administration en vue de la destruction des germes ou, mieux encore, de la prévention de leur diffusion. L'œuvre accomplie à cet égard dans le monde depuis le $\mathrm{XIX}^{\mathrm{e}}$ siècle est à porter tout entière au crédit de l'Occident : c'est lui qui a établi une administration régulière partout où son influence s'est manifestée et c'est du fait de cette administration que les conditions de la survivance humaine se sont transformées révolutionnairement depuis deux générations. Sans la technique médicale et chirurgicale aucun de ces résultats n'eût pu sans doute être atteint, mais en l'espèce c'est, je crois, l'intervention administrative qui constitue le facteur essentiel d'efficacité. Voilà pour la défense ; mais en même temps, que ce fût directement ou subrepticement, les offensives des germes trouvaient dans le progrès même l'occasion d'accroître leur efficacité. Avec l'aviation les trajets devançaient l'incubation de vitesse, cependant que, les obstacles naturels étant survolés magistralement, telles résistances anciennes dues à la lenteur ne jouaient plus : des contacts inattendus, hier même inimaginables, mettaient en présence des gens qui précédemment ne se fussent jamais rencontrés.

1 Dr Yves Biraud, directeur des services d'épidémiologie et de statistiques sanitaires (O.M.S.) : Santé du Monde, mars-avril 1958. 
La technique d'autre part progressait plus vite que le maniement des hommes. Les foules d'Asie, dans leur [p. 37] profondeur quasi insondable, opposaient spontanément une sorte d'inertie aux interventions d'une administration désarmée devant leur massive impénétrabilité. Quiconque connaît l'effrayante agglomération humaine de Calcutta réalisera que, contre pareil degré de densité sociale, la lutte devient inefficace. Des foyers endémiques d'infection se maintiennent ainsi, dont aucune technique d'hygiène médicale n'a pu jusqu'ici avoir raison, cependant que, dans telles forêts ou déserts inaccessibles, persistent des foyers d'infection animale, ou le virus, vaincu ailleurs parmi les hommes, se maintient. À l'autre extrémité, les progrès, faudrait-il dire les abus de l'hygiène moderne, ont pour effet d'atténuer l'immunisation naturelle, d'où deux types de maladies sociales, à l'étage inférieur et à l'étage supérieur : dans les premières la maladie provient d'une absence de soins préventifs, dans les secondes de leur excès. Si le trachome est, dans ces conditions, une maladie sociale, la poliomyélite à sa façon l'est aussi.

Il arrive ainsi qu'en Occident la maladie renaît des efforts mêmes accomplis pour la supprimer. Mais ailleurs on n'a pu supprimer jusqu'ici, soit les foyers d'infection humaine de l'Assam ou de la Chine méridionale, soit les foyers d'infection animale des singes ou des rongeurs de l'Amérique ou de l'Asie des steppes. Selon des lois encore mal connues, telles infections, temporairement contenues, sont susceptibles à certains [p. 38] moments de reprendre de la virulence, débordant hors du foyer endémique, se répandant sur la planète sous forme d'épidémies ou de pandémies. Dans un temps où la notion du réservoir animal n'était même pas soupçonnée, le génie de Pasteur avait discerné l'importance de la question : « Cette question du retour à la virulence, écrivait-il, est du plus grand intérêt pour l'étiologie des maladies infectieuses. Une épidémie que l'affaiblissement de son virus a éteinte peut renaître par le renforcement de ce virus sous certaines influences... La peste est une maladie virulente, propre à certains pays. Dans tous ces pays son virus doit exister, prêt à y reprendre sa forme active quand des conditions de climat, de misère, de famine s'y montrent à nouveau... ${ }^{1}$ »

Nous voudrions, dans les pages qui suivent, étudier les routes suivies par les maladies infectieuses dans leur diffusion, nous rendre compte dans quelle mesure les germes empruntent les mêmes voies que les échanges intercontinentaux, sur terre, sur mer ou dans les airs. Il s'agit moins, dans notre pensée, de technique sanitaire que de géographie médicale. La géographie n'a pas en somme de domaine particulier qui lui appartienne en propre et en dehors duquel elle ne soit plus à sa place, car, comme nous le disions plus haut, [p. 39] l'aspect de la répartition topographique s'impose à un moment donné à toute étude. Les routes suivies par les germes sont à cet égard aussi intéressantes à observer que celles suivies par les hommes ou les échanges. Nous savons par où a passé Alexandre pour déboucher en Inde, nous connaissons les routes suivies par les invasions

Pasteur, De l'atténuation des virus et de leur retour à la virulence (1881). 
mongoles, et dans les airs celles adoptées par les cigognes dans leurs migrations. Est-il moins suggestif de rechercher les voies que pratiquent, dans leurs déplacements planétaires, les rats porteurs de puces pesteuses, ou celles, plus secrètes, des singes d'Amérique centrale transportant d'arbre en arbre les germes de la fièvre jaune ? Dans tous les cas envisagés, il y a toujours au bout menace latente de mort pour l'humanité. 
[p. 41]

2

\section{Conditions déterminant les routes suivies par les maladies contagieuses}

\section{CONDITIONS GÉNÉRALES DE LA TRANSMISSION DES INFECTIONS}

\section{$\underline{\text { Retour à la table }}$}

Les énergies destructrices qui s'attaquent aux êtres vivants sont innombrables, dans l'air, les aliments, les déjections, à l'intérieur même des organismes. Leur action est constante et elle n'attend même pas pour s'exercer la naissance des individus. Le terme général par lequel on désigne habituellement ces ennemis de l'homme est celui de germes ou d'agents pathogènes.

On distingue parmi eux des microbes proprement dits, des champignons, des protozoaires, des vers et [p. 42] des insectes (la distinction ancienne entre microbes et virus ou ultra-virus n'a plus de raison d'être depuis que l'ultra-virus lui-même est devenu visible au microscope électronique). Les formes de l'offensive sont diverses: il y a tantôt attaque directe, sous forme libre ou parasitaire, tantôt attaque indirecte, quand le germe, porté par un hôte (rongeur par exemple) est transporté a un hôte nouveau par un vecteur (puce ou moustique), intermédiaire nécessaire à la transmission. Le dommage causé aux organismes attaqués provient de la sécrétion par le germe attaquant des poisons destructeurs de la substance vitale qui, déréglant le jeu normal des réactions internes, causent ainsi les maladies infectieuses. 
La transmission s'opère de trois façons principales, soit directement d'homme à homme, soit par un parasite, soit par l'action d'un parasite hématophage inoculant le germe.

Dans le cas de la transmission directe d'homme à homme, deux termes seulement sont en présence, l'homme et l'agent pathogène. Le contact infectant peut s'exercer immédiatement par la peau ou les muqueuses; il peut se produire également par l'air et les voies respiratoires, par pénétration dans les voies digestives de particules souillées, par les selles ou urines de malades. Il s'agit toujours en somme de contagion, par les mains, la salive, ou l'absorption d'aliments souillés.

[p. 43]

L'attaque par un parasite est plus complexe et plus variée dans ses formes. Il peut s'agir d'un ver, ayant éventuellement une existence indépendante et opérant une agression caractérisée contre l'organisme. Mais il peut s'agir aussi d'un parasite ne pouvant se développer au dehors qu'à l'état de larve et pénétrant ensuite dans l'organisme humain pour y évoluer, tel par exemple l'ankylostome (hook worm) de l'anémie des mineurs ou le ver de la bilharziose. La contamination se fait généralement par l'eau, souillée d'œufs par les excréments humains, soit qu'on la boive, soit qu'on y patauge, la transmission étant alors limitée au pays où le ver se développe : pareille contagion, locale, ne présente qu'un moindre danger de diffusion, parce que le germe ne se déplacera pas tout seul, mais un homme infecté pourra le transporter au loin et par ses excréments contaminer des eaux indemnes.

Le cas est infiniment plus complexe quand des vecteurs entrent en jeu. Les insectes véhiculateurs d'infection sont légion, puces, poux, moustiques... Certains vivent en parasite sur la peau de l'homme, d'autres agissent par piqûre pompant le sang d'un organisme infecté et l'inoculant ensuite par piqûre également à un organisme sain ; c'est ainsi que se transmettent les bacilles pesteux, le virus de la fièvre jaune, etc. La complication de la transmission peut être extraordinaire, presque inimaginable, car si [p. 44] certains insectes passent directement d'un homme à un autre, il en est qui vivent aussi sur des animaux leur servant d'hôtes, susceptibles de les transporter au loin, carnassiers, herbivores, rongeurs, le rat étant l'un des plus dangereux. Pour que la diffusion se produise, il faut que certaines conditions se conjuguent, éventuellement contraires à toute vraisemblance : d'abord que le vecteur, moustique de la fièvre jaune, puce de la peste, pou du typhus, soit transporté, survive et reste infectant ; puis que l'hôte soit très mobile, par exemple le rat qui transporte la puce pesteuse ; enfin que le milieu extérieur, c'est-à-dire le climat, se prête à la survie du vecteur : c'est surtout en effet dans les régions tropicales que celui-ci prospère, le froid lui étant au contraire fatal. Il y a cependant des transgressions subtropicales occasionnelles et il arrive même qu'il y ait extension temporaire jusque dans les pays tempères.

En résume, trois conditions sont nécessaires à la transmission à distance : $1^{\circ}$ il faut à la source un germe, susceptible de persister dans des réservoirs de virus où 
s'entretient l'infection, sous forme éventuellement : bénigne ou même inapparente. $2^{\circ}$ Ensuite un vecteur, agissant directement ou se déplaçant par l'entremise d'un hôte. $3^{\circ}$ Enfin un milieu où le germe puisse développer sa nocivité, faute de quoi, même transmis, il reste stérile. Ces conditions de milieu sont [p. 45] les mêmes, ou du moins de même nature, pour le germe, le vecteur ou l'hôte : si l'insecte ou le pou sont détruits, si l'hôte est arrêté dans sa migration, la maladie ne se transmet pas.

Ces conditions sont fondamentales, elles commandent toute forme de diffusion, elles déterminent les itinéraires que suivront les maladies dans le cheminement des épidémies. Chose singulière, elles paraissent s'appliquer également à la diffusion des idées, des doctrines religieuses, des propagandes politiques: les notions de germe, de vecteur, de milieu demeurent les mêmes, sous la réserve d'une simple transposition, quelle que soit la nature du germe, du vecteur ou du milieu.

\section{DISTRIBUTION GÉOGRAPHIQUE DES MALADIES}

\section{$\underline{\text { Retour à la table }}$}

La distribution géographique des maladies dans le monde répond aux conditions que nous venons de résumer. Le « complexe pathogène » comporte des zones de possibilités maximales : des endémies tendent alors à s’y établir, à s'y perpétuer, avec des explosions épidémiques occasionnelles débordant hors de ces foyers.

Les circonstances qui favorisent la diffusion varient selon le mode de transmission. Si celle-ci se fait [p. 46] d'homme à homme, tout ce qui met les êtres humains en contact la provoque : migrations, mouvements d'armées, grands travaux collectifs entraînant un recrutement massif de main-d'œuvre, densité du peuplement, saleté du logement, prescriptions religieuses surannées, conditions du vêtement, de l'alimentation (le typhus par exemple est associé à la présence du pou, la fièvre de Malte se transmet par le lait de chèvre). Il faut ajouter que la diffusion s'accroît en nocivité quand elle s'attaque à des populations non immunisées. S'il y a entremise nécessaire d'un vecteur, éventuellement porté luimême par un hôte, le transport du vecteur ou de l'hôte réservoir devient une circonstance essentielle de l'expansion du germe : il faudra d'abord que vecteurs ou hôtes soient transportés, sur des bateaux, des avions, dans les bagages des caravanes ou des armées, à moins que, comme le rat, ils ne soient capables, par leurs propres moyens, de traverser, comme dit le poète « les déserts et les ondes ». Il faudra cependant encore, par surcroît, que le climat permette au vecteur de survivre dans le milieu nouveau où il aura passé : par exemple le moustique de la 
fièvre jaune périra si la température tombe au-dessous d'un certain niveau ; il en est de même pour la mouche tsétsé. Si enfin la transmission se fait par certains vers, la flore et la faune de l'eau où leurs œufs sont déversés doivent permettre à leurs larves de prospérer. C'est là [p. 47] une condition sine qua non ; la qualité des eaux, vives ou stagnantes, marécageuses, boueuses, est alors essentielle à considérer. Viendra ensuite le contact humain avec cette eau. Pour ce qui est de l'aulcylostomiase, l'infection ne se fera que pour les sujets aux pieds nus, les mendiants en contact avec la terre humide souillée par les excréments.

En analysant les conditions de la diffusion, nous avons par là déterminé les défenses qu'on peut lui opposer ou qui s'y opposent spontanément. La principale est la lenteur des communications: le vecteur succombe alors avant d'avoir transmis le germe et, la chaîne étant rompue, la maladie se perd en quelque sorte dans les sables ; c'est le cas de ces caravanes qui semblent n'arriver jamais, de ces trajets maritimes d'antan qui, contournant les continents, s'attardaient indéfiniment dans le sommeil des calmes plats. Une défense non moins efficace est l'immunisation spontanée de l'homme ; celui-ci en effet peut s'accommoder à ses parasites et à ses germes, la maladie se perpétuant sans doute mais tendant à devenir bénigne et à le rester tant qu'il n'y a pas de nouveau contact avec des nonimmunisés. Il se forme ainsi un équilibre entre l'attaque contre l'infection, la formation d'anticorps. Mais la défense peut aussi être consciente, voulue, concertée et il y a là une des œuvres les plus utiles de la civilisation. Les efforts des hommes pour circonscrire [p. 48] les contaminations ne sont cependant pas en effet uniformément bienfaisants, et il arrive qu'ils empêchent l'immunisation spontanée de se produire.

Du fait de ces conditions de diffusion et de leur limitation même, la distribution des maladies infectieuses présente un caractère zonal. Les infections dont l'aire est la plus étendue sont celles qui se transmettent directement d'homme à homme, et l'on comprend aisément pourquoi, dès l'instant qu'elles ne sont pas limitées dans leur expansion comme les maladies parasitaires par les conditions qui circonscrivent impérativement la survivance des vecteurs. Elles tendent naturellement à devenir universelles, telles la variole ou la tuberculose. Leur destin dépend du milieu ou de la vie même de la maladie, qui comporte une jeunesse, une maturité et une vieillesse : c'est dans ce sens que Nicolle a parlé du « destin des maladies infectieuses ». Quant aux maladies liées à l'entremise d'un vecteur, elles ne peuvent s'étendre plus loin que la zone où la survivance de celuici est possible. Il arrive du reste qu'elles ne s'étendent même pas jusque-là : on sait par exemple que l'Aëdes Aegypti existe en bien des régions où il n'y a pas de fièvre jaune, celle-ci ne profitant pas de toutes ses possibilités. Il y a enfin toute une série d'infections dont l'agent ne peut se déplacer et qui restent, en conséquence, strictement localisées géographiquement: [p. 49] c'est le cas de toutes celles qui sont dues à des vers.

Dans son livre de base, Les fondements biologiques de la géographie humaine, M. Max Sorre a donné la description suivante des grandes zones mondiales de maladies. La ceinture tropicale des régions chaudes en constitue le foyer essentiel, 
car, en dépit de transgressions occasionnelles, les autres régions se défendent mieux. Les zones subtropicales ont leurs endémies propres, qui sont dues soit au climat, soit aux conditions sociales, mais dont la virulence, la morbidité sont d'une façon générale moindres; elles sont du reste sujettes aux transgressions immédiates des maladies tropicales, étant géographiquement exposées aux invasions voisines des vecteurs en provenance des foyers initiaux: la peste bubonique est apportée par les rats des bateaux, la peste pulmonaire par les rongeurs des steppes. Selon l'expression saisissante de M. Sorre, ces zones latérales prennent de ce fait périodiquement une «couleur pathologique de paysage médical exotique ». Quant aux zones tempérées ou froides, elles ont également leurs endémies, liées soit au climat, soit à une atmosphère sociale que la civilisation tend à rendre à la fois meilleure par le progrès et pire par les excès de ce progrès même.

Ces zones s'étagent naturellement selon la latitude, mais, s'il s'agit de diviser le globe en aires de maladies, c'est à une classification verticale qu'il faut recourir, [p. 50] avec une aire atlantique et une aire pacifique bien distinctes l'une de l'autre et même jusqu'ici sans contact de contagion véritable, du moins dans le sens Ouest-Est. L'aire Atlantique, axée sur cet océan, se divise elle-même en deux secteurs. Celui de l'Atlantique septentrional recouvre essentiellement, soit en Amérique soit en Europe, ces régions que la race blanche a aménagées selon l'esprit et les méthodes de la civilisation occidentale. L'industrialisation, l'urbanisation y ont été poussées au maximum, souvent à l'excès, d'où le développement des maladies dites sociales comme la tuberculose... Les facteurs de diffusion y sont essentiellement météorologiques et surtout sociaux, résultant du genre de vie, des inévitables excès de son intensité, cependant que le climat vaut à ses habitants des avantages, dont ceux-ci, quand ils ne connaissent pas l'Orient et surtout l'Asie tropicale, sont bien loin de réaliser l'extraordinaire privilège : saisons nuancées et équilibrées, absence de grandes chaleurs ou de grands froids, atmosphère tempérée invitant au travail... Le secteur Atlantique méridional est caractérisé au contraire par l'importance des endémies tropicales. Il se divise en deux groupes bien distincts : l'africain, traditionnellement marqué par la maladie du sommeil, et le sud-américain, domaine classique de la fièvre jaune. Il faudrait classer à part une zone méditerranéenne, intermédiaire [51] et sujette à des transgressions de toutes origines.

L'aire Pacifique comporte fondamentalement un secteur indien et un secteur chinois, auxquels il faut ajouter, sur leur frange, un secteur eurasiatique et un secteur insulaire océanique. Le secteur indien (Inde et accessoirement côte orientale africaine et Madagascar) présente un extraordinaire et terrifiant exemple de conditions favorisant au maximum le «complexe pathogène » : entassement humain prodigieux générateur de contagions irrésistibles, sous-alimentation chronique, invraisemblable absence d'hygiène, souvent entretenue par les préceptes mêmes de la religion ; d'où le caractère foudroyant des épidémies et une convergence unique au monde de toutes les maladies. Choléra, peste, malaria, typhoïde, dysenterie y sont endémiques, généralisés. Point n'est besoin de 
compétence médicale pour s'en apercevoir : le plus simple, le moins averti des voyageurs recule épouvanté, dans les grandes villes indiennes, devant le spectacle impressionnant d'une humanité portant sur elle-même tous les stigmates de la maladie, présente, habituelle et même acceptée : c'est la cour des miracles ! Le secteur chinois est à peine moins malsain, et pour les mêmes raisons. C'est le foyer endémique de la lèpre, qui rayonne par émigration vers la Mandchourie et le Pacifique, le berceau des deux pestes, bubonique et pneumonique. Plus d'un demimilliard d'hommes en Chine, quatre cents millions [p. 52] aux Indes, donc plus du tiers de l'humanité vivent dans cette partie du monde et c'est aussi là qu'on meurt le plus, la mort étant même admise comme un complément nécessaire de la vie, comme un voisin familier, auquel on finit par ne même pas résister. Le secteur eurasiatique s'étend sur la zone des steppes et des déserts qui va de l'Amour jusqu'au Don et jusqu'à la Mer Rouge. Là est le berceau de la peste pneumonique, de la fièvre récurrente, des leishmanioses. Une influence contaminant s'insinue, par la chaîne des oasis, vers la Chine, l'Inde, la Russie, et même, à travers l'Asie occidentale, jusqu'au Sahara. Le secteur insulaire (Malaisie, Îles du Pacifique) apparaît ensuite, par comparaison, d'une salubrité relative: la densité du peuplement y est moindre, la présence de l'océan y joue comme un facteur favorable... Un point dangereux cependant : l'intrusion de l'Occident dans ce milieu non immunisé comporte la menace de terribles offensives, dont la virulence qu’y prend la grippe apparaît comme un fatal exemple.

Il résulte de ce tableau que deux foyers sont particulièrement à redouter : d'une part l'Amérique du Sud, repaire de la fièvre jaune, même si cette maladie est contenue ou vaincue ; d'autre part l'Inde et la Chine, d'où nous viennent le choléra et la peste. Une remarque importante s'impose cependant, à savoir que les deux foyers sont distincts, leurs maladies n'étant [p. 53] pas les mêmes et d'une façon générale ne s'échangeant pas : ni la fièvre jaune, ni la maladie du sommeil par exemple ne se sont étendues à l'Asie. Il se peut du reste que cette séparation, étanche jusqu'ici, ne survive pas au régime des communications ultra-rapides nées de l'aviation. Telle qu'elle existe, il est vraisemblable que la lenteur ou même dans certains cas l'inexistence des rapports humains en donne la principale explication. La dorsale montagneuse continentale constitue en effet une barrière que pendant longtemps les hommes ne traversaient pas. Mais la vitesse, seul vice nouveau que l'âge moderne ait inventé, ne respecte rien. En dépit de protections de plus en plus strictement exercées, cette immunité de l'Asie aux grandes infections africaines durera-t-elle toujours ? De toute façon, la fièvre jaune, qui a poussé des pointes jusqu'à la Mer Rouge et l'Océan Indien, n'a jamais pénétré jusqu’à l'Inde. 


\section{LES ROUTES SUIVIES PAR LES MALADIES DANS LEUR DIFFUSION}

$\underline{\text { Retour à la table }}$

On peut classer ces routes suivant que les germes s'y transmettent d'homme à homme, ou bien qu'il s'agit des voies suivies par les vecteurs ou leurs hôtes. Il faut distinguer aussi les routes selon quelles sont terriennes, maritimes ou aériennes.

[p. 54]

Sur terre les itinéraires des infections sont ceux qu'ont adoptés traditionnellement depuis des siècles les caravanes, et ce sont sur l'écorce terrestre comme des sillons tracés par les âges : ils suivent nécessairement telles lignes d'oasis, déterminées elles-mêmes par la présence souterraine des eaux, dans l'immensité des déserts et des steppes ; le trace de la route ne peut éviter de passer par certains cols, certains gués, certains isthmes, selon la structure même des continents. C'est inscrit sur la carte, à tel point qu'à cette heure où les caravanes tendent à disparaître, ces mêmes routes sont adoptées à leur tour par les voies ferrées, les camions automobiles et même dans le sous-sol par les pipe-lines pétroliers. Les rats, les rongeurs les empruntent également, avec les germes qu'ils transportent: on sait l'extraordinaire mobilité des rats, celle des rongeurs de la steppe et les contagions qui menacent de ce fait les chasseurs de fourrures; on peut suivre de même, dans les forêts de l'Amérique centrale, la diffusion par les moustiques arboricoles et par les singes transportant d'arbre en arbre les germes de la fièvre jaune.

Les routes maritimes sont les plus faciles à déterminer en tant que voies de contagions: les bateaux portent des hommes, éventuellement contaminés, également des rats, qui descendent sur terre aux escales. Les ports deviennent ainsi, tout naturellement, des foyers secondaires de dispersion, cependant que cer- 
[p. 55]

Retour à la table des cartes

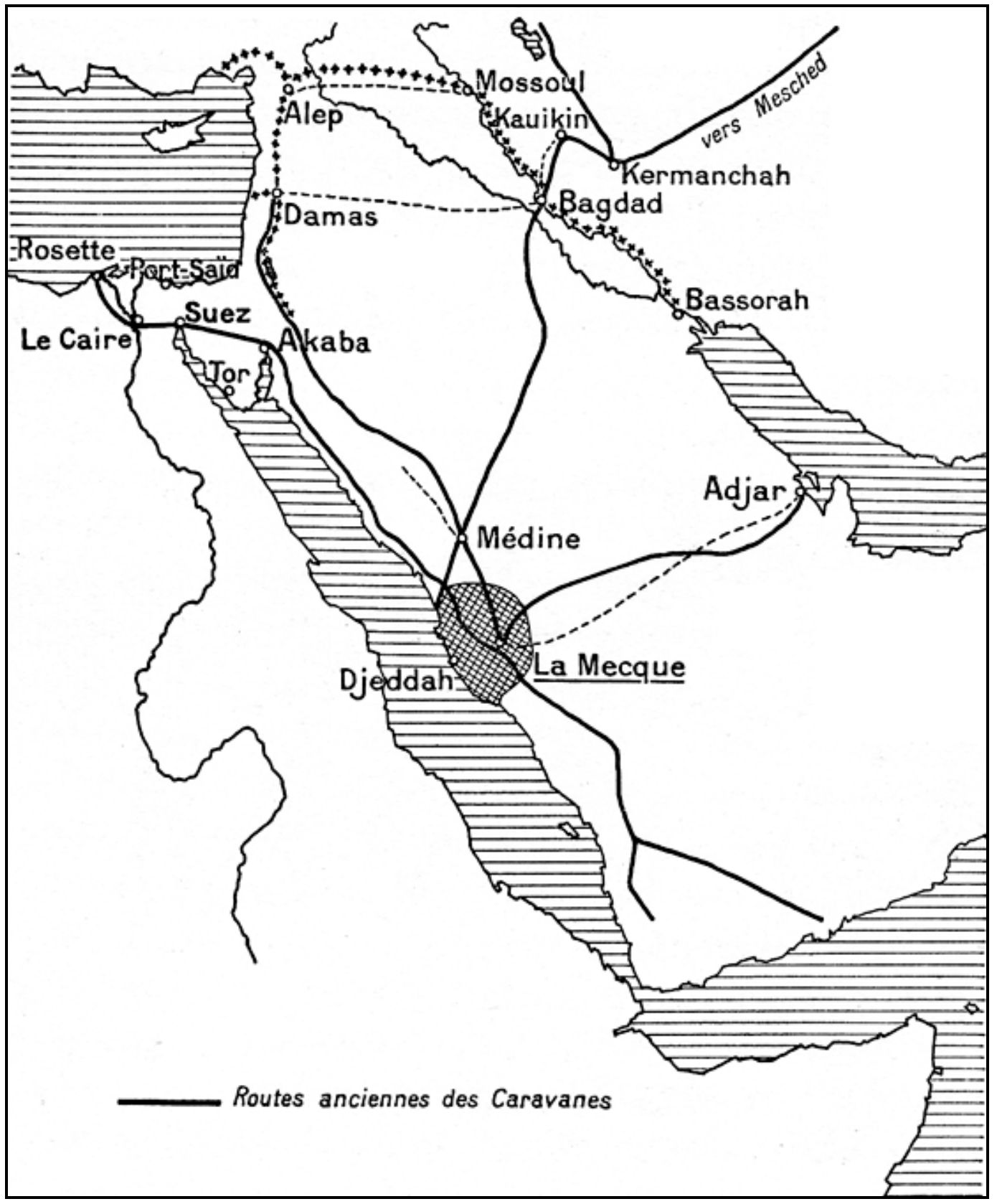

Voies transarabiques 
[p. 56]

Retour à la table des cartes

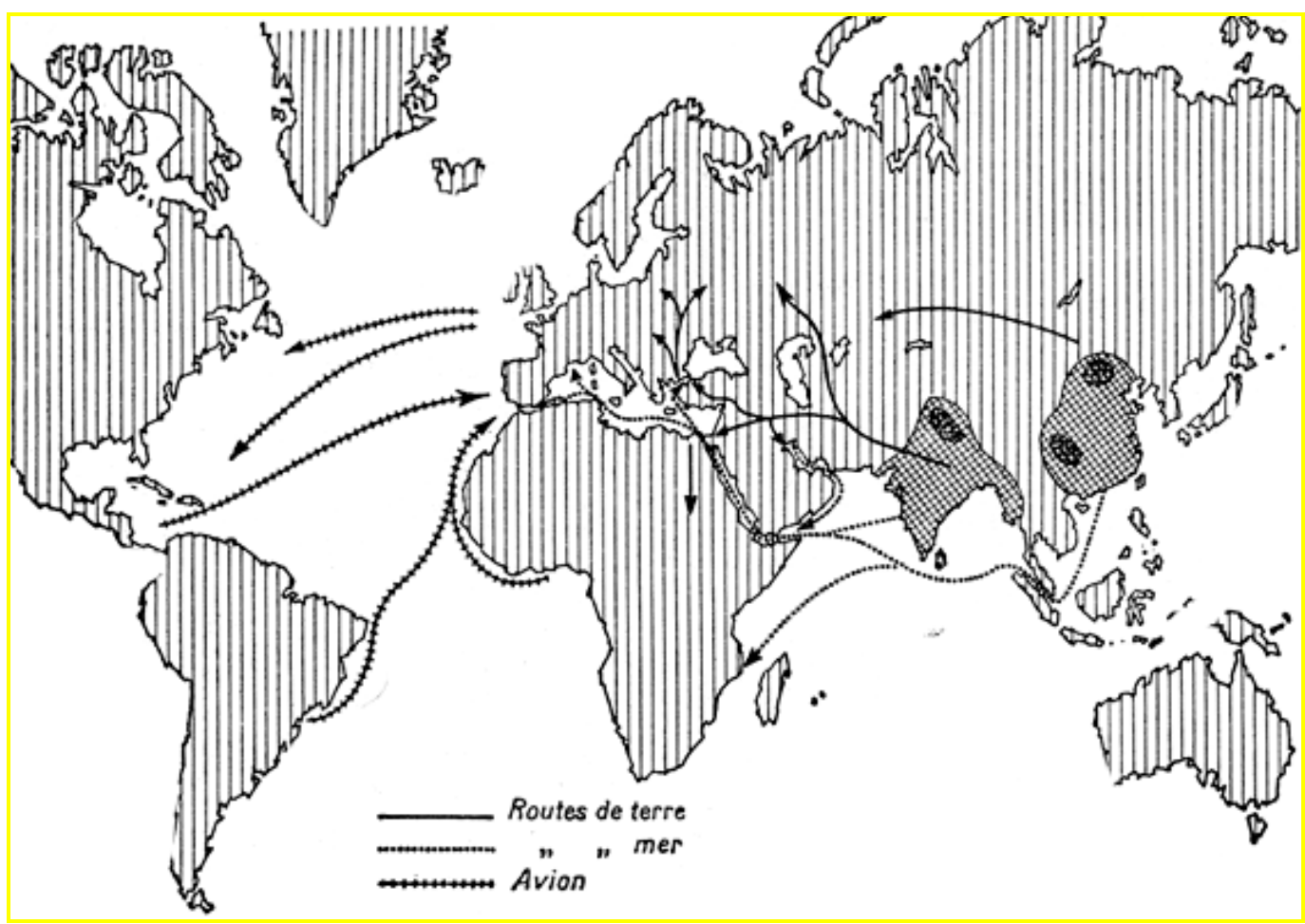

Carte schématique :

Routes suivies par les maladies infectieuses

taines directions à travers l'immensité marine s'imposent de même que tels guichets par lesquels il faut passer, caps à doubler, détroits, canaux internationaux. Quant aux routes de l'air, nous commençons seulement à les connaître, mais en dépit de la liberté magistrale dont paraît disposer l'avion, elles connaissent elles aussi, leurs impératifs, largement quoique de moins en moins dépendants des infrastructures. Leur rôle dans la [p. 57] diffusion s'est manifesté de suite, surtout dans les transmissions directes qui négligent les stations secondaires, de sorte qu'en présence de certaines soudainetés d'offensives les défenses traditionnelles ne jouent plus.

Dans ces conditions une carte stylisée des itinéraires principaux suivis par les germes peut être établie. Nous savons déjà que les deux aires essentielles de maladies demeurent en général distinctes et séparées. Pas au point toutefois que des transgressions ne se produisent. Si les infections américano-africaines ne passent pas en principe en Asie, les maladies asiatiques pénètrent en Europe et même parviennent jusqu'au Nouveau Monde, cependant que la fièvre jaune 
projette parfois des fusées vers l'Europe. Il y a donc double convergence, soit de l'Amérique tropicale et de l'Afrique Atlantique vers l'Europe sud-occidentale (c'est la route de la fièvre jaune), soit de l'Asie vers l'Europe orientale ou méditerranéenne, d'une part par la route maritime de Suez, de l'autre par la route des caravanes issue de l'Inde à travers la passe de Khyber ou les passes voisines, enfin par les steppes de l'Asie centrale. Pendant longtemps les chemins de pèlerinage conduisant à La Mecque ont été les routes classiques de la peste et du choléra. La Méditerranée apparaît ainsi comme une sorte d'antichambre de l'Europe : c'en est le point d'entrée le plus menacé, avec un [p. 58] climat et une pathologie déjà subtropicaux, et c'est aussi la voie de pénétration qui doit être le plus attentivement surveillée.

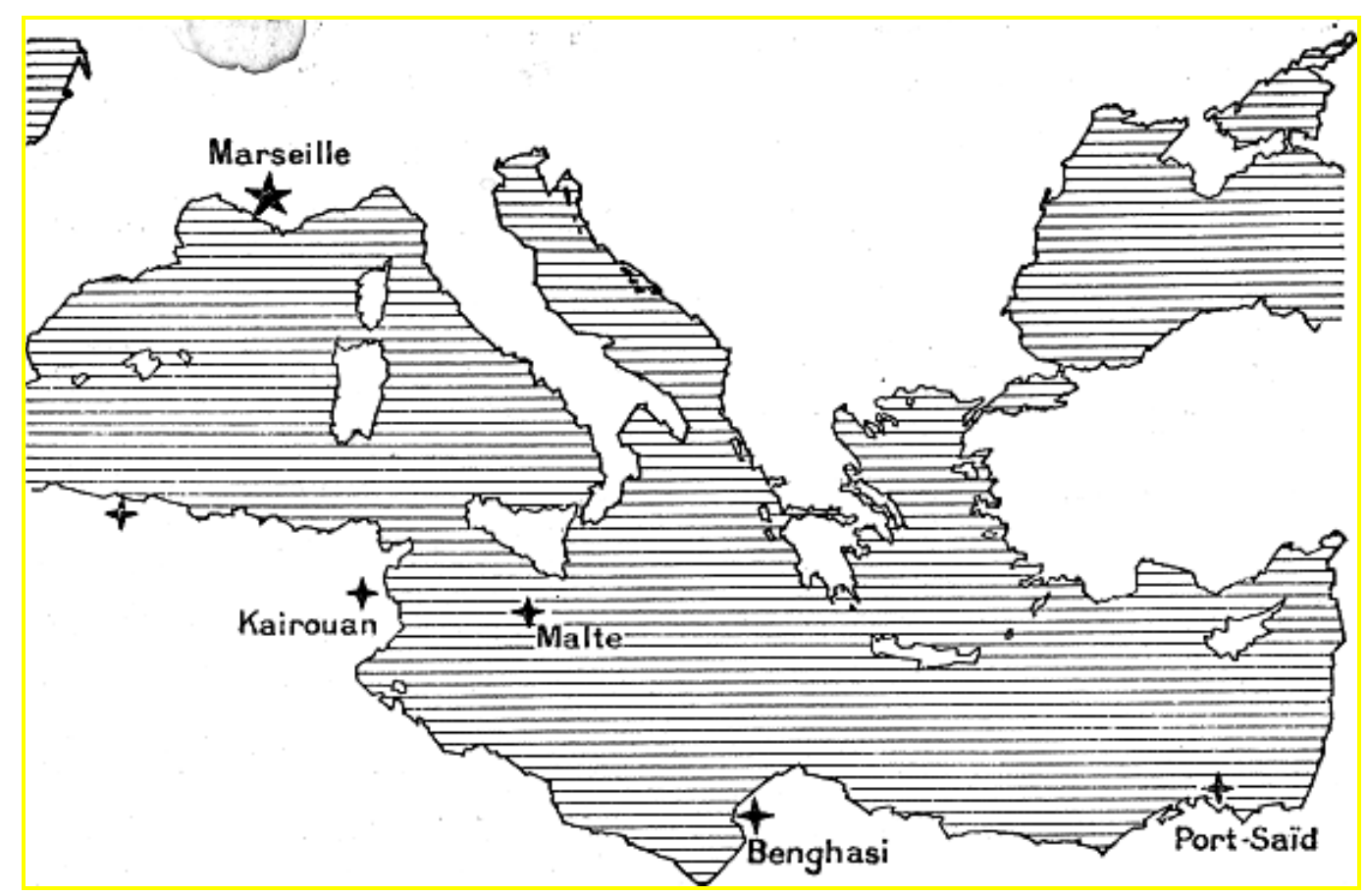

\section{Foyers méditerranéens de dispersion des maladies}

$\underline{\text { Retour à la table des cartes }}$

Ces voies d'infection proviennent d'un petit nombre de foyers initiaux, qui sont le Bengale, la vallée du Gange, le Yunnan, la Mandchourie et la Mongolie. Elles sont jalonnées par des foyers de dispersion secondaires, tels que La Mecque, Port-Saïd ou Alexandrie, Benghazi, Malte, Kairouan, et, s'il s'agit de l'Atlantique, les Canaries, Lisbonne, Cadix, Alger. Il faut dire que ce tableau est essentiellement rétrospectif, [p. 59] car la lutte contre les grandes maladies infectieuses a été dans l'ensemble victorieuse : les mesures prises pour arrêter ou 
ralentir leur diffusion ont été efficaces au point que les grandes pandémies du choléra ou de la peste appartiennent au passé depuis la fin du premier quart du $\mathrm{XX}^{\mathrm{e}}$ siècle. D'autre part les merveilles récentes des traitements antibiotiques ont permis, dans certains cas, la cure rapide et intégrale de maladies jusqu'alors mortelles. L'étude de ces pandémies, que les gens de mon âge ont encore pu connaître, demeure d'un intérêt certain, soit par les leçons médicales qu'elle comporte, soit par les clartés qu'elle jette sur la géographie de notre planète.

On peut en somme juxtaposer une carte des climats et une carte de l'état sanitaire, et d'autre part cette même carte serait superposable à telle autre donnant soit l'état économique, soit le degré d'éducation des populations, soit même l'équilibre politique mondial. Si les techniques de défense sont nées dans les Pays tempérés, qui depuis la Renaissance se sont révélés les plus civilisés, l'influence occidentale a maintenant étendu partout ces techniques, de telle sorte que le paysage médical international est en train de se transformer. Pas suffisamment toutefois pour que la connaissance des conditions de diffusion d'un passé récent ne demeure toujours utile et pleine d'enseignements.

[p. 60]

Tel est le dessin général de ces itinéraires, si profondément inscrits sur l'écorce terrestre. Il faut, pour les saisir avec plus de précision et de signification, considérer comment ils se comportent en ce qui concerne un certain nombre de maladies particulièrement typiques. 
[p. 61]

\section{SECONDE PARTIE}

\section{Les routes suivies par les maladies à transmission}

Retour à la table 
[p. 63]

3

\section{Le choléra}

\section{LA MALADIE ET LES CONDITIONS DE SA DIFFUSION}

Retour à la table

Le choléra dit «asiatique » est une maladie infectieuse grave, qu'il faut distinguer de simples états infectieux intestinaux provenant de germes plus faiblement pathogènes et qui, jadis étaient appelés choléra nostras ou la cholérine. Sous sa forme épidémique, il n'est apparu en Europe qu'au XIX $\mathrm{X}^{\mathrm{e}}$ siècle, ses offensives étant de celles qui ont le plus effrayé le monde civilisé : celles-ci n'ont donc jamais passé inaperçues, ce qui fait qu'il est aisé d'en suivre la progression sur les grandes voies de la planète. Le [p. 64] choléra est aujourd'hui virtuellement vaincu, moins dans sa cure quand il se déclare que dans sa prévention par une vaccination efficace et surtout par la protection des eaux qui autrefois le charriaient. Mais ses foyer endémiques traditionnels subsistent, susceptibles d'éventuelles expansions que les progrès de la technique sanitaire réussissent de plus en plus à circonscrire. Il s'agit donc ici d'une étude largement rétrospective, mais dont l'intérêt médical et géographique reste entier.

L'agent pathogène est un vibrion, sorte de petit bacille incurve (d'où son nom de bacille virgule), muni d'un cil vibratoire terminal, très mobile, qui se développe dans les milieux alcalins mais auquel l'acidité nuit. Chez le malade, le vibrion se développe quand il aboutit à l'intestin, provoquant une diarrhée dont, en deux à six jours, l'effet est éventuellement mortel, par déshydratation aiguë de l'organisme. 
Le choléra se transmet, d'homme à homme, soit par les selles qui souillent les vêtements, le linge, les mains du malade, ce qui permet la transmission par contact, soit surtout par absorption d'eau ou d'aliments contaminés, par les déjections cholériques.

Les selles restent dangereuses plusieurs jours après la guérison. Mais ce sont les selles de sujets qui font des formes légères, ambulatoires de la maladie qui permettent la transmission à distance. Cette transmission [p. 65] se fait soit directement par contact ou en filière, d'une maison à l'autre, d'un quartier à l'autre, soit par voie indirecte. Les véhicules en cause sont alors, ou bien l'eau, souillée par les déjections, les lavages de linges (eau du Gange, pluies par ruissellement, l'eau de mer elle-même), soit les objets ayant appartenu au malade, soit les cadavres eux-mêmes. La contamination annexe peut aussi se faire par les mouches, par les poissons des rivières et des zones marines infectées, coquillages, huîtres, cependant que les aliments souillés par la manipulation de quelque porteur de bacilles sont également dangereux (le bacille en effet survit 30 heures dans le sucre et dans le sel, 7 jours dans le pain, 8 jours dans la viande, 7 jours dans le melon, 3 jours dans la tomate, le concombre ; le lait, vite acide, n'est pas longtemps infectant, mais mêlé d'eau il peut être très nocif).

Dans son livre sur Le Pèlerinage de La Mecque, le docteur Duguet montre de façon frappante à quel point la contamination s'accroît du fait des mœurs et plus particulièrement de certains rites religieux de l'Orient : « Une fois établi dans la place, écrit-il, le choléra n'en devait plus partir que difficilement et à la faveur de mesures sévères que l'on mit plus de quarante ans à modifier. Il trouvait là en effet un aliment tout préparé pour son développement, dans l'énorme agglomération de peuples, qui, venus de [p. 66] toutes parts, sans contrôle, se pressaient dans les lieux saints, dans les conditions sanitaires les plus défectueuses sous l'œil indolent des autorités locales, à la fois ignorantes et désarmées. À la même époque, les mêmes conséquences tragiques se reproduisaient ailleurs, à l'occasion de pèlerinages dans l'Inde et dans la Perse, semant par milliers les cadavres sur leur route... La voie de Perse est non seulement le chemin des pèlerins de La Mecque, mais aussi celui des pèlerins chiites, se rendant avec les cadavres de leurs parents aux sépultures des anciens califes abbassides, à Kerbela, Nedjef, Samara. À ce point de vue, les routes de Kanikine et de Bassorah sont les plus menacées, puisque de 1873 à 1891, 663000 pèlerins ont traversé Kanikine, avec 96766 cadavres ${ }^{1}$. "

La propagation est donc épidémique, mais quand l'eau de profondeur est infectée, des foyers endémiques tendent à s'établir, d'où surgissent, plus ou moins périodiquement, des épidémies. Leur caractère et leur intensité sont très variables : tantôt locales, avec des cas peu nombreux toute l'année dans les zones d'endémie, ou bien régionales à un degré plus avancé. Quelquefois, la propagation

M. L. F. Duguet, Le Pèlerinage de La Mecque, 1932 (Conseil sanitaire maritime et quarantenaire d'Égypte). 
se faisant à grande distance, on aboutit à des pandémies, s'étendant comme le mot l'indique à la terre entière.

[p. 67]

Le foyer endémique est en Asie, essentiellement aux Indes et au Bengale ; des foyers secondaires se manifestent dans d'autres régions de l'Inde, du Pakistan, de Birmanie, les îles d'autres territoires de l'Asie des moussons, et secondairement dans la Chine du Sud. Il s'agit de régions basses et humides, densément peuplées, où l'eau des deltas et des rivières est utilisée pour les besoins courants par des populations dépourvues de tout équipement hygiénique : la contamination, dans ces conditions, s'étend des eaux de surface à celles des puits. Quant aux grandes épidémies, s'épanouissant occasionnellement en pandémies, elles se sont succédé à travers tout le $\mathrm{XIX}^{\mathrm{e}}$ siècle et jusqu'au début du $\mathrm{XX}^{\mathrm{e}}$ : de 1817 à 1823 (six ans), de 1826 à 1837 (onze ans), de 1846 à 1862 (seize ans), de 1863 à 1875 (douze ans), de 1883 à 1896 (treize ans), de 1899 à 1911 (douze ans). Par la suite il n'y a plus eu de pandémies à l'échelle mondiale et les épidémies sont restées localisées à des pays asiatiques, avec l'exception, fort intéressante et dont nous parlerons plus loin, de l'épidémie égyptienne de 1947. C'est en ce sens que l'étude de cette maladie est largement rétrospective, mais pour nos parents, grands-parents et arrière-grands-parents, le choléra représentait un des grands fléaux de leur temps (je me rappelle, quant à moi, l'épidémie qui terrorisa Le Havre en 1892). Ce qui prouve les remarquables progrès de la défense contre la maladie et sa propagation [p. 68], c'est que l'épidémie égyptienne de 1947 a pu être circonscrite et finalement maîtrisée.

Cherchons maintenant, avec plus de précision, quelles sont les conditions géographiques et sociales de la propagation cholérique. Attaché à l'homme, à l'exclusion des animaux, le choléra voyage avec lui, d'autant plus vite que les communications se font plus rapides et plus aisées. De ses foyers initiaux l'infection rayonne le long des grandes voies de communications humaines, de sorte que tout ce qui favorise les échanges d'hommes ou de produits favorise en même temps sa diffusion. C'est pour cela que les pèlerinages comportent un tel danger et c'est pour cela aussi que les nœuds de communications constituent des foyers secondaires d'où la contamination se répand en tous sens si la protection des eaux n'y est pas assurée. La diffusion se fait soit par mer, soit par terre (quand l'aviation est survenue, la défense était déjà suffisamment efficace pour que les communications par air ne se soient pas révélées dangereuses). Au temps de la voile, la lenteur des traversées équivalait à une protection. Sur certaines mers comme la Mer Rouge, les vents étaient si incertains que les bateaux s'immobilisaient pendant des semaines entières. On renonçait même de ce fait aux traversées en ce qui concerne La Mecque et c'est par caravanes que les pèlerins gagnaient les lieux saints. Quand la vapeur eut mis Djeddah à quelques jours de Suez la [p. 69] situation changea : c'est en 1858 que l'on commença d'arriver par mer, avec la conséquence que La Mecque devint sans tarder la station de relai entre le Bengale et le delta du Nil : de 1813 à 1912 le choléra ne faisait pas moins de vingt-sept apparitions en Égypte. Mais la propagation par terre n'est pas moins 
dangereuse. Elle se développe en fonction de la rapidité du trajet, car si celui-ci est très lent, comme c'est le cas pour ces caravanes qui s'éternisent dans le désert, la maladie s'estompe, se perd, s'évanouit. Mais la diffusion est également fonction de la densité des régions traversées : c'est ainsi qu'il existe une relative immunité pour les grandes caravanes traversant le désert sur trois ou quatre cents kilomètres, tandis que les zones densément peuplées, comme l'Yémen, l'Assyr ou le Harraaut, entretiennent la transmissibilité de l'épidémie. Quelles que soient les réserves à faire, il faut dire que la propagation par caravanes reste toujours redoutable. Le docteur Duguet cite à ce sujet des exemples probants : en 1846, La Mecque est infectée par des pèlerins venus de Bagdad à travers l'Arabie ; en 1859 et 1893, l'infection provient d'une caravane partie du Yémen; en 1872, c'est encore une caravane issue de l'Inde qui apporte la contagion. On se rendra compte des possibilités infinies de la contamination si l'on réalise qu'en 1893 par exemple sont arrivés à Djeddah 16325 Égyptiens, 15711 Algériens, 20397 Indiens, 13856 [p. 70] habitants des Indes néerlandaises, 9675 Soudanais, 2644 Persans, 1641 Russes, 13477 Turcs, 120 Bosniens, etc. Un nouveau péril est apparu avec l'automobile, du fait de son utilisation sur les pistes désertiques. Quand les caravanes de l'Inde ou de l'Asie centrale arrivaient au Golfe Persique, il leur fallait encore pour atteindre la ville sainte, soit faire un long trajet à travers les solitudes de l'Arabie, soit transborder passagers et marchandises sur des bateaux contournant longuement la péninsule. En automobile, du Golfe Persique à Djeddah, c'est affaire d'une soixantaine d'heures tout au plus, tandis que par Bab El-Mandeb il fallait pour le moins une dizaine de jours. La vertu stérilisante des caravanes disparaît ainsi, comme avait disparu devant la vapeur la valeur stérilisante de la voile.

On voit donc que le choléra pénétrait au Hedjaz avec les pèlerins : il arrivait avec le retour des fêtes, se disloquait quand les fidèles se dispersaient. Venant des Indes ou de l'Extrême-Orient, il parvenait généralement par la Mer Rouge, mais exceptionnellement c'est par terre qu'il s'insinuait à travers l'Afghanistan, la Perse, la Mésopotamie, la Syrie. S'il atteignait l'Égypte, le mal prenait les proportions d'une catastrophe, car il s'agissait là d'un pays-clef, d'où l'épidémie pouvait rayonner sur la Méditerranée, l'Afrique, l'Europe orientale et occidentale. La Russie, la Mer Noire, les Balkans sont susceptibles d'être atteints par [p. 71] terre, à travers les steppes de la Sibérie ou de l'Asie sud-occidentale et l'ont été de façon répétée au siècle dernier. Dans ces conditions la défense sanitaire de l'Égypte s'est révélée comme étant de toute première importance. Une surveillance attentive s'est exercée depuis l'ouverture du canal de Suez en 1869. Le Conseil sanitaire maritime et quarantenaire d'Égypte, organisme international créé en 1881 et maintenu tel jusqu'en 1938, a exercé pendant toute cette période une protection efficace. Soit à Suez, soit à Tor en Arabie s'est interposé un barrage, en vertu duquel on ne passait de Mer Rouge en Méditerranée qu'après avoir été soumis à un sérieux examen. Par voie de terre, le filtrage était moins sérieux parce qu'il était généralement possible de passer à travers les mailles du filet. Depuis la Convention sanitaire internationale de 1938, ce sont les Services égyptiens qui 
assurent cette protection. L'œuvre a été efficace : le choléra persiste, mais la transmission des pandémies par l'Égypte appartient au passé.

[p. 72]

\section{LES ROUTES SUIVIES PAR LES ÉPIDÉMIES DE CHOLÉRA}

\section{$\underline{\text { Retour à la table }}$}

Il faut distinguer la diffusion selon qu'elle se fait par terre ou par mer. Du foyer indien, c'est-à-dire du Bengale, de l'Assam ou de la vallée du Gange, le choléra gagne l'Europe à travers la partie occidentale du continent asiatique, par les routes classiques des caravanes et des invasions : passe de Khyber ou passes voisines, Mesched en Perse, puis de là vers la Syrie, l'Arabie, la Russie. Si l'Égypte est atteinte, la diffusion s'opère ensuite, une fois la Méditerranée traversée, par les ports, les nœuds de chemins de fer, les capitales, sources ultimes de rayonnement. L'Atlantique enfin sert éventuellement de véhicule vers le Nouveau Monde, la planète entière étant alors encerclée.

Le dessin des routes maritimes est plus net encore. Des foyers chinois ou indien, l'épidémie suit la grande voie maritime en direction de Suez, du moins depuis l'ouverture du canal ou des trajets organisés par transbordement à travers l'Isthme, car auparavant la Mer Rouge formait cul de sac : si ses rivages étaient atteints, c'était éventuellement depuis le Golfe Persique par la navigation contournant le continent arabique. Quelquefois, quand l'origine est dans la vallée du Gange, le choléra s'étend non seulement vers l'Ouest mais vers [p. 73] l'Est, en direction de l'Indochine, des Indes néerlandaises et de l'Extrême-Orient. Quand il a atteint la Méditerranée ou la Russie, la richesse même des échanges occidentaux multiplie les possibilités de son rayonnement: de Port-Saïd, d'Alexandrie, de Beyrouth les germes se répandent de tous côtés, en Afrique comme en Europe ; de même, de la Baltique vers la Mer du Nord, enfin d'Angleterre ou de France vers le Nouveau Monde, la planète se trouvant dans ces conditions encerclée. Les courants issus de l'Asie terrienne et de l'Asie maritime se sont ainsi rejoints, par les relais de la Mer Rouge et de la Mer Noire, des fusées lointaines se projetant vers les deux Amériques dans une ultime expansion.

Donnons maintenant avec plus de détails - cela en vaut la peine - la marche géographique de quelques-unes des épidémies les plus typiques du $\mathrm{XIX}^{\mathrm{e}}$ siècle : dans le Dictionnaire encyclopédique des sciences médicales, sous la signature de Laveran, au chapitre « Choléra », figurent les données les plus précises à ce sujet. 
Voici d'abord l'itinéraire de l'épidémie de 1817. Partie en juin du Haut Gange, elle atteint Jessore en août, Calcutta en septembre, se répandant au cours de l'automne sur le Bengale, le Sind, le Plateau de Malwa. En février 1818 Madras est rejoint, puis, par une sorte de périple autour du Cap Comorin et de Ceylan, c'est le tour de la côte du Carnatic et de Bombay [p. 74] en août. De Colombo l'épidémie gagne la péninsule de Malacca vers la fin de l'année, Singapour, le Siam et l'Indochine, en 1819. Bornéo, Canton et Shang-Haï sont contaminées en 1820, les Philippines, les Célèbes, les Moluques et Pékin en 1821, le Japon seulement en 1823. Dans une autre direction, l'épidémie, de Calcutta, a gagné Maurice des 1819, l'T̂le Bourbon en 1820, s'arrêtant ensuite sans que l'Afrique du Sud ait été touchée et le cap de Bonne-Espérance contourné. Mais, de Ceylan, l'infection s'est étendue vers l'Ouest. Mascate, Bassorah, Bender-Abbas, Bagdad sont touchés en 1821 (la Perse est menacée, mais Ispahan, qui se ferme aux caravanes, est préservée). De Mésopotamie, la maladie gagne Mossoul, Diarbékir en 1822, Alep en décembre de la même année, d'où avec des caravanes elle franchit le Taurus, Damas étant rejoint en 1823. Finalement, par Bakou, elle parvient à travers la Caspienne à Astrakan le 22 septembre 1823, pour s'arrêter là : c'est la fin de cette importante épidémie.

On remarquera que la propagation se fait surtout par mer, d'abord vers l'Extrême-Orient sur la grande route de la Chine par Singapour, puis vers l'Île Maurice et la Réunion, enfin vers le Golfe Persique. Mais il est intéressant de noter qu'il n'y a extension maritime, ni vers le cul-de-sac de la Mer Rouge dont les calmes plats découragent la voile, ni vers le Cap et ses au-delà, en dépit qu'il y ait là une route achalandée de voiliers, 
[p. 75]

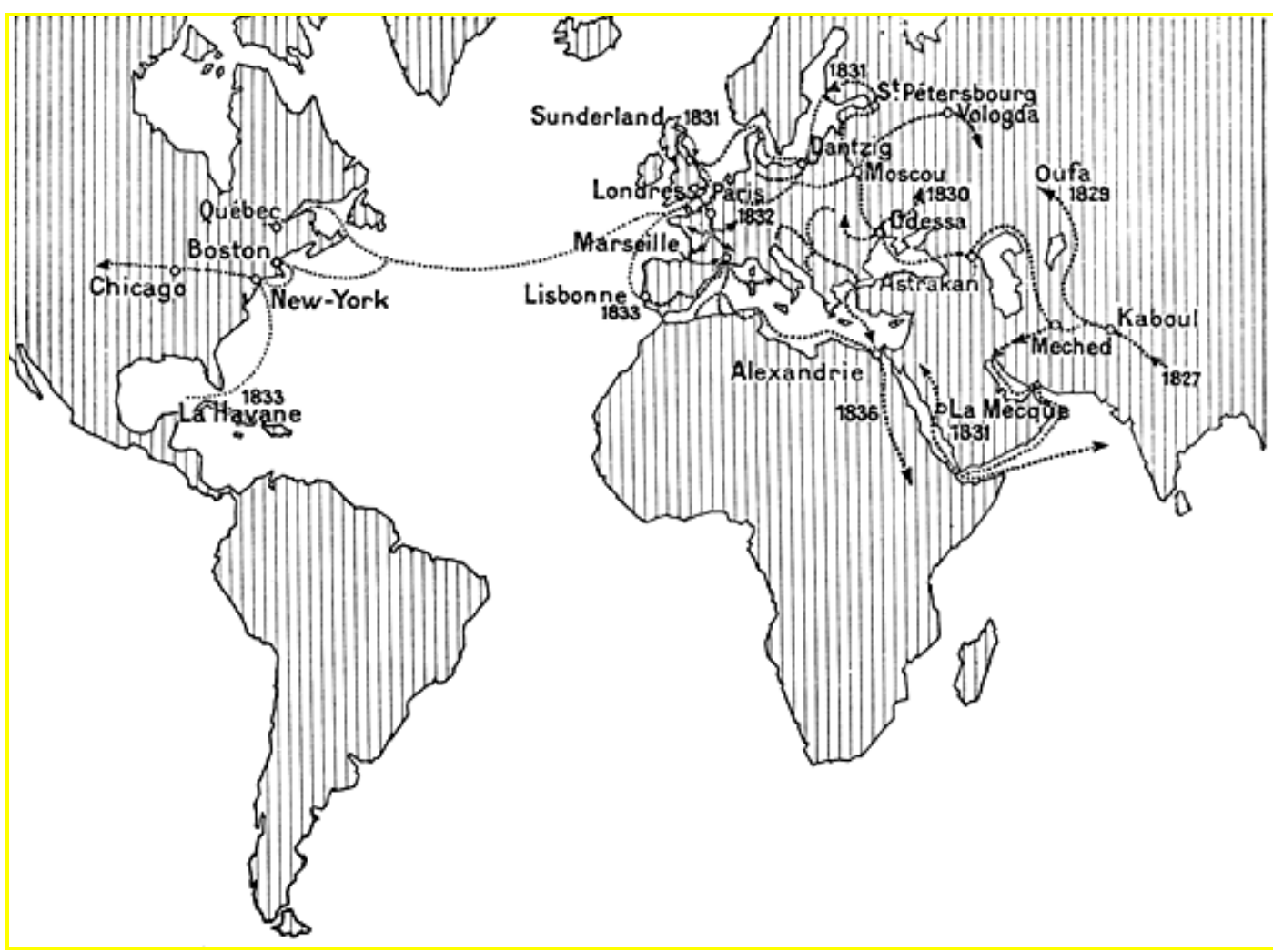

\section{Choléra \\ Épidémie de 1827-1837.}

$\underline{\text { Retour à la table des cartes }}$

[p. 76]

mais les délais y sont longs et la maladie y épuise ses effets. Enfin, à Maurice et à la Réunion, c'est comme un terminus, après quoi il n'y a plus rien. Quant à la propagation par terre, on voit qu'elle se fait le long des voies de trafic de la vallée du Gange, cependant qu'a Jessore elle bute contre les montagnes de l'Afghanistan et s'arrête. C'est par mer qu'elle atteint le Golfe Persique, d'ou la diffusion s'opère selon le réseau des caravanes, en remontant notamment l'itinéraire d'Alexandre, ou vers la Caspienne. Les contrées qui sont en dehors du courant de la grande navigation océanique, comme la Polynésie ou l'Australie, celle-ci encore presque vide à cette époque, demeurent indemnes.

Après une pause de quatre ans, l'épidémie reprend sa marche, mais selon un tracé différent. Réveillée aux Indes en 1827, elle franchit cette fois la passe de Khyber, chemin classique des caravanes, atteint Kaboul, d'où elle rayonne d'une part vers Mesched, de l'autre vers Orenbourg, qu'elle touche en 1829 par une route directe caravanière passant au nord de la Mer d'Aral. En 1830, de Mesched, 
l'infection, par la côte Est de la Caspienne, gagne Astrakan, impliquée déjà dans l'épidémie précédente, mais pour le dépasser cette fois vers la Crimée et Odessa, d'où elle s'étend entre Dniéper et Volga dans le pays des Cosaques du Don. Cette même année elle remonte vers la Volhynie, la Podolie, joignant Minsk en septembre, d'où se produit un rayonnement [p. 77] vers Grodno, Vologda et Nijni Novgorod. En même temps, de la Mésopotamie, des pèlerins, contournant l'Arabie par mer, l'ont introduite à La Mecque en juillet 1830 : Akaba cependant est épargnée et de ce côté l'infection trouve son terminus. Mais, des bords de la Mer Noire, le cheminement continue, sur la Bessarabie, la Moldavie, la Bulgarie (juillet 1830) ; des troupes russes l'insinuent en Pologne, Varsovie étant atteinte en avril 1831. De là le choléra gagne la Silésie, la Prusse (3 juin 1831), la Lithuanie (juillet) et ce même mois les ports de la Baltique, la Livonie, la Courlande, Saint-Pétersbourg. Helsingfors reçoit la contagion en août, Abo en septembre, puis c'est le tour de Dantzig, de Stettin, de Berlin. À partir de là la virulence s'atténue, le Hanovre, Hambourg sont peu touchés, le Sud-Ouest de l'Allemagne reste indemne. Mais, de la Hongrie la maladie, en juin 1831, s'est étendue a la Basse-Autriche, au Banat, à la Styrie, tandis que, des côtes de la Mer Noire, elle rejoint Constantinople et, de là, Smyrne, l’Égypte, Tunis et l'Algérie. Pendant ce temps l'épidémie a passé de la Baltique à la Mer du Nord : on signale sa présence à Sunderland le 14 novembre 1831, à Édimbourg en janvier 1832, à Londres en février, d'où elle gagne Calais (15 mars 1832) et enfin Paris le 26 mars : le premier ministre, Casimir Périer, est une de ses victimes et aujourd'hui même la terreur causée par le fléau n'est [p. 78] pas encore oubliée. De l'Angleterre la contamination a par mer gagné le Portugal, puis, à travers l'Atlantique et prenant décidément le caractère d'une pandémie, le Canada: Québec est touché en juin 1832, la maladie ayant été apportée par des émigrés irlandais, puis Montréal, Boston et New York en juillet et de là le Maryland, le Kentucky, l'Ohio, l'Illinois. Une fusée projette l'infection jusqu'au Pacifique, tandis que le golfe du Mexique, la Havane sont atteints en février-mai 1833. Entre temps l'épidémie s'est ravivée au Portugal du fait de l'arrivée d'Angleterre de recrues pour l'armée de don Pedro, à Oporto; de Vigo, l'infection envahit l'Espagne. D'Espagne, nouveau foyer, le choléra gagne les côtes de la Méditerranée occidentale, Marseille (décembre 1834), Agde, Lunel, la Montagne Noire, la vallée du Rhône, et de Marseille, comme on pouvait s'y attendre, l'Algérie, attaquée cette fois par le Nord, alors que précédemment elle l'avait été par l'Est. L'Italie est touchée en juillet 1835, dans la vallée du Pô d'abord et en Ligurie, puis les années suivantes, 1836 et 1837, dans les États de l'Église, à Naples, sur la côte adriatique. En mai 1837 l'épidémie reparaît à Marseille, d'où elle provoque une reviviscence d'infection à Bône et à Constantine, cependant qu'une reprise d'offensive se produit en Europe orientale, s'étendant de là au Tyrol, à l’Illyrie, à la Bohême, à la Galicie et jusqu'à l'Allemagne du Sud-Ouest précédemment [p. 79] épargnée. En 1836-1837, l'épidémie, qui avait sévi en Égypte, se déclare en Nubie et en Abyssinie : c'est la poussée ultime de cette pandémie, qui a duré onze ans. 
L'épidémie de 1865, la quatrième dans l'histoire du choléra, n'est pas moins instructive. Issue de Batavia et de Singapour, elle atteint, en avril Djeddah, en mai Suez, le 2 juin Alexandrie. À partir de là on a l'impression d'un barrage qui se serait rompu, la maladie se répandant de tous côtés par de multiples canaux. La liste chronologique de ses apparitions, telle que donnée par Laveran, est extraordinairement parlante et le mieux est de la reproduire sans commentaires :

Le Caire : 17 juin 1865

Smyrne : 24 juin

Constantinople : 28 juin

Jaffa : $1^{\text {er }}$ juillet

Beyrouth : $1^{\mathrm{er}}$ juillet

Dardanelles : $1^{\mathrm{er}}$ juillet

Chypre : 8 juillet

Ancône : 8 juillet

Valence : 8 juillet

Gibraltar : 19 juillet

Barcelone : 22 juillet

Marseille : 23 juillet

San Severo : 25 juillet

Volo : 26 juillet

[p. 80] Borche (Podolie) : 28 juillet

Damas : $1^{\mathrm{er}}$ août

Salonique : $1^{\mathrm{er}}$ août

Trébizonde : 2 août

Odessa : 6 août

Toutltcha (Danube) : 7 août

Alep : 11 août

Madrid : 15 août

Kerch : 17 août

Palma : 19 août

Galata : 20 août

Erzeroum : 22 août

Altenbourg (Saxe) : 24 août

Toulon : 26 août

Sansonn : 31 août

Bassorah : 4 septembre

Séville : 6 septembre

Carthagène : 10 septembre

Acqui (Italie du Nord) : 12 septembre

Southampton : 17 septembre

Paris : 18 septembre

Alger : 24 septembre

Bagdad : 25 septembre 
Essex : 26 septembre

Trieste : 27 septembre

Kiev : 27 septembre

Trente : 28 Septembre

[p. 81] San Giovanni de Naples : 28 septembre

Kherson : $1^{\mathrm{er}}$ octobre

Elvas : $1^{\mathrm{er}}$ octobre

Oporto : $1^{\text {er }}$ octobre

Jérusalem : $1^{\text {er }}$ octobre

Naples : 6 octobre

Taganrog : 12 octobre

Pointe-à-Pitre : 12 octobre

New-York : 3 novembre

Vilna : 16 octobre

Saint-Pétersbourg : 17 octobre

Ainsi, l'épidémie s'est avancée finalement dans trois directions extrêmes, l'Amérique, la Russie, la Méditerranée, où elle revient vers son point de départ. En Amérique, la contagion s'étend en 1866 vers Halifax d'une part, de l'autre vers la Nouvelle-Orléans, le Texas, la Californie, l'Amérique centrale, le Brésil, l'Uruguay, le Paraguay, l'Argentine. En Russie, elle se répand sur les pays danubiens, la Podolie, la Volhynie, la Chersonèse, Kovno, Tver, la Finlande. En Méditerranée, elle déborde de l'Afrique du Nord sur l'Afrique occidentale, pour atteindre, en 1970, l’Océan Indien, la côte orientale africaine, les Seychelles, les Comores...

Voilà donc un exemple typique de diffusion par mer, liée manifestement au développement de la navigation à vapeur à cette époque : celle-ci en effet se [p. 82] substitue rapidement à la voile, et d'autre part, encore que le canal de Suez ne soit pas encore achevé ou s'achève seulement, l'habitude s'est prise depuis une vingtaine d'années de gagner l'Inde par l'Égypte, avec transbordement par chemin de fer d'Alexandrie à Suez. Il faut souligner qu'une fois la barrière de Suez franchie, que ce soit dans un sens ou dans l'autre, la maladie se répand sur le monde entier. Le docteur Duguet, dans son livre sur le pèlerinage de La Mecque, a montré de façon saisissante comment le germe, une fois l'isthme franchi, n'a plus trouvé d'obstacle: "En 1865, écrit-il, le choléra sévissait à Java et à Singapour. Il est introduit à Djeddah et à La Mecque par des pèlerins indiens et javanais. On compte bientôt deux cents décès par jour à La Mecque. Les pèlerins javanais, au nombre de 10000 , ont 3000 morts. On estime que, sur 90000 pèlerins, il y a plus de 15000 décès. Du 19 mai au 15 juin, dix navires ramènent 15000 Égyptiens à Suez. Les capitaines des deux premiers navires déclarent n'avoir eu, parmi les pèlerins, au cours de la traversée, que des décès par maladies ordinaires non contagieuses. Ils obtiennent de débarquer leurs passagers en libre pratique. On apprit par la suite, mais trop tard, qu'un de ces bateaux avait dû jeter à la mer plus de cent cadavres: il s'agissait de choléra. Les résultats de ces 
déclarations mensongères ne se firent pas attendre. Ils dépasseront tout ce [p. 83] que l'imagination peut concevoir. Trois jours après le débarquement, le choléra se déclare à Suez. »

Ces quelques données, fragmentaires mais d'une rare précision, nous permettent de déterminer les routes suivies par le choléra dans les épidémies du $\mathrm{XIX}^{\mathrm{e}}$ siècle. Il se propage naturellement le long des grandes voies de communications maritimes que le progrès occidental a aménagées : la carte de l'épidémie de 1865 reproduit celle des grands courants d'échanges de l'époque sur les principales mers du globe. La maladie se répand de la même façon le long des voies terrestres les plus achalandées. Lorsqu'il s'agit des caravanes, le dessin est aussi net que celui des lignes de navigation, mais lorsqu'il est question de pays densément peuplés, la contagion se répand de proche en proche sans qu'il soit possible de tracer schématiquement sa progression. Particulièrement instructive est l'observation des zones épargnées : ce sont celles qui demeurent en dehors des routes commerciales le plus habituellement fréquentées. Le docteur Duguet cite, comme étant dans ce sens, «les îles du Nord de l'Europe : Féroé, Hébrides, Islande, les contrées polaires du Groenland, la baie de Baffin, la baie d'Hudson, l'Amérique russe (Alaska), la Patagonie, la côte Ouest de l'Amérique, la Polynésie, l'Australie, à l'exception de quelques points isolés de la côte Ouest, l'Afrique centrale »... Il est significatif d'observer que [p. 84] l'épidémie, qui atteint l'Argentine, ne double pas le cap Horn, que, sévissant sur la côte orientale de l'Afrique, elle ne double pas le cap de Bonne-Espérance, qu'ayant atteint Maurice et la Réunion elle y trouve effectivement un terminus. Il y a ainsi en effet quelques points terminus au-delà desquels la contamination s'arrête ou s'épuise, soit qu'effectivement les communications n'aillent pas plus loin, soit que la longueur des itinéraires ou la lenteur des trajets épuise la maladie : c'est sans doute le cas, s'il s'agit du cap Horn ou du cap de Bonne-Espérance, car ces voies étaient malgré tout fréquentées, la première notamment plus qu'aujourd'hui au temps des grandes épidémies du siècle dernier. Le docteur Duguet, observateur sociologique avisé, remarque en outre que «c'est par les points les plus ouverts aux communications extérieures que le choléra franchit les frontières qu'il envahit » : en Perse, par Bender Bouchîr, Mesched, Mawer, villes de commerce ; en Russie, par Bakou, Astrakan en Angleterre, par Sunderland, Hull, Southampton en France, par Calais, Dunkerque, Marseille ; au Portugal, par Oporto; en Amérique, par Québec, New York la Pointe-à-Pitre. Les foyers recevant de plein fouet l'infection sont les agglomérations se rencontrant sur le chemin des épidémies ; c'est ainsi que les lieux de pèlerinages, les concentrations d'armées constituent des proies désignées pour la contagion. À cet égard, rien de [p. 85] nouveau sous le soleil, car sous le régime des caravanes ou des bourres sillonnant l'océan Indien, la diffusion se produit de la même façon qu'avec les lignes de navigation modernes, à ceci près que c'est plus lentement. 
En développant le facteur de la vitesse, le $\mathrm{XX}$ siècle suscitait un péril accru de diffusion, mais il développait, dans une mesure autrement efficace, les instruments de la défense contre les propagations. Depuis une cinquantaine d'années en effet, le choléra a pratiquement disparu de l'Occident. Les dernières épidémies se sont déclarées pendant la première guerre mondiale, au Japon de 1912 à 1922, en Russie en 1921, avec extension à la Pologne et dans le Golfe Persique (1923) mais l'Europe proprement dite, ainsi que le Nouveau Monde, ont été épargnés. La diffusion, sous forme pandémique, avait été liée pendant le XIX ${ }^{\mathrm{e}}$ au progrès rapide des communications, cependant que la défense se trouvait devancée et débordée. Depuis que celle-ci a été organisée mondialement par les pays civilisés de l'Occident, leaders du progrès sur la planète, c'est elle qui s'est manifestée la plus forte. Les épidémies peuvent encore jaillir de foyers endémiques qu'il n'a pas été possible jusqu'ici de supprimer, mais on est désormais armé pour les circonscrire. L'épidémie égyptienne de 1947, d'une actualité toute proche, fournit un exemple probant des conditions dans lesquelles la maladie se comporte aujourd'hui et peut être jugulée.

[p. 86]

\section{L'ÉPIDÉMIE ÉGYPTIENNE DE 1947}

\section{$\underline{\text { Retour à la table }}$}

Depuis 1892 il n'y a plus eu de grandes pandémies, l'Occident devenant indemne, au point que la plupart des médecins, n'ayant pas l'occasion de l'observer de première main, n'ont plus au sujet du choléra que des notions livresques. Ce n'est pas que la thérapeutique de la maladie ait fait de grands progrès : les antibiotiques ne sont pas efficaces en l'espèce, de sorte que, lorsque la maladie se déclare, la proportion des cas mortels est élevée. Mais le vaccin, connu depuis la fin du siècle dernier, constitue une arme de défense de valeur réelle bien que temporaire, cependant que les mesures préventives d'hygiène préservent efficacement ceux qui s'y soumettent. C'est donc affaire de progrès dans les mœurs, de sorte que la où la vaccination généralisée n'est pas aisée ou ne se révèle possible qu'accidentellement, là où les conditions d'entassement démographique rendent difficile l'hygiène collective et individuelle, l'endémicité cholérique se perpétue malgré tout. C'est ainsi que l'Inde demeure un foyer d'infection, bien que le choléra y soit manifestement en régression : les épidémies, encore fréquentes, y sont plus faibles que jadis. Quant à l'Égypte, dont la contamination provenait directement de La Mecque, elle n'a plus été touchée depuis que le choléra a disparu [p. 87] du Hedjaz: la dernière des épidémies égyptiennes antérieures à celle de 1947 remonte à 1902. 
La seconde guerre mondiale est l'occasion d'une recrudescence du choléra aux Indes : le corps médical s'y trouve désorganisé par les mesures de mobilisation, tandis que les médicaments tendent à manquer ; la population, qui afflue dans les villes déjà surpeuplées, souffre de disette et bientôt de famine. Les statistiques reviennent aux chiffres du $\mathrm{XIX}^{\mathrm{e}}$ siècle et ne baissent que lentement lors du retour à la paix. Mais en 1947, les mouvements de population résultant de la scission entre le Pakistan et l'Inde et la misère des réfugiés aggrave la situation. Du Bengale, foyer d'endémie permanente, une épidémie s'étend à toute la vallée du Gange et jusqu'au Pendjab, et voici qu'elle se déclare subitement, en septembre de cette même date, à Korein, sur le canal d'eau douce qui relie la ville à la zone du canal de Suez. C'est le centre d'un district dattier, qui abrite des travailleurs employés dans un camp d'aviation anglais voisin, car à cette époque l'occupation militaire britannique de l'isthme persiste encore. Du fait de la panique provoquée par l'apparition de la maladie, l'infection se répand en trois semaines sur toutes les provinces de la Basse Égypte, au Fayoum, puis, avec retardement et dans une moindre proportion, sur la Haute Égypte. Dès octobre-novembre, il y a déclin et en décembre, l'épidémie est [p. 88] terminée : il y a eu en tout 20808 cas et 10276 morts. Le caractère de l'infection est significatif : elle ne touche que peu les villes, où l'adduction des eaux se fait dans des conditions satisfaisantes, mais la maladie manifeste toute sa nocivité dans le delta où les eaux polluées du Nil se répandent partout, contaminant massivement des populations dépourvues d'hygiène, trop denses et par dessus le marché rendues particulièrement vulnérables par une longue absence d'immunité. Dans ces conditions, la maladie reste en fait limitée aux fellahs, les citadins, les classes moyennes et les étrangers demeurant indemnes. Une défense énergique comportant essentiellement une vaccination générale a, comme on le voit, rapidement raison de l'épidémie, qui, poussant simplement une pointe rapidement maîtrisée en Syrie à la fin de l'année, s'arrête, sans autre développement.

Les épidémies égyptiennes antérieures provenaient de La Mecque, celle-ci indiscutablement des Indes. Il ne semble pas qu'il y ait eu négligence des autorités sanitaires à Suez, où le barrage s'est révélé efficace depuis bien des années, mais les conditions du delta comportent évidemment un risque constant d'explosion cholérique, que le moindre relâchement demeure toujours susceptible de déclencher. Sans qu'on puisse exactement le prouver, et en dépit des dénégations britanniques, il est vraisemblable que la propagation [p. 89] s'est faite par les boys indiens d'aviateurs anglais qui se repliaient à cette époque vers la Méditerranée en raison de l'accession de l'Inde et du Pakistan à l'indépendance.

Ces circonstances confirment du reste ce qu'une longue expérience nous enseigne sur les conditions de diffusion du choléra, mais ce qui ressort de cette épidémie extra-indienne, c'est que la maladie tend à devenir une maladie des pauvres, n'affectant que les couches les moins favorisées des populations de l'Orient. Il n'y a pas de prédispositions ethniques au détriment de telle ou telle race, mais le niveau de vie se révèle un facteur décisif : les étrangers résidant dans des zones infectées restent sûrement indemnes dans la mesure où ils prennent les 
précautions nécessaires, et de même les classes sociales indigènes acquises aux façons de faire des Occidentaux. D'autre part, les techniques sanitaires modernes sont désormais capables de circonscrire efficacement toute diffusion. Dès lors le choléra demeure "asiatique ", justifiant ainsi son qualificatif, mais l'ère des épidémies et plus encore des pandémies du passé est désormais terminée. 
[p. 91]

4

\section{La grippe asiatique}

\section{CARACTÈRE ET INTÉRÊT GÉOGRAPHIQUE DE LA GRIPPE ASIATIQUE}

\section{$\underline{\text { Retour à la table }}$}

L’épidémie de grippe dite «asiatique » de 1957 s'est étendue en quelques mois à tous les continents, dans l'hémisphère austral comme dans l'hémisphère boréal, témoignant ainsi d'une extrême capacité de propagation. Elle appartient à une série dont l'influenza de 1889 et la grippe espagnole de 1918 sont les deux principales manifestations antérieures.

Le virus, apparenté peut-être à celui de 1889, diffère considérablement de ceux qui ont été observés [p. 92] dans les grippes des vingt-cinq ou trente dernières années, d'où cette conséquence que les populations, non immunisées, n'ont, en la circonstance, opposé à la contamination que la plus faible résistance : il était naturel, dans ces conditions, que l'épidémie dégénérât en pandémie. S'il n'existe pas de traitement spécifique de la grippe, le vaccin peut du moins limiter ses effets en jugulant des infections secondaires par d'autres germes et en évitant ainsi une mortalité élevée, ce qui était en l'espèce d'autant plus aisé qu'il s'agissait presque toujours d'une atteinte bénigne. Il n'y a donc eu, en général, que peu de décès, mais on peut citer le vers de La Fontaine : « Ils ne mouraient pas tous mais tous étaient frappés. » Le caractère le plus original de la contagion, c'était que la transmission s'effectuait moins par contact individuel que par contamination collective, dans les groupements permanents ou occasionnels les plus denses, écoles, camps, selon les concentrations des ports, des villes, des vacances. Il ne 
s'agit donc pas, comme dans le choléra tel qu'il a évolué, d'une maladie n'atteignant que certaines classes, plus vulnérables en raison de leur absence d'hygiène, mais d'une affection devant prendre facilement une extension quasi universelle. D'où les circonstances et les conditions géographiques de sa diffusion.

[p. 93]

\section{ITINÉRAIRES SUIVIS PAR L'ÉPIDÉMIE}

Retour à la table

Comme dans certaines des pandémies antérieures, le foyer initial se situe dans la Chine du Sud. L'épidémie y a fait son apparition dans la province de KoueiTchéou en février 1957, d'où elle, s'étend en mars au Yunnan, puis au nord du Yang-Tse, le virus étant isolé pour la première fois à Pékin, ce même mois. Des réfugiés en provenance du continent l'apportent à Hong-Kong en avril, d'où elle se répand, dans les deux mois suivants, sur tout l'Extrême-Orient, à Formose et Singapour d'abord (avril), puis au Japon, en Indochine et Indonésie et jusqu'à Cairns et Melbourne (mai), cependant qu'une pointe la porte à Guam, en plein Pacifique, et une autre à Madras (juin). Il est facile de voir que l'infection s'est répandue par les lignes de navigation et d'aviation, ce que manifestent des fusées rapides vers Tokyo, Melbourne et Madras.

En juillet, la maladie atteint Hawaï et la côte californienne, l'ensemble de l'Inde jusqu'à Lahore, le Golfe Persique, Aden, et par une projection lointaine la Hollande, et même Newport en Nouvelle-Angleterre, où elle parvient par l'Atlantique. Elle s'étend à la Tasmanie, à la Nouvelle-Zélande, à Fidji, à la côte occidentale d'Amérique, atteignant La Paz, et au nord-est Terre-Neuve ; ce même mois elle gagne la [p. 94] Mer Rouge, l'Égypte, la Méditerranée orientale, le Soudan, l'Éthiopie, l’Afrique du Sud, Maurice. En août, la voici dans les Antilles, en Guyane, dans l'Uruguay et l'Argentine, cependant qu'elle parvient sur la côte occidentale d'Afrique et d'autre part, à travers la Turquie, en Europe orientale, en Italie, en Allemagne. C'est en septembre que la grippe asiatique prend sa plus grande extension dans tous les pays de l'Europe centrale, occidentale, méridionale et même septentrionale, la France étant un des derniers pays atteints, en septembre-octobre, ce qui semble indiquer un lien avec la rentrée des classes et les mouvements de fin de vacances. Ainsi le monde est encerclé et il s'agit bien d'une pandémie.

Le rythme de la diffusion montre aisément que, sur les lignes de grande communication, maritime ou aérienne, l'infection s'étend presque immédiatement, du fait de tels voyages rapides, portant par exemple sans tarder la contagion, 
d'Extrême-Orient jusqu'à des destinations aussi lointaines que Melbourne, San Francisco ou Rotterdam. La dissémination ne s'effectue ensuite que plus lentement selon la diversification des chenaux locaux. La saison joue un certain rôle, favorable à la maladie dans l'hiver austral, qui est notre été, et à la fin de cet été boréal, mais c'est surtout dans les régions densément peuplées de l'Asie, Indonésie, Indochine, Inde, Europe, que l'épidémie prend toute [p. 95] son extension. Quand elle se généralise, il devient impossible, dès l'instant qu'elle se transmet d'homme à homme, de suivre ses itinéraires. Le hasard des moindres contacts humains suffit à la répandre, selon des répercussions relevant de la plus imprévisible fantaisie. Pour trouver des voies de diffusion précises, limitées, déterminées, constantes, c'est aux maladies se transmettant par vecteurs qu'il faut avoir recours.

L'histoire détaillée de cette pandémie a été donnée dans le Relevé Épidémiologique Hebdomadaire de l'Organisation Mondiale de la Santé.

Notons en passant qu'une autre pandémie grippale de même origine, de virulence et diffusion semblables, se manifesta en 1953 et suivit à peu près le même itinéraire. Mais comme elle ne fut pas baptisée " asiatique », elle n'attira pas l'attention des journalistes, ni l'intérêt des foules. L'analogie inconsciente avec le choléra ne joua pas en ce qui la concerne.

Le parallélisme d'évolution de deux pandémies successives le long des mêmes routes est bien digne de remarque. 
[p. 97]

\title{
TROISIÈME PARTIE
}

\author{
Les routes suivies \\ par les diffusions \\ s'exerçant par vecteurs
}

$\underline{\text { Retour à la table }}$ 
[p. 99]

5

La peste

\section{CARACTÈRES DE LA MALADIE ET CONDITIONS DE TRANSMISSION}

Retour à la table

La peste ${ }^{1}$ est une maladie infectieuse dont l'agent pathogène est le bacille découvert en 1894 par Yersin. Ce bacille, dont le nom technique actuel est Pasteurella pestis, est pathogène, non seulement pour l'homme mais pour un certain nombre d'animaux, notamment les rongeurs, rats, souris, cobayes, sans [p. 100] parler de plus de deux cents espèces de rongeurs sauvages, circonstances essentielles en ce qui concerne les conditions de la diffusion du virus et de sa conservation.

Cliniquement, la peste comporte trois aspects principaux. La peste dite bubonique est caractérisée par l'apparition de bubons, l'infection prenant l'aspect à sa phase terminale d'une septicémie pesteuse. La peste septicémique n'est que la généralisation du processus précédent, le bacille passant alors d'emblée dans le sang. Quant à la peste pulmonaire ou pneumonique, elle comporte une localisation pulmonaire, sévissant en conséquence plutôt dans les pays froids ou durant les saisons froides des pays chauds; c'est ainsi que des cas pulmonaires se trouvent mêlés aux cas buboniques. Cette maladie, qui a semé la terreur au cours des âges et jusqu'au $\mathrm{XX}^{\mathrm{e}}$ siècle lui-même est aujourd'hui vaincue par les antibiotiques : les sulfamides sont efficaces contre la bubonique, la streptomycine

1 Cf. les études, faisant autorité, du docteur G. Girard, chef de service de l'Institut Pasteur de Paris, notamment: Revue Médicale française, «La Peste, situation actuelle et inconnues épidémiologiques », (janvier 1957). 
a sûrement raison, si prise à temps, de la pneumonique, hier encore à cent pour cent mortelle. Il s'agit désormais d'infections devenues bénignes par traitement.

Le mode de transmission varie selon qu'il s'agit de telle ou telle forme de peste. La pulmonaire est directement transmissible d'homme à homme par la toux, l'haleine, les crachats. La bubonique ne se transmet au contraire que par la conjugaison de deux [p. 101] agents, la puce et un type quelconque de rongeur. Le germe est inoculé par la piqûre d'une puce infectée, portée elle-même et transportée, éventuellement à de grandes distances, par des rats ou des rongeurs quelconques ou par l'homme lui-même. Il y a corrélation entre la peste des rongeurs et la peste humaine. C'est la puce qui est le vecteur, le rongeur n'étant que l'hôte : un rat sans puces ne contamine pas, c'est la puce qui contamine, par le bacille pesteux inclus dans son canal alimentaire. L'épizootie précède toujours l'épidémie, le rongeur faisant figure de réservoir et d'intermédiaire, mais c'est la puce qu'il faut détruire, d'autant plus qu'elle est non seulement vecteur mais aussi réservoir de virus, susceptible qu'elle est de survivre à l'infection pendant des mois, tout en demeurant infectante (il peut y avoir jusqu'à cent puces sur un même rat).

L'infection pesteuse est chronique chez de nombreux rongeurs, qu'il faut distinguer en domestiques et sauvages. Parmi les domestiques, deux espèces principales de rats : le rat noir (Epimys rattus) ou rat de maison, originaire de l'Asie occidentale, d'où il aurait émigré en Europe, soit au VI ${ }^{\mathrm{e}}$ siècle après J.-C., soit seulement au temps des croisades; et le rat brun (Epimys norvegicus), rat d'égout ou surmulot, originaire de l'Asie centrale, d'où il n'a passé en Europe qu'au XVIII ${ }^{\mathrm{e}}$ siècle, refoulant peu à peu son congénère. C'est [p. 102] lui qui possède actuellement la suprématie dans le vieux continent, en Afrique du Nord et en Afrique occidentale : bon nageur, capable de traverser des continents entiers, intelligent, actif, c'est un migrateur de premier ordre, sachant se servir des moyens de transports humains, notamment des navires ; en cas de disette, il va de ville en ville, de pays en pays, fréquentant les caves, les égouts, les soutes des bateaux ; le rat noir, plus casanier, habite de préférence les maisons : le rat de ville et le rat des champs de La Fontaine étaient des rats noirs, le fabuliste ne connaissant pas encore le surmulot, du reste moins sympathique.

Parmi les rongeurs sauvages, la peste affecte la gerbille de l'Afrique du Sud, le spermophile ou souslik de la Russie méridionale, le tarabagan des steppes asiatiques, l'écureuil de Californie.

Comment se fait la transmission de l'animal à l'homme ? On admet que les rats pesteux, aux confins de ces régions semi-désertiques que sont le Vold sud africain, la steppe Kirghize, les plaines de la Mandchourie ou de la Sibérie, la sierra californienne, contaminent les rongeurs sauvages, sensibles au virus pesteux. Ceux-ci, par leurs parasites, le transmettent aux êtres humains avec lesquels ils peuvent avoir un contact occasionnel : bûcherons ou chasseurs de fourrures. Il s'établit ainsi une distinction entre le virus continental, qui se perpétue sur les rongeurs sauvages, et [p. 103] le virus océanique, celui des puces 
du rat domestique. Il existe une certaine spécificité de la puce à son hôte : il y a des puces d'hommes, de rats, de chiens, mais cette spécificité n'est pas absolue, la puce pouvant abandonner le rat ou le rongeur pour l'homme - surtout lorsque la mort le refroidit - et inversement, ce qui explique la transformation des épizooties en épidémies. L'infection se transmet alors à l'homme par un mécanisme singulier et compliqué. "Les déjections de la puce, explique le professeur Lavier, contiennent immédiatement du bacille pesteux. La transmission se fait toutefois, moins par les déjections que par un mécanisme extrêmement curieux, élucidé par Martin et Bacot. L'estomac de la puce est précédé par un renflement musculeux, le proventricule, qui agit au moment de la succion du sang, à la manière d'une poire de caoutchouc pour faire aspiration. Dans le sang qui arrive à l'estomac, il y a quelques bacilles ; ceux-ci, dans le milieu sanguin qui leur est très favorable, vont se multiplier aussitôt, formant des colonies compactes, qui augmentent très rapidement leur taille, au point de remplir la cavité proventriculaire et la cavité gastrique. On a ainsi, après quelques jours, une véritable bille flottante de bacilles, qui, dans l'aspiration, vient bloquer complètement, au moment de la succion, l'étranglement qui sépare le proventricule de l'estomac : c'est ce qu'on nomme le blocage proventriculaire.

[p. 104-105]

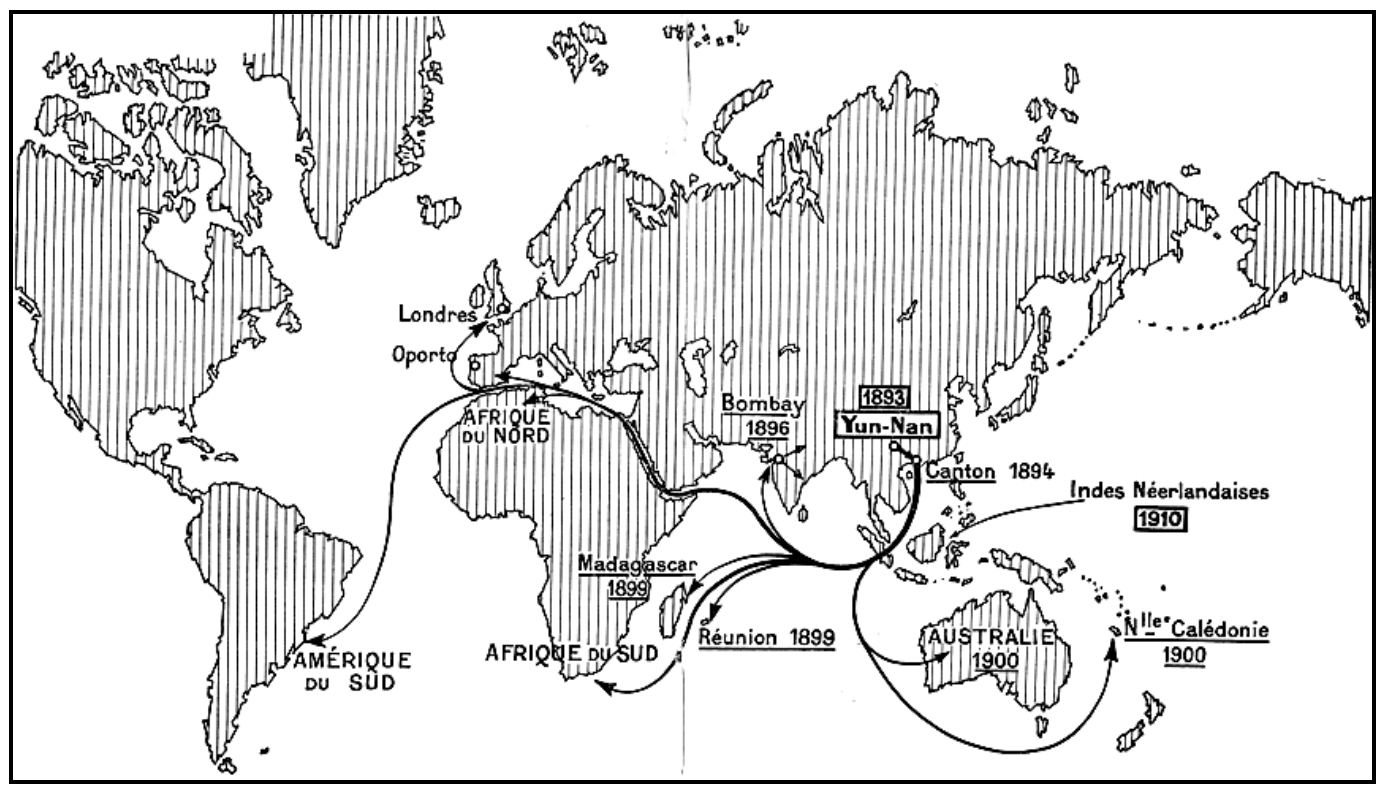

Épidémie partie du Yun-Nan en 1893 
[p. 106]

Quand il est réalisé, chaque fois que la puce piquera, un peu de sang de l'individu piqué arrivera jusqu'au proventricule, entrera en contact avec le bouchon de bacilles, en dissociera quelques-uns de la périphérie, mais le sang ne peut progresser jusqu'à l'estomac. Après quelques efforts vains, la puce cesse l'aspiration, le sang reflue alors au lieu de la piqûre, chargé de quelques bacilles. La puce finit par mourir, après avoir multiplié les essais infructueux et par suite multiplié les piqûres infectantes. »

Je ne sais si ce processus est une imagination de l'esprit du mal, dans sa volonté de nuire. S'il en est ainsi, il faut constater que ses méthodes sont d'une complication peu rationnelle, et l'on pense au calcul de l'humoriste qui, pour compter les moutons, compte les pattes et divise par quatre. Il faut donc une conjugaison de circonstances bien particulières pour que l'infection se transmette. Elle y réussit cependant, et fort bien. Il y a, nous l'avons dit, des puces qui ne piquent pas l'homme et qui en conséquence ne sauraient transformer l'épizootie en épidémie, mais certaines puces du rat dans les régions chaudes passent à l'homme, de sorte que l'épidémie de murine, devient humaine. Là ne se borne pas le rôle nuisible de la puce, car une fois que la peste est établie chez l'homme, la Pulex irritans, encore qu'elle ne pique pas le rat, peut devenir à son tour vectrice d'homme à homme.

\section{[p. 107]}

La propagation, dans ces conditions, peut prendre plusieurs aspects. Elle s'effectue à distance, selon les déplacements des rats pesteux: ceux-ci se déplacent sur des navires, d'où ils descendent dans les ports, et de là se répandent dans les agglomérations voisines, à la recherche de nourriture. Dans les villes ou les villages, la dissémination se fait de proche en proche, d'autant plus que la promiscuité est plus accusée. C'est la propagation à distance qui est le cas le plus fréquent. Elle dépend, d'abord des conditions de transport du rat, puis des conditions de survie de la puce ou du moins de ses larves. Celles-ci étant détruites par le froid, et la chaleur favorisant leur développement, il sera naturel que les épidémies commencent avec les saisons chaudes et finissent quand le froid apparaît : c'est du reste aussi le moment où le rat devient plus casanier. 


\section{LES ÉPIDÉMIES DE PESTE DU PASSÉ}

$\underline{\text { Retour à la table }}$

La peste est connue depuis les temps les plus reculés, à tel point que le terme de peste est souvent employé dans le sens d'épidémie en général. On peut considérer comme relevant de la peste authentique les épidémies de 1320, 1060, 1000 avant J.-C. Hippocrate, Rufus d'Ephèse (100 apr. J.-C.) ont reconnu et décrit son [p. 108] bubon. Au VI ${ }^{\mathrm{e}}$ après J.-C., la peste existe en Égypte, d'où elle gagne Byzance et envahit progressivement le continent européen. Au Moyen Âge, plusieurs épidémies éclatent en Europe et dans le bassin Méditerranéen. La plus célèbre est la fameuse peste noire du $\mathrm{XIV}^{\mathrm{e}}$ siècle, surtout pulmonaire, qui fit, diton, 25 millions de victimes. La progression vers la Mer Noire et le monde méditerranéen a pu être suivie depuis la Chine occidentale. Depuis lors et jusqu'au $\mathrm{XIX}^{\mathrm{e}}$, la peste demeure plus ou moins endémique en Occident : au $\mathrm{XVI}^{\mathrm{e}}$, durant les deux premiers tiers du XVII ${ }^{\mathrm{e}}$, il n'y a pour ainsi dire pas d'année sans quelque explosion de la maladie dans telle ou telle partie du continent. Ensuite elle disparaît, d'abord de l'Angleterre, puis du reste du Continent. On peut croire que le fléau a disparu, mais un foyer chinois subsiste : il se réveille à partir de 1850, reprenant son expansion et, à partir de 1894, une nouvelle pandémie envahit l'Extrême-Orient, les Indes, la Mer Rouge, d'où par Suez elle pénètre en Méditerranée, en Europe, devenant finalement mondiale et atteignant pour la première fois dans l'histoire l'hémisphère austral. Dès cette époque toutefois, l'épidémiologie de la peste est suffisamment avancée pour que les mesures de défense opposées à la contagion éteignent assez rapidement les foyers de l'infection. Mais en octobre 1910, apparaît la grande épidémie pneumonique de Mandchourie, d'une extrême [p. 109] violence, mais localisée à la Mongolie, à la Mandchourie, à la Chine du nord : elle dure tout l'hiver et s'éteint au printemps. Une deuxième épidémie de même origine et d'étendue similaire se produisit en 1920 et présenta une gravité identique. Elle était jugulée en 1921 et ne reparut plus depuis lors.

Mais la dernière pandémie de peste bubonique a suscité de nouveaux foyers, persistant sous des formes diverses qu'il convient de distinguer. La peste classique, celle qui transmise par les rats, constitue pour les êtres humains le péril le plus direct, répond à un type épidémiologique qu'on peut appeler urbain. L'endémicité est, dans ce cas, entretenue par des rongeurs vivant dans les agglomérations en contact plus ou moins proche et permanent avec l'homme. Des foyers de cette peste sont aux Indes et en Chine, dans le Yunnan ; mais des foyers de moindre importance se manifestent encore de temps en temps en Indochine (Cholon, Cambodge, Annam), en Indonésie, en Asie occidentale, au Kurdistan (Iran), en Afrique (Ouganda, Tanganyika, Kenya, Madagascar), en Amérique du 
Sud, en Europe. La technique sanitaire est en mesure de contenir efficacement toute expansion en dehors de ces foyers.

Mais il existe en outre une peste rurale, dite sylvatique, en provenance des rats urbains, qui sévit parmi les rongeurs sauvages. La maladie est alors rurale, épizootique, toujours susceptible cependant de se [p. 110] transmettre aux hommes, de sorte qu'il y a là un réservoir latent de virus, probablement indéracinable. Sans doute cette peste sauvage ne menace-t-elle pas directement l'être humain: les puces des animaux impliqués ne piquent pas normalement l'homme, et du reste il s'agit de régions généralement peu habitées. Tant que le rat urbain demeure indemne, la transmission ne s'opère pas, mais la source subsiste et il peut y avoir réveil de foyers longtemps silencieux, selon des cycles dont la périodicité demeure obscure, le virus pouvant se maintenir vivant chez certains rongeurs sans lui conférer l'immunité. Les foyers actifs de peste sylvatique (avec cas sporadiques humains) sont la Mongolie, la Transbaïkalie, les steppes de la Volga, l'Iran, le Kurdistan, l'Afrique du Sud, le Congo belge, le Nord-Ouest du Brésil, l'Extrême-Nord de l'Argentine, le Pérou, le Venezuela, la Californie, les Montagnes Rocheuses tant canadiennes qu'américaines.

Il s'établit ainsi une relation entre l'épizootie et l'épidémie, si un échange de parasites se produit entre les rongeurs sauvages des steppes et les rongeurs des zones urbaines ou du moins peuplées avec quelque densité. L'existence du rongeur sauvage infecté dépend ensuite des disponibilités de nourriture, d'où un lien entre le complexe pesteux et les formations végétales des steppes ou du désert. La maladie se trouve ainsi entretenue et, dans certaines circonstances, elle peut [p. 111] refluer sur l'homme. En règle générale, l'épizootie précède l'épidémie dont elle est la cause, et la violence de l'explosion épidémique est en relation avec la densité du peuplement animal. Les puces, abandonnant les cadavres refroidis des rats, se réfugient sur l'homme, qui constitue pour elles un hôte de suppléance, et, si l'on ose dire, un pis-aller. L'expansion du bacille demeure cependant limitée, par le fait que sa transmission n'est pas directe et aussi parce que l'épizootie murine entrave la multiplication des puces ellesmêmes. Mais l'espèce infectée n'est jamais détruite toute entière, réduite seulement, de sorte que la maladie peut se ralentir sans que les termes du complexe aient été annihilés. Le passage de l'endémie à l'épidémie et le retour de l'épidémie à l'endémie s'expliquent par ce cycle, dont la loi est parfaitement logique. Si cependant ces conditions ne se réalisent pas, le cycle ne se déclenche pas, ce qui fait qu'une épizootie murine, même violente, peut n'avoir aucune répercussion humaine, soit qu'il n'y ait pas de puces vectrices, soit que les rats en cause ne soient pas domestiques et par conséquent ne mettent pas le germe en contact avec l'homme. Les foyers de peste sylvatique, qui, on le voit, demeurent nombreux, ne sont donc pas un danger nécessairement grave. Ils peuvent le devenir, et engendrer des épidémies locales, si les conditions de contact propres à la diffusion viennent à se produire entre le monde sauvage et le [p. 112] monde civilisé. En ce sens la peste, encore qu'elle se guérisse et se circonscrive efficacement, ne peut être considérée comme intégralement vaincue. 


\section{GÉOGRAPHIE DE LA DIFFUSION}

$\underline{\text { Retour à la table }}$

La diffusion géographique de la peste dans le monde obéit à des lois beaucoup plus complexes que le choléra, puisqu'elle met en jeu trois facteurs, les vecteurs, leurs hôtes et l'homme lui-même.

Distinguons d'abord, comme plus simple, la diffusion de la peste pneumonique, dont logiquement l'étude eût dû trouver place dans les chapitres précédents. Le point de départ de l'épidémie de 1910 se situe en Mongolie, parmi les chasseurs de fourrures. De là le fléau reflue vers l'est, le long des lignes de chemin de fer alors existantes, pour atteindre Kharbine, où l'infection sévit a la fois chez les jaunes et chez les blancs, dans le faubourg chinois de Foudiaxdian. De là c'est le rayonnement normal, le long des voies habituelles de trafic, soit vers le sud le long de la ligne de chemin de fer Kharbine-Moukden-Dalny, soit vers l'ouest en direction de Tien-Tsin et de Pékin. Au printemps l'épidémie s'arrête, sans que sa propagation ait été plus loin. Mais pourquoi ? L'explication ne paraît pas avoir été donnée, car étant donné l'extraordinaire [p. 113] densité démographique de la Chine du Nord, une expansion plus accentuée vers le sud eût paru vraisemblable.

Plus compliqué est le cas de la peste bubonique. Il faut que la puce inoculatrice soit transportée, qu'elle survive, et, pour qu'elle puisse être transportée, il faut que le rat, son hôte, soit transporté lui-même : c'est donc un aspect de la migration des rats. Suivons donc les étapes de l'épidémie de 1894. Elle part, comme on sait, du Yunnan, d'où elle apparaît sans tarder à Hong-Kong, rayonnant de là sur la Chine du Sud et le Tonkin. En 1896, elle est à Bombay, d'où elle s'étendra à l'Inde entière, y faisant en seize années huit millions de victimes; en 1897, elle atteint Djeddah, en 1899, Suez et Alexandrie (rentrant d'Inde en Europe au printemps de 1900, je me rappelle le bateau s'arrêtant à bien des reprises pour jeter des cadavres à la mer et l'on s'était assuré au départ de Bombay que les aisselles ou l'aine ne laissaient pas apparaître de bubons). Des Indes, le germe gagne l'Australie, la Nouvelle Calédonie, la Réunion et Maurice, les ports de l'Afrique orientale, le Cap, où l'infection paraît s'arrêter. D'autre part, des Indes également, mais selon les voies de terre, l'épidémie, ayant traversé le col de Khyber et les passes voisines, rejoint la Perse, d'où elle gagne d'un côté la Russie par la Caspienne, de l'autre la Mésopotamie, la Turquie, et enfin, par les caravanes du [p. 114] désert, l'Arabie. D'Égypte c'est le départ d'une authentique pandémie: presque tous les ports européens sont atteints, Marseille, Trieste, Porto, Liverpool, Glasgow, Hambourg... Puis la maladie traverse l'Atlantique, apparaissant à Santos puis Sao Paulo, à Rio de Janeiro, dans les Antilles, à San 
Francisco. Il est quasi impossible de donner ensuite une liste complète, car pratiquement c'est la terre entière qui est impliquée.

Le commentaire géographique de cette diffusion pandémique est intéressant à donner. Des foyers initiaux, qui sont à l'intérieur des terres, l'infection descend d'abord vers les ports, comme par gravité. Des ports, elle rayonne selon le dessin des lignes de navigation, telles que nous avons pu déjà observer pareil rayonnement à propos du choléra, mais sans pénétrer immédiatement au centre des continents. Le mécanisme de cette limitation topographique est assez clair : les rats voyagent avec les navires, qu'ils affectionnent, puis descendent à terre dans les ports, emportant avec eux leurs puces infectées, qu'ils passent aux populations marines locales immédiatement voisines de la côte. Mais ces rats demeurent dans les agglomérations côtières, de sorte que l'intérieur est moins expose à la contagion. La carte de l'épidémie reproduit, dans ces conditions, celle des grands itinéraires maritimes de l'époque, le bateau fournissant un véhicule convenant parfaitement aux mœurs des rats. Signalons [p. 115] cependant, comme nous l'avions fait pour le choléra, que certaines de ces fusées de diffusion s'arrêtent d'elles-mêmes: la maladie par exemple trouve un terminus à la Réunion ; le long de la côte orientale d'Afrique, elle atteint le Cap de BonneEspérance, mais ne va pas plus loin ; elle rejoint les Açores, et s'arrête. La raison doit en être cherchée, soit dans le fait qu'il s'agit de terminus, soit dans la longueur des trajets, au cours desquels l'infection tend à s'épuiser et à disparaître.

Si, des ports, la contamination pénètre à l'intérieur, c'est plutôt sous la forme sylvatique qu'on la retrouve ensuite. Elle constitue alors ces zones d'enzootie où le virus ne se manifeste que chez l'animal. Une fois encore, les conditions de la diffusion apparaissent compliquées, et heureusement telles : le rat des ports est un rat de ville, ne fréquentant pas naturellement cette espèce de rat des champs qu'est le rongeur des steppes ou des forêts ; celui-ci n'a pas de raisons particulières de quitter sa solitude : s'il le fait, c'est chassé par la faim ou simplement pour fuir luimême l'épizootie et il peut contaminer alors les rongeurs locaux de l'arrière-pays, plus ou moins commensaux des humains. Quand les zones de peste sylvatique ne sont pas trop éloignées des ports, ceux-ci ne sont pas à l'abri de toute menace, même aujourd'hui.

Dès l'instant que la peste se guérit, se prévient par [p. 116] vaccination et se limite avec efficacité, elle ne conserve d'actualité que dans ses foyers. Dans ces conditions la géographie de sa diffusion est d'un intérêt surtout rétrospectif Nous avons pensé cependant que, de ce point de vue strictement géographique, l'étude méritait d'être faite. 


\section{La fièvre jaune}

\section{DÉFINITION, FORMES DIVERSES ET MODES DE TRANSMISSION}

\section{$\underline{\text { Retour à la table }}$}

Cette maladie infectieuse, appelée selon les lieux fièvre jaune, vomito negro, vomito preto, fièvre amarile, provient d'un virus localisant principalement son attaque dans le foie et les reins et générateur d'une septicémie. Le rythme de l'infection comporte une première phase de trois à quatre jours, puis une seconde, celle de la fièvre jaune proprement dite, de cinq à six jours. On distingue trois types épidémiologiques : la fièvre jaune urbaine, longtemps la seule forme connue de la maladie ; la fièvre jaune [p. 118] rurale et la fièvre jaune sylvestre. Les deux premiers types se classent ensemble, comportant le même mode d'extension, ne différant que selon la densité des populations.

Le réservoir de virus de la fièvre urbaine et rurale est uniquement constitué par les hommes malades et seulement pendant les trois jours de la première phase de la maladie, quelle que soit la gravité de l'atteinte. La fréquence des cas atténués et même des affections inapparentes accroît le danger de contamination, permettant et facilitant l'établissement de l'endémicité.

La fièvre jaune se transmet par vecteur, l'Aëdes Aegypti (autrefois appelé Stegomia fasciata), moustique domestique ou péri-domestique se développant dans les plus petites flaques d'eau et pénétrant dans les maisons. La piqûre devient infectieuse après huit jours, de sorte que les conditions de survie de l'insecte correspondent à un élément important de la diffusion : l'optimum de survie de l'Aëdes se réalise entre 27 et 32 degrés centigrades ; au-dessous de 25 degrés son activité se réduit; au-dessous de 17 degrés il disparaît et la gelée le détruit sûrement. La chaleur est donc l'ambiance nécessaire à l'activité biologique de ce 
vecteur, et comme il a besoin d'eau pour ses gîtes larvaires, ce sont les pays tropicaux humides qui se prêtent le mieux à sa multiplication, surtout à la fin de la saison chaude, c'est-à-dire en février-mars dans [p. 119] l'hémisphère austral. L'endémie s'institue quand l'Aëdes vecteur, étant entré en contact avec des malades et s'étant infecté de ce fait, infecte à son tour des sujets sains. La sensibilité hygro-thermique de l'insecte étant très vive, il se développe naturellement si la température s'élève et alors, même dans un pays généralement sain, il peut se produire une épidémie. La diffusion, supposant une transmission constante des germes, se manifeste principalement dans les centres densément peuplés : dans les milieux de population dispersée l'épidémie meurt d'elle-même ; il s'ensuit qu'en Amérique du Sud par exemple la fièvre ne se maintient que sur les côtes, l'intérieur n'étant que relativement atteint ; mais la même, une fois qu'elle y a pénétré, l'infection est susceptible de se maintenir. Il est constaté qu'un séjour prolongé en pays chaud tend à immuniser: le nouveau venu est, dans ces conditions, plus vulnérable. On observe aussi qu'en Afrique c'est le noir qui est plus sensible à l'infection, en Amérique le blanc.

La fièvre sylvestre est d'un comportement épidémiologique différent. Le réservoir de virus en effet n'est pas constitué par l'homme, mais par des animaux sauvages ; le vecteur n'est pas non plus l'Aëdes Aegypti, qui n'existe pas dans les régions à fièvre sylvestre, mais un moustique d'autre espèce. En Amérique du Sud, en Amérique centrale, en Afrique, le réservoir de virus est constitué par des singes, les vecteurs étant [p. 120] divers espèces d'Aëdes, mais le virus est le même que celui des autres formes de la maladie : introduit dans les régions où existe l'Aëdes Aegypti, il peut être le point de départ d'une épidémie de type rural ou urbain. La femelle du moustique, qui seule pique, s'attaque non seulement au singe mais aux animaux les plus divers ; elle peut même se passer de sang, se nourrissant de fruits, de jus sucrés, qu'elle pique comme un animal, d'où le danger de certaines cargaisons de sucre ou de bananes. La fièvre sylvestre existant dans des régions d'accès difficile, ou l'homme éventuellement ne pénètre même jamais, est relativement statique dans sa distribution, encore, comme nous le verrons tout à l'heure, qu'on ait pu suivre, dans les forêts vierges, le sens de ses extensions, de sorte que le danger de contamination humaine est en l'espèce réduit. Il faut, pour que l'homme soit atteint, qu'il pénètre dans la région infectée : ce sera par exemple le cas de tels bûcherons ou trappeurs s'y aventurant par métier. Même ainsi, la diffusion ne s'effectuera qu'à courte distance, car l'incubation est de deux à six jours, l'infectiosité de trois jours tout au plus. Si cependant l'homme atteint rentre pendant ce temps dans les agglomérations voisines, il peut en résulter d'authentiques épidémies. 
[p. 121]

\section{CONDITIONS DE PROPAGATION}

\section{Retour à la table}

L'épidémie se déclenche par l'introduction du virus dans une région où l'Aëdes existe, le virus pouvant être introduit, soit directement chez l'homme, soit chez l'Aëdes.

Si c'est chez l'homme, le danger n'existe que pendant trois jours, ce qui signifie que la propagation restera strictement locale dans les pays où les déplacements ne se font qu'à pied ou à cheval; la navigation, en dépit de sa lenteur, sera quand même à redouter, mais davantage l'automobile ou le rail. En revanche l'aviation comporte un péril certain, puisqu'il n'est plus de point de la planète qui ne se puisse atteindre dans ce délai de trois journées.

Dans le deuxième cas au contraire, le virus fixé dans l'insecte reste longtemps nocif. Une fois infecté, l'Aëdes Aegypti demeure infectieux toute sa vie, dont la durée dépend des conditions thermiques et nutritives qu'il rencontre. Sans doute son activité diminue-t-elle au-dessous de 23 degrés, mais elle persiste au ralenti jusqu'à 14 degrés, l'engourdissement et la mort de l'insecte ne se produisant qu'avec un froid caractérisé. L'hiver européen et américain est invariablement efficace à cet effet, mais dans les régions tropicales la survivance se produit toute l'année. Que se passe-t-il [p. 122] quand le virus arrive ainsi dans une région ? S'il s'agit d'un climat tempéré, Europe occidentale par exemple, plusieurs éventualités peuvent se produire : le virus étant apporté par un malade, il n'y aura pas de second cas, quelle que soit la saison; si c'est un Aëdes qui est responsable de l'infection et que ce soit l'hiver, l'insecte mourra sans qu'il y ait aucune suite ; mais, en été, il pourra piquer quelques personnes au cours d'une brève survie, provoquant ainsi quelque petite épidémie. Dans les régions tempérées déjà plus chaudes, non plus l'Angleterre ou la France, mais l'Espagne, le Portugal, le Maroc, où l'Aëdes existe pendant l'été, le virus apporté soit par l'homme soit par l'insecte suscitera éventuellement une épidémie qui pourra durer autant que l'été, mais pas davantage : c'est le cas des épidémies espagnoles ou louisianaises. S'il s'agit enfin de régions tropicales où l'Aëdes existe toute l'année, le virus, quelle que soit la forme sous laquelle il arrive, pourra prendre pied, donnant naissance à une nouvelle zone d'endémicité. Quels que soient les progrès sensationnels qui ont été réalisés dans la défense contre la fièvre jaune, le danger de son extension à des régions non touchées et par conséquent non immunisées subsiste, notamment en ce qui concerne l'Océan Indien et l'Inde, indemnes jusqu'ici. 
[p. 123]

\section{DISTRIBUTION GÉOGRAPHIQUE DE LA FIÈVRE JAUNE}

\section{$\underline{\text { Retour à la table }}$}

Depuis qu'au début du $\mathrm{XX}^{\mathrm{e}}$ siècle la technique sanitaire de défense a atteint une quasi parfaite efficacité, l'âge des grandes épidémies, qui menaçaient jusqu'à l'Europe, est passé, mais il y subsiste des endémies, éventuellement en sommeil, susceptibles de se réveiller occasionnellement, sans parler de leur danger d'extension à des continents traditionnellement épargnés.

La distribution géographique de la maladie ne coïncide pas avec celle de l'Aëdes Aegypti. Il existe de nombreuses régions, telles l'Asie et l'Océanie, où le moustique abonde et ou cependant la maladie n'a jamais paru. En revanche, et il s'agit là d'une notion relativement récente, il y a des régions où l'Aëdes n'existe pas et où cependant la maladie existe dans sa forme sylvestre; c'est le cas de telles zones américaines et africaines.

En Afrique, l'aire de la fièvre jaune a été effectivement limitée par la pratique généralisée des vaccinations. L'affection animale subsiste, sans qu'on en connaisse exactement l'étendue, mais les atteintes à l'homme sont devenues rares, au point d'apparaître comme un accident, révélateur de quelque enzoo-épizootie voisine. La carte correspond à une zone limitée au nord par le [p. 124] Sahara, au sud par le Kalahari, à l'est par la dorsale africaine, au delà de laquelle la savane, relativement sèche, ne se prête pas à la conservation du virus amaril et à sa diffusion. À l'est du $35^{\mathrm{e}}$ méridien, il n'y a pratiquement pas de cas de fièvre jaune : la fièvre jaune ne s'est jusqu'ici jamais manifestée, ni en Éthiopie, ni en Érythrée, ni dans les Somalies, ni au Tanganyika, ni à Zanzibar, ni dans les Rhodésies et le Nyassaland, ni dans la partie méridionale du Betchouanaland, ni dans le Mozambique, ni dans l'Union sud africaine ; dans le Kenya et l'Ouganda, on ne signale que des cas extrêmement rares et ne pouvant être considérés comme typiques. La partie la plus orientale de cette aire, où la maladie ne s'est encore pas manifestée autrement que par la positivité des tests de séro-protection est souvent appelée la « zone silencieuse ». Il y a la une barrière mondiale de la fièvre jaune, qui jusqu'ici n'a pas été transgressée, mais nous n'avons nulle garantie qu'elle ne le soit pas quelque jour.

En Amérique, la fièvre jaune urbaine n'a plus que quelques foyers côtiers restreints, au Brésil, mais la fièvre rurale s'observe encore dans l'intérieur, et surtout la sylvestre. C'est celle-ci qui représente l'aspect le plus actuel de l'endémie, les nombreuses prospections effectuées durant ces dernières années 
montrant sa fréquence, due à la fois à sa propagation par vagues épidémiques et aussi au fait qu'on la connaît de mieux

[p. 125]

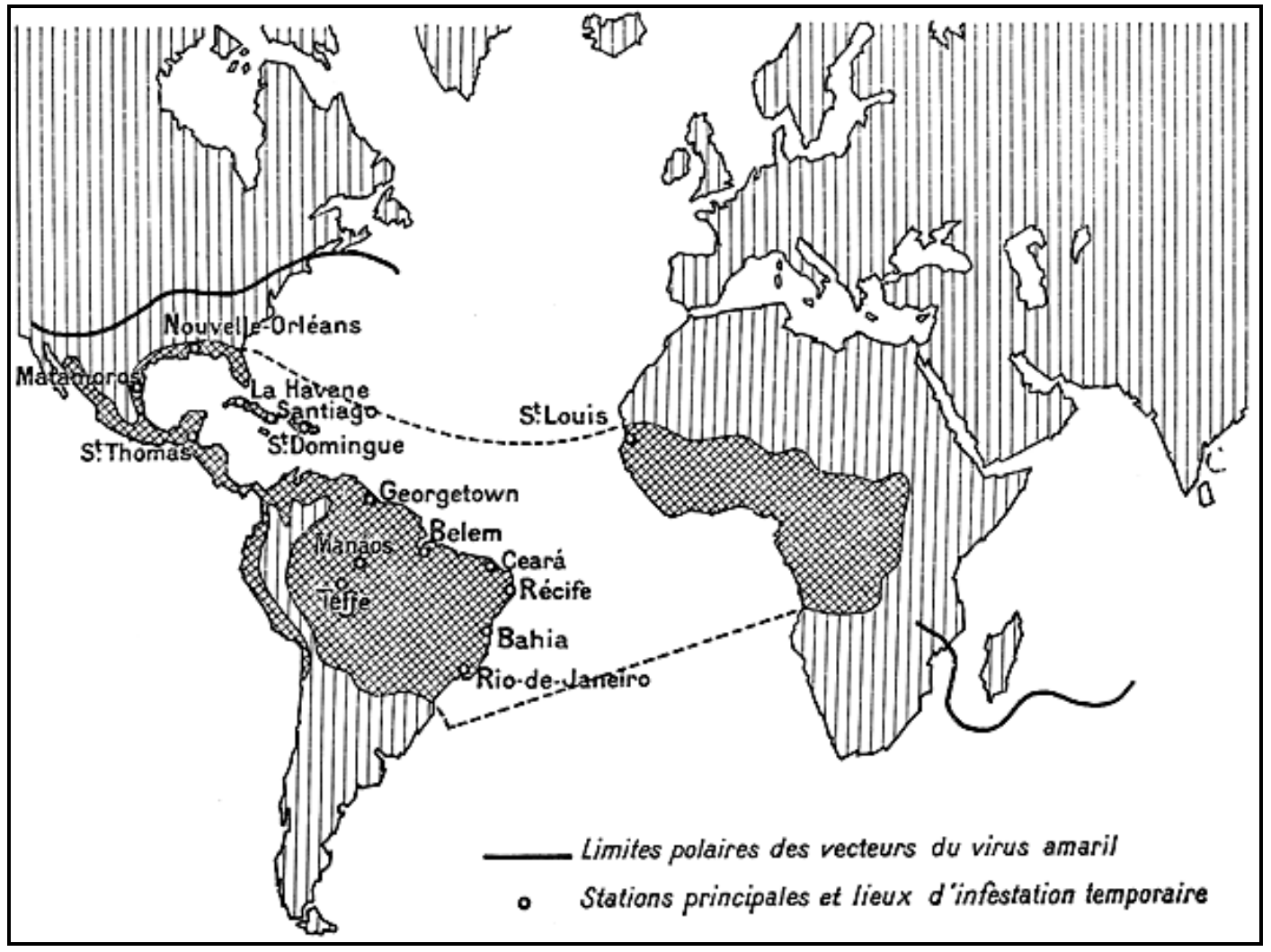

$\underline{\text { Retour à la table des cartes }}$

\section{Domaine endémique de la fièvre jaune}

[p. 126]

en mieux, la dépistant ainsi plus sûrement. Elle s'étend à toute la zone nord-ouest du continent sud-américain, à la zone des isthmes de l'Amérique centrale ; sa dernière vague a progressé à travers l'isthme centre-américain jusqu'à la frontière sud du Mexique, menaçant ce pays et même le sud des États-Unis.

La progression de l'infection amarile à travers la forêt équatoriale est assez régulière, quelques centaines de kilomètres par an, qui correspondent au vol des moustiques vecteurs arboricoles infects et parmi eux surtout l'Haemagogus spegazzini. Le vent leur fait faire des bonds en avant, et c'est ainsi qu'a pu être franchi le Canal de Panama. 
Les singes de la forêt sont piqués par les Haemagogus, subissent l'infection amarile, à laquelle la plupart du reste succombent, mais pendant les premiers jours de la maladie servent de réservoir et de relai à la fièvre jaune.

La mort des singes rend muette la forêt équatoriale après le passage de la vague épizootique qui disparaît ainsi spontanément et ne pourra revenir que lorsqu'une nouvelle population de singes réceptifs se sera reconstituée.

Le processus évolue à l'insu de l'homme et sans l'atteindre, à moins que la hache du bûcheron n'amène à son niveau les essaims d'Haemagogus infectés de la cime d'un arbre, qui lui feront contracter la fièvre jaune sylvestre.

[p. 117]

Contre l'Aëdes, le moustique domestique des zones urbaines, les procédés de destruction et surtout le D.D.T. pulvérise dans les habitations se sont révélées intégralement efficaces. Contre les moustiques de la forêt, on est désarmé. On ne peut pas vacciner les singes et autres réservoirs animaux d'une affection dans laquelle l'homme n'est qu'un épiphénomène. La vaccination difficile à appliquer à l'homme isolé dans la forêt n'est qu'un palliatif. Cependant le mal est contenu puisque les villes jadis foyers et étapes de la Fièvre Jaune sont protégées ; on peut donc dire que la science médicale et la technique sanitaire l'ont vaincu. Mais quelles sont les routes suivies par les épidémies anciennes, quelles sont celles que pourraient emprunter de nouvelles diffusions, sur des terrains encore vierges?

\section{LES ROUTES SUIVIES PAR LA FIÈVRE JAUNE}

\section{$\underline{\text { Retour à la table }}$}

On croyait généralement autrefois que l'Amérique constituait le foyer le plus ancien de la fièvre jaune et c'est en effet dans le Nouveau Monde que la maladie était le plus anciennement connue. En vertu d'une thèse plus récente, le foyer initial serait africain. On estime aussi que, de part et d'autre, il y aurait eu immémorialement une infection amarile indépendamment de toute relation entre les deux continents.

[p. 128]

La première description reconnaissable de la fièvre jaune a été donnée, en 1635, par le P. du Tertre, qui l'avait observée aux Antilles. Vers le milieu du XVI ${ }^{\mathrm{e}}$ siècle, on en constate l'existence dans le golfe du Mexique et sur la côte brésilienne. La propagation se poursuit par les bateaux, à la fois vers l'Amérique du Sud et l'Amérique du Nord : Boston, New York, Philadelphie ; il y a en outre pénétration le long des voies fluviales: Mississippi, Ohio, Amazone, Rio de la Plata. La côte du Pacifique, au nord et au sud, est atteinte jusqu'en Colombie et 
jusqu'au Chili. Ainsi, dès le début, la fièvre jaune s'avère un obstacle sérieux à la colonisation : en 1764 par exemple, une tentative d'établissement en Guyane française échoue lamentablement, douze mille Européens, à Cayenne, à Kourou, succombant à la maladie. En Afrique, il y a identification au Sénégal, en 1759, 1766, 1769, mais, des le $\mathrm{XVI}^{\mathrm{e}}$ siècle, il semble que la fièvre jaune ait sévi au Cap Vert, aux Canaries, dans le golfe du Bénin : il faut, dans toutes les entreprises de colonisation, compter avec elle.

L'Europe, restée longtemps indemne, est atteinte dès le début du XVIII ${ }^{\mathrm{e}}$ du fait des contacts naturellement dus à la navigation. En 1723, une épidémie importante se déclare à Lisbonne ; en 1730 la maladie apparaît à Cadix, y reparaît en 1733, en 1741, causant cette fois 10000 décès ; puis c'est aux Baléares que [p. 129] l'infection s'insinue, en 1744. Le $\mathrm{XIX}^{\mathrm{e}}$ siècle, avec l'accroissement des relations par mer entre le vieux et le nouveau continent, voit les épidémies se multiplier, surtout sur ces « bords mystérieux du monde occidental » chantés par Heredia, mais où la protection antérieure du mystère n'existe plus. Une grave épidémie éclate a Cadix en juillet 1800, et cette fois le fléau s'étend à Séville, Carthagène. La maladie prend pied en Espagne, où, dit-on, elle aurait fait cette année-là près de 80000 morts. En effet, les années suivantes, la fièvre jaune reparaît à Malaga, y faisant des milliers de victimes. Puis, en 1810 et les années suivantes, c'est à Cadix, à Barcelone, où il y a 25000 décès. Il est naturel, en raison de sa position géographique en forme de proue, que la péninsule ibérique se soit trouvée être le lieu le plus exposé. Cependant, des 1802, une petite épidémie s'est déclarée à Brest, tandis qu'un bateau introduit le germe à Livourne en 1804. La Grande-Bretagne, dont les relations océaniques sont plus développées, a connu la contamination dès 1777, et jusqu'en 1865 on compte cinq offensives, à Falmouth, à Swansea, à Southampton. Dans la seconde moitié du $\mathrm{XIX}^{\mathrm{e}}$, les épidémies européennes se font plus rares, plus restreintes aussi : Porto, 1851, 1856 ; Lisbonne, 1857 ; Saint-Nazaire, 1861 ; Barcelone, Alicante, Valence, Palma, 1870 ; Torre Annunziata, 1884 ; Trieste, 1894 ; de nouveau Saint-Nazaire, 1898. [p. 130] Cette date, du début du $\mathrm{XX}^{\mathrm{e}}$ siècle, marque la dernière apparition de la fièvre jaune en Europe. À la vérité, si sur les côtes méditerranéennes, et dans la péninsule ibérique, il s'agit bien d'épidémies, plus au nord, ce ne sont que des pseudo-épidémies, des infections humaines causées par des moustiques apportés vivants par les navires mais sans infections de moustiques locaux pouvant renouveler le cycle évolutif de l'épidémie. Ces épidémies européennes n'ont donc plus aujourd'hui qu'un intérêt historique, sous cette réserve qu'une surveillance constante demeure d'autant plus nécessaire dans les villes où pullulent encore des Aëdes et à quelques heures de vol seulement des foyers américains.

Cette disparition, sous nos latitudes, d'un fléau naguère encore redoutable n'est du reste pas un fait simplement local. Des la fin du siècle dernier, sauf quelques flambées épidémiques intermittentes, c'est également en Amérique et en Afrique qu'on constate une régression des foyers infectés, régression qui s'accentue au 
$\mathrm{XX}^{\mathrm{e}}$ grâce aux mesures défensives et préventives que permet une notion meilleure de l'épidémiologie de la fièvre jaune.

Le $\mathrm{XIX}^{\mathrm{e}}$ siècle a donc été le grand siècle de la fièvre jaune. L'épidémicité, la diffusibilité y sont portées au maximum. Au Brésil, les épidémies reparaissent chaque année : il s'agit, non d'une endémie, mais d'une infection [p. 131] qui se renouvelle constamment. Les bateaux à destination de l'Europe opèrent automatiquement une diffusion se produisant en quelque sorte en série. Rio, Vera Cruz sont des ports mal famés, qui semblent marqués par le destin. Quand un Lesseps vieillissant entreprend, dans les années quatre-vingts, de percer le canal de Panama, le principal obstacle ne sera pas tant pour lui la structure de l'isthme ou les guets-apens de la finance, que le moustique infectant. Mais il ne le sait pas : les godets remplis d'eau sur lesquels on élève les pieds des lits pour écarter les fourmis sont justement un milieu qui semble fait tout exprès pour le pullulement de l'insecte. Aussi, à Colon, à Panama, meurt-on en série, depuis le plus humble travailleur jusqu'à l'ingénieur en chef et à toute sa famille : à vingt-cinq ans, le jeune polytechnicien Bunau-Varilla se trouve promu à la responsabilité technique suprême, la mort ayant fait le vide au-dessus de lui. Vingt ans plus tard, les Américains se joueront de ce barrage que la mort fait à la vie.

C'est qu'une des plus sensationnelles conquêtes de la science s'est produite. En 1900, le médecin cubain Carlos Finlay (on sait la grande valeur médicale des docteurs d'Amérique latine) a pressenti et affirmé le rôle du moustique dans la transmission de la fièvre jaune ; des confrères nord-américains en apporteront la preuve au péril de leur vie.

\section{[p. 132]}

Il s'agira donc de détruire le moustique ou de l'empêcher de se reproduire. La lutte contre la maladie tend de ce fait à se déplacer: il va s'agir moins de traitement médical que d'action administrative, et partout ou cette action s'exerce, dans les conditions de discipline draconienne nécessaires, le succès est complet. Dans son Hiver Caraïbe, Paul Morand, sous une forme humoristique mais en réalité doublement évocatrice, a ainsi résumé l'offensive panaméenne sous l'égide des États-Unis : «Aujourd'hui la fièvre jaune, qui sévit à Dakar [ces lignes sont écrites il y a déjà une trentaine d'années], a disparu du Brésil, du Panama, du Guatemala. C'est que les Américains appliquent les règlements : «Vous avez là dans votre jardin une marmite avec de l'eau, il faut la vider, cela attire les moustiques. » Le lendemain l'officier de santé passe, la marmite est toujours là. «C'est 20 dollars d'amende, et la prochaine fois ce sera trois mois de prison. » À Colon, sitôt qu'un habitant aperçoit un moustique il doit le signaler par téléphone aussitôt un jeune garçon accourt, armé d'un filet le moustique est capturé, puis expédié par le service compétent au laboratoire, où l'on découvre son lieu d'origine. Cela déclenche une offensive de l'Hygiène publique, masquée et gantée de blanc, qui arrive sur place en automobile, comme les pompiers. »

Les routes géographiques suivies par la fièvre jaune sont, dans ces conditions, celles que peut adopter [p. 133] le moustique dans ses déplacements, soit locaux 
soit transocéaniques. Il est facile de voir, sur les cartes de progression des épidémies, que les réseaux intercontinentaux de diffusion sont ceux des lignes de navigation. Il se dessine ainsi des chenaux de première grandeur, entre les grands ports américains et les grands ports européens. Ces derniers sont les premiers touchés (Lisbonne, Cadix), mais ensuite des liaisons maritimes annexes transportent moustiques et germes en dehors des grandes voies commerciales, non sans que ne se produisent des fusées, éventuellement lointaines. Si le moustique est ainsi transporté trop loin, hors de son climat, il ne survit pas et l'infection meurt d'elle-même, ce qui explique que la Méditerranée ait été vulnérable, mais que, dans la Manche ou la Mer du Nord, les manifestations de la fièvre jaune n'aient jamais été qu'occasionnelles et essentiellement temporaires.

Reste cependant le cas du virus amaril chez les singes de l'Amérique du Sud ou de l'Amérique centrale, de même aussi chez les singes africains. La maladie persiste alors, susceptible de se développer, de s'étendre, selon des itinéraires autrement difficiles à déterminer que pour les hommes, mais que cependant la science réussit à repérer. Quand je visitais les Llanos de la Colombie, ces immenses espaces de plaines, mi-steppes, mi-déserts, mi-jungles sauvages [p. 134] s'étendant à la lisière orientale des Andes, on m'a bien souvent montré des forêts se profilant à l'horizon, où sévissait la fièvre jaune des animaux : on se gardait de s'en approcher. Or il apparaît actuellement que, durant ces dernières années, l'affection amarile des singes gagne régulièrement de l'Amérique bolivarienne du nord-ouest vers et à travers l'Amérique des Isthmes. Elle y a progressé régulièrement, dans le Honduras et le Guatemala du sud en 1956, vers le Guatemala du nord et le Honduras britannique en 1957. Les routes suivies par l'infection ne sont plus en l'espèce celles des hommes, et il ne s'agit pas de chaussées, de chemins de fer ou de paquebots. Les moustiques et singes infectés hantent les hautes branches des arbres de la forêt vierge, tandis que les hommes sont en bas, sur les pistes des sous-bois. Il n'y a pas normalement, et fort heureusement, rencontre. Mais de branche en branche la diffusion se fait, de telle sorte que le Mexique pourrait à la longue finir par être atteint, sans que des mesures de protection puissent utilement être prises. En Afrique la propagation s'arrête, nous le savons, à la dorsale centrale du continent et il y a là une des barrières les plus efficaces et les plus intéressantes à observer, qu'il s'agisse de la fièvre jaune humaine ou animale.

Que la fièvre jaune ne se soit jamais étendue à l'Océan Indien, au ProcheOrient, à l'Inde, il y a là [p. 135] un phénomène qui semble paradoxal, car toutes les conditions requises pour la diffusion existent dans ces milieux, qui sont traditionnellement des foyers classiques d'infection. Aux Indes en particulier les moustiques vecteurs sont nombreux, notamment l'Aëdes Aegypti qui se rencontre dans les maisons, l'Aëdes albopictus dans la jungle. Les conditions de température sont par ailleurs favorables à la survie, à la multiplication du vecteur, donc au développement du virus. Il y a, d'autre part, abondance d'une population simienne infectable, de sorte que la maladie, une fois introduite chez les singes sous sa forme sylvestre, serait pratiquement impossible à extirper. La contagion serait 
d'autant plus facile chez l'être humain que la densité du peuplement est effrayante et qu'aucune immunité innée ou acquise n'existe en l'espèce. Le déclenchement d'une épidémie pourrait dans ces conditions avoir des conséquences incalculables, et l'on s'explique la crainte, la hantise des autorités locales à cet égard. Il suffirait en effet qu'un moustique infecté parvienne dans la zone jusqu'ici épargnée ou bien que le moustique indien devienne lui-même infectant, que les singes autochtones soient eux-mêmes atteints, la propagation serait impossible à circonscrire et c'est par millions que les cas de fièvre jaune se produiraient. À la vérité, ces conditions ne se sont pas réalisées, mais la menace est toujours là, d'autant plus dangereuse qu'à l'âge [p. 136] de l'avion le transport quasi immédiat d'un moustique infecté, d'un passager en état d'incubation peut apparaître comme la chose la plus normale, la plus inévitable du monde. Cependant la dorsale africaine, avec sa barrière de montagnes et de forêts, continue de jouer son rôle de protection : la fièvre jaune n'a pas conquis l'Asie et pour une fois, sur les routes intercontinentales, vecteurs et virus se sont arrêtés, contrairement à tout ce que la raison aurait pu prévoir. 
[p. 137]

\section{QUATRIÈME PARTIE}

\section{Diffusion des idées et des propagandes}

Retour à la table 
[p. 139]

7

\section{Conditions de diffusion et détermination des routes suivies}

\section{DIFFUSION DES GERMES ET DIFFUSION DES IDÉES}

\section{$\underline{\text { Retour à la table }}$}

Entre la diffusion des germes et la diffusion des idées ou des propagandes le parallélisme est frappant. D'un côté il s'agit d'un virus, transportable et transmissible dans des conditions déterminées, qui favorisent ou limitent transport et transmission; de l'autre, ce sont des idées, des religions, des doctrines, subversives ou non, jouant le rôle de ferment et qu'on peut qualifier de germes, bienfaisants ou malfaisants, selon le point de vue auquel on se place. Ces germes peuvent exister dans un foyer, y [p. 140] demeurer stériles ou bien en sortir par dissémination contagieuse. Le vocabulaire qui se présente normalement à l'esprit est logiquement celui de la médecine. Les conditions de contagion seront du reste aussi les mêmes que dans le domaine de la santé. Pour que la diffusion s'opère, il faudra nécessairement un germe, un vecteur et un milieu réceptif. Ce sera donc, comme dans les épidémies, affaire de contacts, facilités par la technique des communications ou retardés par les obstacles issus des mœurs ou de l'administration. La sociologie et la biologie se rencontrent curieusement en l'espèce. 


\section{CONDITIONS DE DIFFUSION DU GERME INITIAL}

\section{$\underline{\text { Retour à la table }}$}

Ce germe initial ne se transportera pas tout seul, il lui faut un vecteur, qui pourra être un homme, ou bien un journal, un livre, un pamphlet, à moins que ce ne soient les ondes de la radio, l'écran du cinéma ou de la télévision.

L'être humain est en la circonstance l'agent de transmission le plus naturel. Tel homme, se déplaçant, transportera avec lui une doctrine, une religion, un germe d'opposition ou de révolte. Il se pourra que ce soit le fait d'une conviction, celle du missionnaire, de [p. 141] l'apôtre, du propagandiste, mais il se pourra aussi que pareil agent transmetteur soit inconscient de la contagion qu'il exerce, portant un germe dont il ne connaît ni la nocivité ni même l'existence : il y a ainsi des porteurs d'affections inapparentes, ignorants du virus qu'ils abritent et que les médecins eux-mêmes ne décèlent pas. Ce sont les plus dangereux : le vecteur admis comme tel prêchera, haranguera, enseignera, discutera, insinuera, semant ouvertement le germe sur son passage, ce qui fait qu'on pourra l'arrêter ou le réfuter, mais avec le vecteur inconscient ou camouflé la diffusion sera infiniment plus insidieuse : ce sera le soldat d'une armée, en garnison lointaine ou en campagne, quelque colporteur faisant sa tournée, un ouvrier recruté pour quelque entreprise lointaine, ou même le valet de quelque millionnaire en déplacement autour du monde. La fantaisie, l'imprévisibilité des contacts humains sont sans limites, dépassant les possibilités mêmes de l'imagination la plus déchaînée. Nous n'avons qu'à considérer le pollen répandu aux extrémités du monde ancien par ces abeilles que furent les conquérants tartares, la fécondation que les nomades, ces trouble-fêtes, apportent périodiquement aux possédants des solides maisons héréditaires, les incessantes tentations des idolâtries voisines pour les fidèles du vrai Dieu, les transports imprévus de l'esprit opères par les Parthes, les Mongols, les Arabes. Le [p. 142] monde est infiniment plus poreux qu'on ne pourrait le croire et il n'a pas attendu pour l'être que le téléphone, le télégraphe ou l'avion aient supprimé pour nous la distance et le temps.

La contagion, disions-nous, peut se produire par le fait d'une lecture, d'une audition dont la source est lointaine, de la vision d'une image, mais il aura fallu quand même l'intervention humaine : le germe peut être déposé dans un livre, dans une représentation sur l'écran, dans un rite purement formel, il n'en aura pas moins fallu l'intermédiaire de l'homme ; la source reste nécessairement humaine, car on ne peut imaginer une idée sans réservoir humain, comparable au réservoir de germe dans la conservation et la transmission des maladies. S'il s'agit cependant des réservoirs animaux de virus, la comparaison s'arrête, car je ne pense pas que le singe ou le rat puissent jouer, dans les communications de 
l'esprit, le rôle qu'ils jouent dans la fièvre jaune ou la peste, même s'il s'agit des rats de bibliothèque de la Fable.

[p. 143]

\section{LES ROUTES SUIVIES DANS CETTE DIFFUSION}

\section{Retour à la table}

Nous retrouvons ici les toutes déjà rencontrées dans la diffusion des germes, s'inscrivant naturellement dans la classification plus large des communications terrestres en général. Notons ainsi les caravanes, instruments anciens des échanges, les colportages, les pèlerinages, les itinéraires maritimes, les routes d'immigration, les routes missionnaires, souvent indiscernables des toutes de conquêtes, cette liste étant de tous les temps. S'il s'agit des routes modernes, les conditions du contact restent les mêmes, mais la technique des transports fournit la voie ferrée, l'autoroute pour l'automobile, l'air pour l'avion. La nature des échanges ne change pas, mais l'intensité s'accroît, la route devenant par excellence un instrument de pénétration, tantôt massif comme un bélier capable d'enfoncer tout obstacle, tantôt souple, subtil et susceptible de s'insinuer partout : les travaux du Gothard, par l'introduction d'une main-d'œuvre étrangère dans tel canton suisse encore médiéval, en ont changé l'équilibre politique et social. Dans son roman, Les Hommes de la route, André Chamson a décrit pareille révolution apportée dans les Cévennes par une offensive des Ponts et Chaussées. En construisant les routes, en établissant [p. 144] le rail, en constituant sur les mers des chapelets de bases navales, en instituant pour les besoins de l'air un réseau d'infrastructures, les pionniers humains apportent avec eux non seulement leurs techniques mais leurs idées, et puis, après eux, d'autres hommes se servent de ces voies pour véhiculer des produits de tous ordres, y compris ceux de l'esprit. Le hasard des contacts devient alors inimaginable et il faut recourir à la fantaisie démoniaque des associations d'idées pour en donner quelque image. L'insinuation des germes d'idées peut résulter d'une venue de touristes, d'un appoint de travailleurs exotiques, d'un corps d'occupation, d'une inscription d'étudiants étrangers dans quelque université, de l'introduction dans un milieu non immunisé d'un simple individu, quelquefois d'un journal, d'un livre, de la conjonction imprévue d'une lecture avec un état d'âme justement réceptif à ce moment-là : mon grand-père, notaire de chef-lieu de canton dans l'Ardèche, étant parti en bateau sur le Rhône à destination de Lyon pour y voir jouer Rachel, lisait pendant la traversée une Bible qu'un ami - c'était le temps du Réveil - lui avait mise entre les mains ; il ne vit pas Rachel, revint dans son département et, s'étant converti, se fit pasteur ; l'exemple est typique... Les contagions, les épidémies naissent ainsi. « Il y a, dit le moraliste, des folies qui se prennent comme les maladies contagieuses. » [p. 145] Les types 
de vecteurs humains sont innombrables, chacun de nous étant à l'occasion pareil agent de transmission, mais telles catégories d'hommes le sont par profession ou même simplement par tempérament: citons par exemple le missionnaire, le colporteur traditionnel, l'agitateur politique, le «meneur » redouté du patron, l'agent électoral, l'agent de publicité, le salesman américain...; d'un point de vue sociologique la liste, éventuellement sans fin, serait fort intéressante à dresser. De toute façon, le "mauvais esprit», introduit par le plus simple hasard dans un milieu donné, y sème sûrement le trouble et le désordre, et l'on comprend aisément l'employeur, quel qu'il soit, qui s'en défend comme de la peste.

\section{LES CONDITIONS DE MILIEU}

\section{Retour à la table}

Il faut cependant que le milieu s'y prête. Pour que la diffusion se produise il est indispensable que le milieu soit réceptif, c'est-à-dire propre au développement du germe, faute de quoi celui-ci restera stérile ou bien il n'y aura qu'une infection localisée et temporaire. Il arrive du reste que le vecteur humain lui-même disparaisse ou soit purement et simplement supprimé en tant que nuisible : toute la suite des contagions se trouve de ce fait arrêtée radicalement. [p. 146] Dans les études de géographie de l'opinion politique que j'ai faites sur les bords du Plateau Central au contact du monde méditerranéen, j'ai observé bien des exemples de pareille contagion qui remonte et puis s'arrête, se stérilise. Les idées d'extrême gauche prospèrent et prolifèrent sur la côte, sous la forme, selon les temps, du radicalisme, du socialisme, du communisme, et elles ont tendance à remonter le long des vallées vers la montagne, tout comme le font les essences méditerranéennes s'insinuant vers le plateau à la faveur de l'exposition au soleil. De l'Hérault vers l'Aveyron la propagande socialiste, entre les deux guerres, suscitait ainsi, parmi les ouvriers du chemin de fer, a Séverac-le-Château dans l'Aveyron, un petit foyer d'extrémisme; mais le milieu ne s'y prêtait pas évidemment, car, sa virulence demeurait limitée et localisée : si l'extrémisme fleurit dans le bas, l'altitude ne lui est pas favorable. Des avant 1914, je me rappelle avoir constaté, entre l'Hérault, le Gard et la Lozère, une transmission analogue de germes, mais sans lendemain. Dans ces temps lointains de l'Affaire Dreyfus, où une génération nouvelle substituait, dans les milieux d'avant-garde, le socialisme de Jaurès et de Guesde au vieux radicalisme de Clemenceau et de Pelletan, la Faculté de Médecine de Montpellier abritait des étudiants répondant avec empressement à cette propagande. L'un d'eux, appelé Phalippoux (je me rappelle son nom), [p. 147] remontant le long des vallées des Basses Cévennes, avait apporté la bonne parole révolutionnaire, qui était alors le Jaurésisme, jusque dans ces communes de l'arrondissement de Florac où l'élément protestant s'affirmait «de gauche », en vertu d'une tradition de résistance issue du Désert et de la persécution. Beaucoup de bons électeurs huguenots de l'époque votaient 
donc « à gauche » et « toujours à gauche ». Comme me le disait un blanc-bec, tout juste parvenu à l'âge de la majorité : « Moi je suis marxiste et je vote par principe pour le plus avancé... » L'agitateur montpelliérain, avait donc créé, a Pont-deMonvert, à Barre-des-Cévennes, de petits foyers révolutionnaires. Mais l'altitude, physique et morale, ne s'y prêtait sans doute pas et jamais le mouvement ne s'est développé : c'est encore un cas de contagion suscitant un petit foyer et puis mourant de sa belle mort. Les exemples à donner seraient innombrables, dans le domaine religieux comme dans le domaine politique : les rares et sporadiques conquêtes du christianisme en Asie relèvent de ces limitations : petits foyers, actifs et non sans vitalité, mais demeurant discontinus et dans l'impossibilité de s'étendre, ne devenant endémiques que par une sorte d'adaptation au milieu, comme dans le cas du catholicisme portugais de la côte de Malabar. Il suffit quelquefois que le plus parfait hasard, ou bien l'établissement d'un itinéraire de transports, amène au [p. 148] loin quelque porteur de conviction religieuse : c'est ainsi qu'on a vu des employés noirs circulant sur les pullman du Southern Pacific entre La Nouvelle-Orléans et Los Angeles, transmettre dans la Californie du Sud le germe de je ne sais quelle secte selon laquelle Jésus et les Apôtres étaient nègres ; on devine que la contagion ne pouvait guère s'étendre au-delà du rail...

\section{LES MESURES DE DÉFENSE ET LEUR DEGRÉ D'EFFICACITÉ}

\section{Retour à la table}

Pour détruire, stériliser un germe, ou simplement circonscrire sa diffusion, on peut, comme dans la défense contre les maladies, procéder de différentes façons. Détruire le germe à sa source sera l'action la plus décisive. Mais c'est souvent difficile. Ou bien on ne le connaît pas, ou bien, si on le connaît, on ne sait pas exactement où le trouver. Il arrive qu'on mesure mal ses possibilités de diffusion. Il se peut aussi que le germe se soit multiplié de telle façon qu'on soit désarmé, tenté de se dire comme ce combattant cerné de toutes parts : « Ils sont trop ! » On comprend alors la réaction de Simon de Montfort à Béziers dans son extermination des Cathares : "Tuez-les tous, Dieu reconnaîtra les siens !» Le germe albigeois fut en [p. 149] effet intégralement détruit et il ne s'est depuis lors perpétué que par souvenir.

Une autre défense, et la plus commune, consiste à supprimer le vecteur ou au moins à l'empêcher de pénétrer sur le terrain qu'on veut préserver. On détruira donc systématiquement tous les agents de diffusion de telle ou telle doctrine. En tout cas on préviendra leur entrée par blocage total à la frontière. C'est par tradition le système russe, qui fut tsariste bien avant d'être, comme aujourd'hui, soviétique. C'est aussi le système américain de la loi d'immigration des quotas, qui tend à limiter l'entrée des immigrants d'origine latine ou slave dont on estime 
que l'influence pourrait compromettre la tradition d'un anglo-saxonnisme orthodoxe. L'Amérique, au lendemain de la première guerre mondiale, a cru qu'elle pourrait ainsi se préserver d'une contagion européenne qu'elle estimait insidieusement communiste. Le Maccarthysme a marqué, au lendemain de la seconde guerre mondiale, un paroxysme, du reste temporaire, de cette hantise de défense. Si cependant l'agent éventuellement contagieux a pu pénétrer (et comment sérieusement l'en empêcher ?), on s'attachera du moins à le surveiller, à l'encadrer, à le stériliser. Sur le degré de sa nocivité il pourra y avoir doute et, dans ce cas, il sera soumis à une sorte de quarantaine. On m'a soutenu que, dans la Province de Québec, dont la foi catholique orthodoxe [p. 150] est bien connue, l'étudiant canadien au retour de quelque université française, est mis en observation pendant un certain temps pour s'assurer qu'aucune maladie contagieuse ne se développe chez lui.

Le plus prudent sera naturellement de procéder à des actions préventives : censure de la presse ou des livres, visite des bagages pour s'assurer qu'ils ne contiennent aucune publication subversive, police des suspects, persécution religieuse, sans parler de ces opérations dites " psychologiques » de rééducation, de défanatisation, de réadaptation qui sont la honte de notre siècle. Russes et Chinois sont passés maîtres dans ce genre de traitement, mais il semble bien qu'il ait été occasionnellement employé dans l'armée américaine lors de la guerre de Corée et je serais bien rassuré de savoir qu'il ne se pratique pas en Afrique du Nord. Hitler a fait progresser cette technique de façon à proprement parler effrayante et depuis lors les progrès démoniaques de la neuro-chirurgie ont mis entre les mains des expérimentateurs en la matière des instruments susceptibles, dans le domaine du mal, d'opérer des miracles.

On peut se demander cependant jusqu'à quel point de pareils procédés sont efficaces contre ce germe ailé, souvent invisible, qu'est l'esprit. Si on les « tue tous », comme dans le cas du manichéisme albigeois, l'entreprise est payante, mais il suffit qu'il en reste un seul [p. 151] pour que la diffusion reprenne, et c'est le cas de la plupart des persécutions: qu'il s'agisse des protestants de la Révocation, des juifs de tous les temps, des Arméniens assassinés en masse par les Turcs, l'opération s'est révélée inutile, car il y a encore des Protestants, des juifs ou des Arméniens. La stérilisation du milieu par suppression de tout contact extérieur produit en Russie les effets qu'on en attend : l'État parvient à empêcher que le citoyen soviétique sache ce qui se passe au dehors et du reste, s'il se produisait quelque velléité de réponse à une propagande venue d'ailleurs, elle serait aussitôt réprimée par une police qu'on peut, en ce sens, qualifier aussi de «sanitaire ». Le rideau de fer, le rideau de bambou sont, de ce point de vue, des protections aussi efficaces que la vieille muraille de Chine, qui protégeait la civilisation raffinée du Yang-Tsé contre les raids des hordes tartares.

Jusqu'ici la comparaison entre les épidémies du corps et celles de l'esprit s'est manifestée féconde. Elle le demeure s'il s'agit des immunisations ou des vaccinations. Les lois de la nature comportent un mécanisme d'auto-défense des organismes, correspondant à un instinct fondamental de retour à l'équilibre. C'est 
le sens des immunités, dont les vaccinations ne sont qu'un dérivé. Dans les défenses que les sociétés humaines opposent aux offensives des propagandes ou des pénétrations d'idées, il y a de même des immunisations [p. 152] et des vaccinations. La virulence de telle doctrine s'attenue par l'adaptation au milieu ou simplement par l'habitude. Il arrive même que l'injection à dose réduite entraîne de soi l'immunisation contre telle forme plus active. Il me semble avoir observé à plusieurs reprises en Amérique latine, notamment en Argentine, que telle forme de démagogie équivaut à un vaccin social contre le communisme. Même remarque aux États-Unis à propos de la démagogie irlandaise, qui jamais n'aboutit à la révolution. Telle réforme, s'inspirant subtilement de la menace elle-même, empêchera souvent la maladie de se déclarer ou au moins de se répandre quand quelque infection locale s'est produite. Une société saine se défend par elle-même contre les contagions qui mettraient en péril l'intégrité de sa personnalité. En revanche une société malsaine attrapera toutes les maladies, réagira à toutes les contagions. Rome, dans sa décadence, ne s'est pas défendue du christianisme. Bismarck disait de la Russie «qu'elle n'avait rien à faire en Europe, qu'elle y attraperait toutes les maladies ». Le freudisme s'est répandu aisément dans les pays protestants, en particulier aux États-Unis, en Suisse, cependant que les milieux catholiques lui opposaient une résistance efficace.

Certaines doctrines, certaines religions se répandent comme des épidémies, suivant les mêmes routes de moindre résistance, se heurtant aux mêmes obstacles, [p. 153] fusant d'abord, selon la commodité des transports, vers les nœuds de communications essentiels, vers les centres de distribution d'où s'opère ensuite un rayonnement généralisé. Les conditions sont les mêmes que celles que nous analysions plus haut en ce qui concerne les grandes pandémies du XIX ${ }^{\mathrm{e}}$ siècle, les centres d'étapes ou d'escales étant d'abord atteints, les lieux écartés n'étant touchés qu'à retardement. C'est ce qui explique que tels cantons isolés, dans leurs montagnes ou leurs forêts, échappent longtemps à la contagion, forteresses de résistance aux contaminations du progrès, suprêmes refuges de la Droite.

Un exemple typique de ces épidémies de l'esprit se trouve dans la diffusion du christianisme à travers le monde antique, exceptionnellement poreux spirituellement à l'époque romaine. En adoptant le vocabulaire biologique, que trouvons-nous ? Le germe initial est à Jérusalem, mais il eût pu ne donner lieu qu'à une contagion locale, limitée à la société juive où s'était exercé l'apostolat du Christ : les apôtres, de bons juifs qui sans doute entendaient demeurer dans leur religion, n'eussent probablement pas fait rayonner leur foi très loin au dehors. Mais il y avait, parmi les premiers chrétiens, des prosélytes, juifs hellénisés ou Grecs judaïsés, et dans leurs rangs Étienne, le premier martyr. Quand celui-ci eût été lapidé par les fanatiques de l'orthodoxie, ses disciples les plus proches, fuyant [p. 154] Jérusalem, s'étaient enfuis de la capitale, se répandant sur les côtes de l'Asie mineure, où, dans les synagogues, se rencontraient juifs et Grecs. Il y avait là un milieu qui se prêtait éminemment à la diffusion de la doctrine à laquelle se refusait Jérusalem, et c'est ainsi que, de proche en proche, il se constituait des foyers chrétiens à Antioche, à Tarse, à Ephèse, à Thessalonique, à Corinthe. Les 
vecteurs, en l'espèce, c'étaient les disciples d'Étienne, les judéo-Grecs convertis, les apôtres en mission, au premier rang desquels saint Paul, le vecteur par excellence dans son immense action missionnaire. Là où le milieu était favorable, des églises naissaient, mais là où il ne l'était pas la semence chrétienne demeurait stérile : ce fut le cas à Athènes, où l'Apôtre prêcha dans le désert. Mais ailleurs il réussissait, et, dans cette Méditerranée où tout tendait à Rome, il était inévitable que tôt ou tard la capitale du monde fût atteinte. De Rome le rayonnement devenait général et la diffusion prenait, toutes proportions gardées, dans l'humanité d'alors, le caractère et la portée d'une pandémie.

Les itinéraires de saint Paul sont, de ce point de vue, singulièrement instructifs. L'apôtre choisissait les grandes villes situées sur les voies de communication les plus fréquentées, parce qu'il y rencontrait la population désaxée et désencadrée la plus accessible à sa prédication, sans doute aussi parce qu'il y trouvait,

[p. 155]

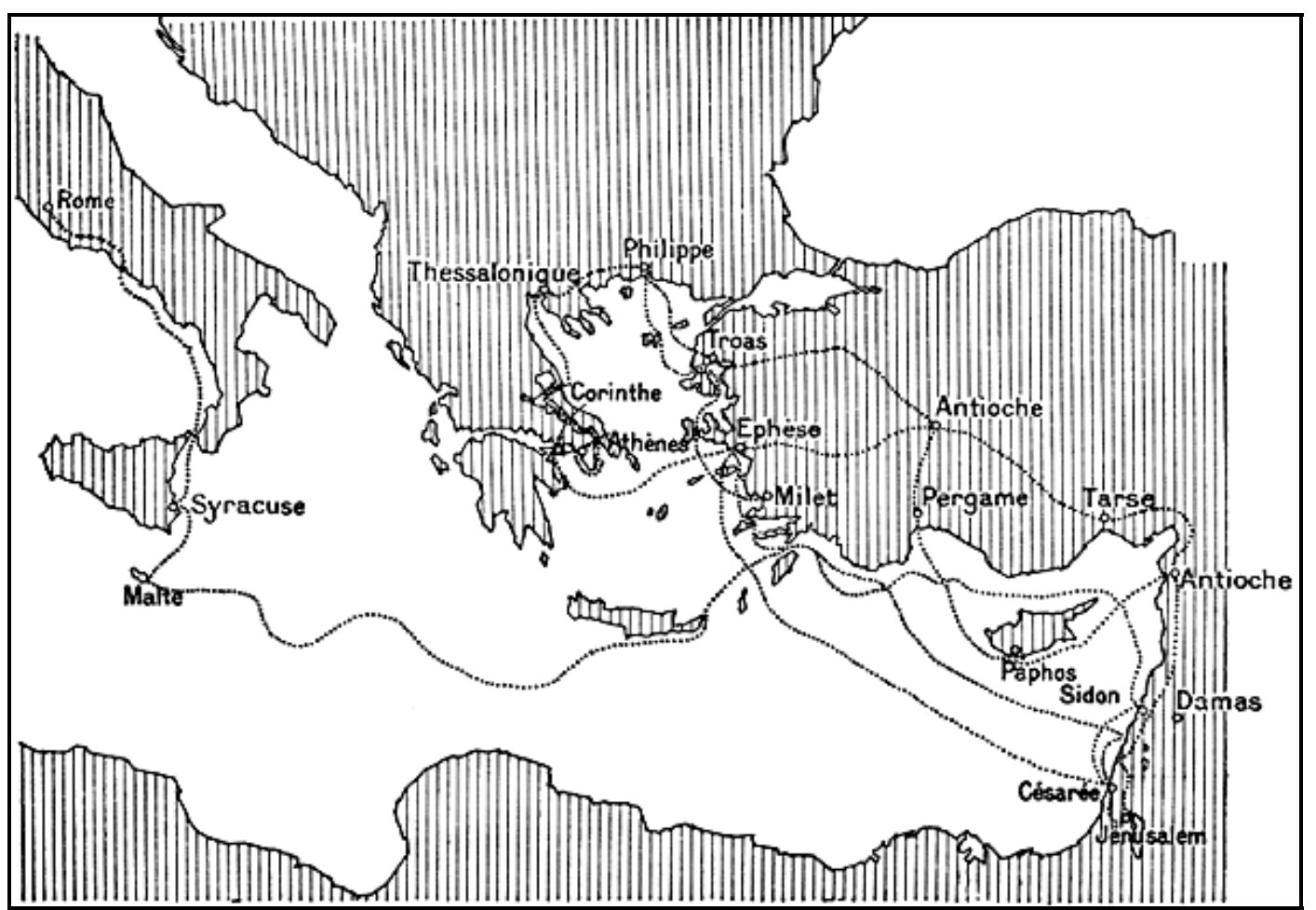

$\underline{\text { Retour à la table des cartes }}$

\section{Voyages de saint Paul}

fabricant de tentes comme on sait, les meilleures possibilités de gagner sa vie. Le dessin des routes, le réseau des lignes de navigation entraient évidemment aussi en ligne de compte, car il y a dans cette méthode missionnaire un curieux mélange 
de plans concertés et d'impulsions irrationnelles. Il était naturel qu'il aboutît finalement à Rome et, s'il n'eût péri dans la persécution néronienne, sans doute eût-il poussé [p. 156] jusqu'en Espagne et en Gaule. La pression de l'Orient sur l'Occident, qui, au $\mathrm{II}^{\mathrm{e}}$ et $\mathrm{III}^{\mathrm{e}}$ siècles, devait atteindre son maximum d'intensité, faisait que tous les développements théologiques se produisant en Asie occidentale avaient leur contrecoup immédiat ou presque immédiat à Rome, où il y avait d'importantes colonies asiates. Maurice Goguel, le grand historien du christianisme initial, à qui je dois ces considérations de géographie religieuse, estimait qu'il y aurait à faire une étude passionnante sur la géographie du christianisme primitif, sur la manière dont l'ancien catholicisme s'est constitué par un mouvement de concentration, fusionnant des types de christianisme d'abord assez divers. Les premiers chrétiens constituaient une population largement mouvante, chez lesquels les voyages et l'exercice très poussé de l'hospitalité contribuaient à l'unification. Le christianisme se déplaçait ainsi vers l'Ouest, le centre de gravité passant de Jérusalem à Antioche, puis à Éphèse et finalement à Rome, après une vaine tentative de Corinthe pour concurrencer la capitale.

Un autre exemple d'extension géographique d'une religion se trouve, à peu près à la même époque, dans la diffusion des mystères de Mithra, comme il ressort des recherches classiques de Franz Cumont. Les principaux monuments mithriaques ont été trouvés sur les frontières de l'Empire et il est évident que ce sont [p. 157] les légions romaines qui ont été le véhicule de la transmission : il s'agit d'une longue traînée, le long et à l'abri du Limes. C'est le cas, fort curieux, d'une contagion du fait d'une profession.

C'est d'un même vocabulaire que nous nous sommes servis pour parler de la diffusion des maladies et de la diffusion des idées et des propagandes : virus, germe, ferment, foyer ; vecteur, terrain, milieu ; contact, contagion, infection, contamination, saturation, endémie, épidémie, pandémie ; prévention, inoculation, stérilisation, immunisation, vaccination, quarantaine. Il y a sans doute là plus qu'une superficielle coïncidence : qu'il s'agisse du domaine biologique ou du royaume des idées, certaines réactions se manifestent qui sont communes à tous les êtres vivants. 